\title{
FARMERS, PEERS, AND TRADERS
}

\section{APPLICATION OF SOCIAL NETWORKS IN MODERN AGRICULTURAL SYSTEMS}

\author{
Dissertation \\ to obtain the degree Doctor of Philosophy Ph.D. \\ at the Faculty of Agricultural Sciences \\ Georg-August-University Göttingen
}

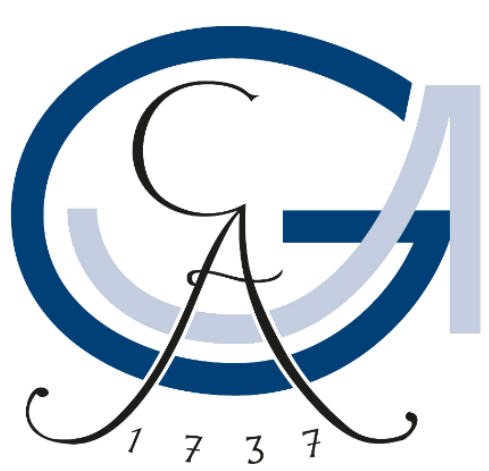

presented by

Claudia Hunecke

born in Rudolstadt, Germany

Göttingen, December 2019 

1. Referee: Prof. Dr. Bernhard Brümmer

2. Referee: Prof. Dr. Stephan von Cramon-Taubadel

3. Referee: Prod. Dr. Thomas Kneib

Disputation: 6. February 2020 



\section{Summary}

In recent research, economic agents are no longer perceived as wholly independent and individual decision-makers, but as embedded in their social environment. Actors in agriculture are no exception. Such a social environment is shaping the agent's behaviour and decisions, for example, regarding the adoption of a specific technology or the choice of trading channels.

To illustrate the social environment of an individual actor, we utilise social networks. Social networks can serve as an instrument to link agents with each other over space and time. The emerging pattern can display the flow of information, the diffusion of technology or the trade flow of products between all kinds of agents. Networks are very flexible constructs, which are defined by their structure. Social networks enable us to overcome close spatial proximity. Thus, neighbouring agents in a network do not need to be located in a limit area.

In the first part of the thesis, the relevance of social networks in the adoption of technology is examined. As information about availability and suitability of innovation is one of the critical factors in the diffusion and adoption process of agricultural technology, its transmission is of crucial importance. Other farmers often mention farming neighbours as the most significant origin of knowledge. However, various sources, like extensions services, technology providing companies, and downstream and upstream industries, are significant stakeholders. Thus, we construct five different network structures to analyse their impact and relevance in the process of diffusion and adoption of automatic milking systems (AMS) in Germany. These five networks are the neighbourhood network, the sales structure network, the dairy factory network, the public advisory network, and the organic farming association network. A spatiotemporal endemic-epidemic model for infectious disease spread is applied to capture the dynamic contagious process of diffusion. Different outcomes occur for the networks. The neighbourhood network provides the best fit, as well as the most substantial impact on the diffusion. The public advisory network, in contrast, performs poorly and influences less than $1 \%$. Still, the diffusion of AMS is driven by exogenous and autoregressive effects.

In the second part of the thesis, the introduced networks are tested while controlling for various factors determining the adoption of AMS in Germany. AMS are often described as a substitute for labour, because of increasing labour costs and simultaneously decreasing 
availability of labour in the agricultural sector. The results confirm the influence of the costs of salaries and the amount of hired and family labour on the farm on the adoption of technology. However, the network effect remains strong. Nevertheless, the autoregressive effect, which can be defined as the agglomeration effect, fosters the diffusion of technology more than the network effect. Agglomeration effects can explain the diffusion of technology in a limited spatial area (here administrative districts in Germany) due to accumulation of farms, regional spillovers, and a pooled labour market. Network effects, in contrary, are crucial to spread a technology over more considerable distances, to ensure diffusion in the whole country. Both effects together explain $50 \%$ of the diffusion of AMS in Germany between 1997 and 2013.

The third part of the thesis explores the construction of trade networks in oil palm and rubber trade in Jambi, Indonesia. In the local value chain of both products, intermediaries are positioned between smallholder producers and processors. Social networks are suitable to display the marketing strategies of those intermediaries choosing the direct or indirect path to distribute the crops. We visualise trading networks for rubber and oil palm trade using a cross-sectional dataset and a panel dataset from three survey rounds in 2012, 2015, and 2018. Rubber trading networks diminishing in size because the number of intermediaries is reducing. The oil palm trade develops in the opposite direction. Applying an exponential random graph $\left(\mathrm{p}^{*}\right)$ model, we analyse factors influencing the network patten in Jambi. The average product price and the provision of loan by the buyer are the primary aspects for forming trade connections in both samples. In contrast, the trading experience and the total traded quantity do not play a significant role. However, the panel sample exhibits disparities between rubber and oil palm and between the considered years. Previous existing links in the trading network do only affect the link formation in the rubber trading network.

By considering the social environment, we are adding more layers to the economic activities of individuals. Networks can help to refine the picture we have about complex processes in agricultural economics and enable us to a better understanding of various challenges and constraints farmers are exhibiting. This thesis highlights two different applications for networks in modern agricultural systems to provide a deeper understanding of economic decision making. 


\section{Acknowledgements}

We are all embedded in our social environment.

So am I.

In the end, a PhD is obtained by an individual — one name on the dissertation and one name on the certificate. However, on the long way towards the $\mathrm{PhD}$, we are surrounded by many people accompanying us. In the following lines, I would like to thank every single one of you.

First of all, I have to thank my supervisor Bernhard Brümmer, who gave me the chance to be a member of his chair and to work on intrinsic research topics. Bernhard, you are a great supervisor and person. You gave me advice when desperately needed and the freedom to work autonomously. I would also like to thank Professor Stephan von Cramon-Taubadel and Professor Thomas Kneib for their time and effort in examining this dissertation.

I would like to thank my chair, colleagues and friends. Especially, I would like to thank Bernhard, Gabriel, Jurij and Tim for the endless patience with me and my coding problems. You indeed preserved me countless times to throw my computer out of the window. Thank you, Ella and Tom, for the last weeks, where I tried to conquer your research area and had to ask so many questions. Thank you, Juliane, that you gave me the push in the right directions in the beginning and helped me to start the network thing. Thank you, Sebastian, for your help applying your model to my case. Thank you, Mary for sharing your office with me in all those years. Thank you, Johanna, for your effort in taking so much work off me. I would like to thank Dela, Elke, Insa, Ioannis, Malte, Marwan, Nina, Nina, Olli, Sebastian, Tinoush, Yashree, Yuan, Yueming for their companionship, advice and all the wonderful hours in the past years.

Zum Schluss geht der Wohl größte Dank an meine Familie. Ihr seid immer an meiner Seite gewesen, bei allen Hochs und Tiefs meine Stütze und Rückhalt. Mama und Papa, vielen Dank für eure Unterstützung auf jede nur erdenkliche Art und Weise. Ihr habt einen großen Anteil daran, dass ich diesen Weg gegangen bin und heute hier stehe. Ihr habt jede noch so verrückte Idee unterstützt und alles ermöglich, damit ich meine Ziele erreichen und meine Einfälle umsetzen konnte. Ihr seid gleichermaßen meine Wurzeln und meine Flügel durch dieses Leben. Anne, was soll ich sagen... vielen Dank das du in den glücklichsten und 
schwersten Stunden immer da bist. Das du mich regelmäßig aus meiner eigenen kleinen Blase herausholst und die Tür immer wieder aufstößt in neue Welten, die wir dann gemeinsam erkunden und vielleicht (ein kleines bisschen) verbessern können. Vielen Dank auch für deinen konkreten Anteil an dieser Arbeit und es tut mir leid, dass am Ende doch so viele Buchstaben in den Formeln waren. Das du es trotzdem gelesen hast werde ich nie vergessen.

Writing this thesis and finalising the $\mathrm{PhD}$ has been a fantastic journey during which I have grown as a person, incredibly. I am excited to see what the future may hold.

Thank you all. 


\section{Table of content}

Summary

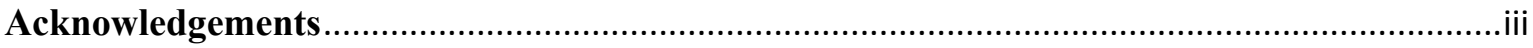

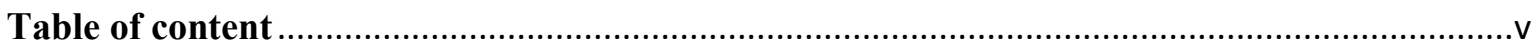

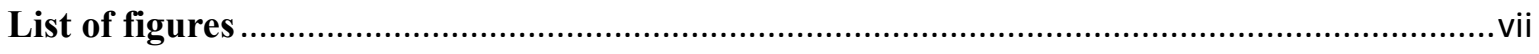

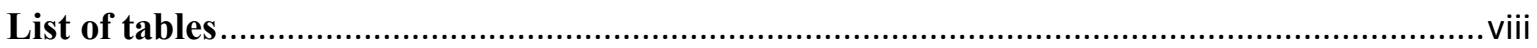

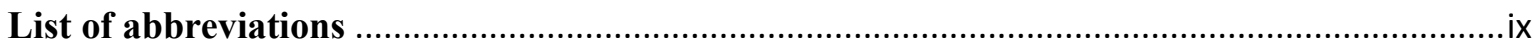

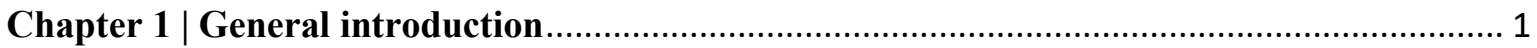

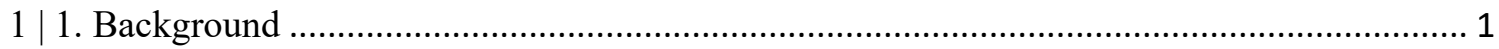

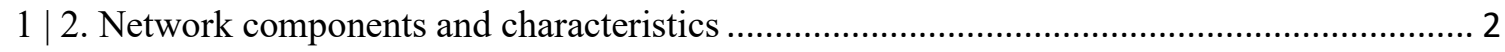

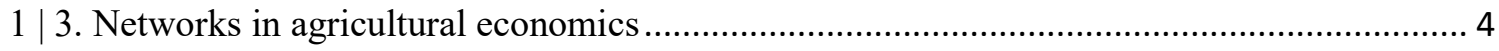

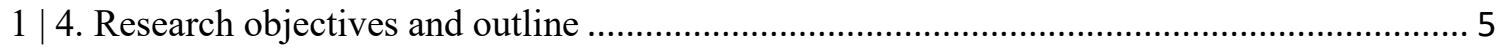

Chapter 2 | Do networks matter? Diffusion through network structures................................. 7

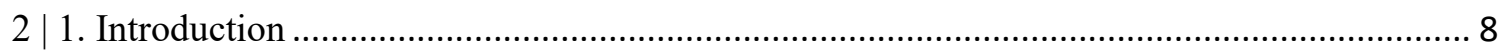

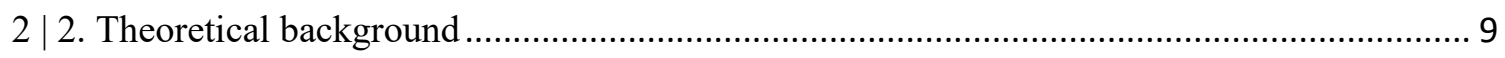

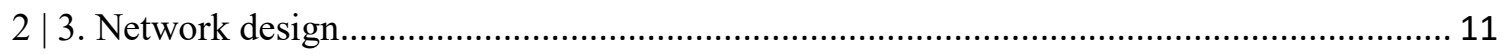

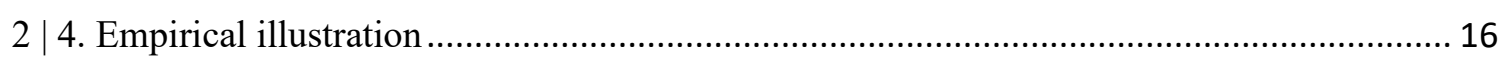

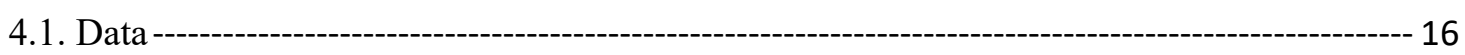

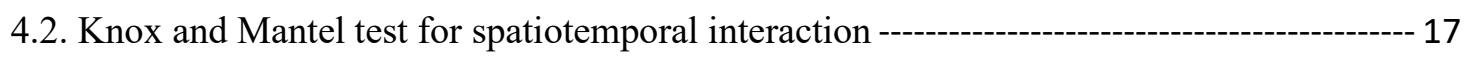

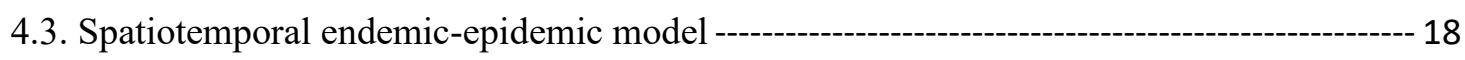

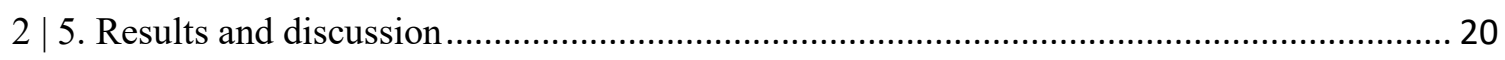

5.1. Model with identical intercepts -----o- 20

5.2. Network effects and network characteristics -- 22

5.3. Robustness validation ---_- 24

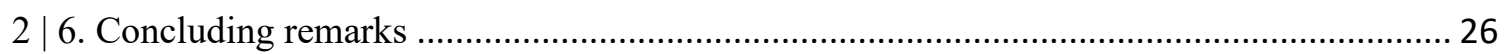

Chapter 3 | Social networks, agglomeration effects, and labour............................................ 27

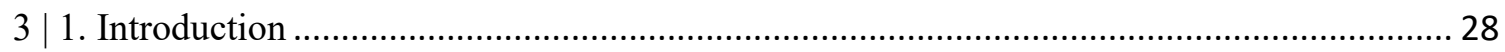

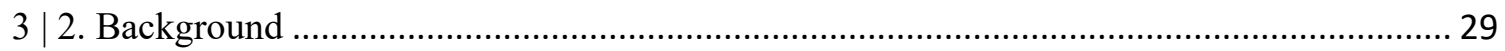

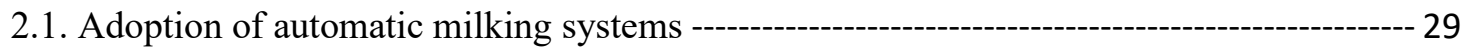

2.2. Network and agglomeration effect ---

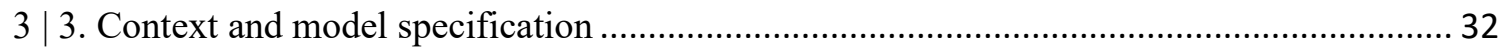

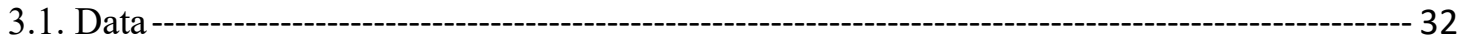

3.2. Network structures ---------- 35

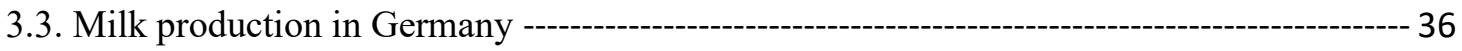

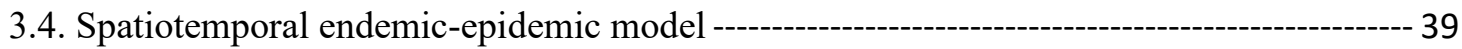




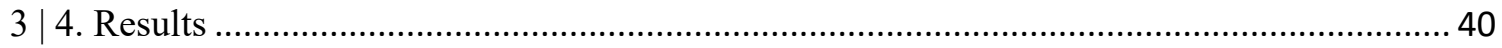

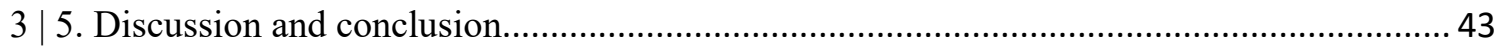

Chapter 4 | A network analysis of local rubber and oil palm trade in Jambi, Indonesia ........ 45

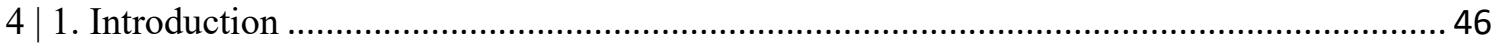

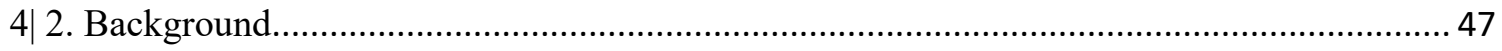

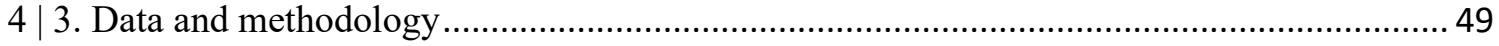

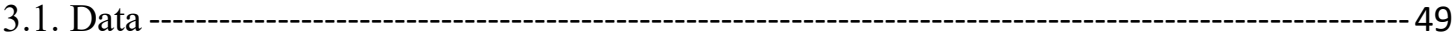

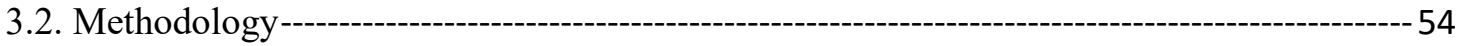

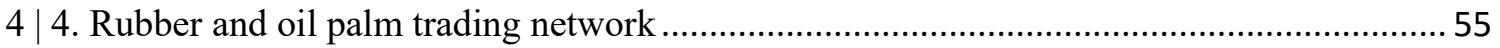

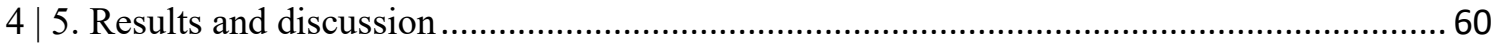

5.1. Cross-sectional dataset --- 60

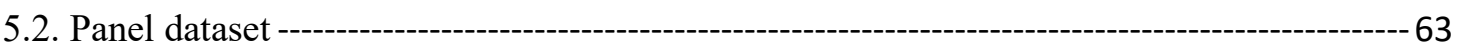

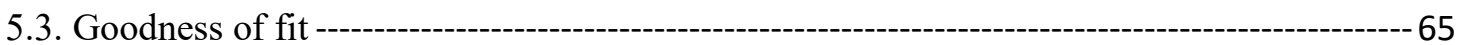

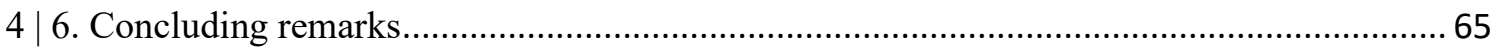

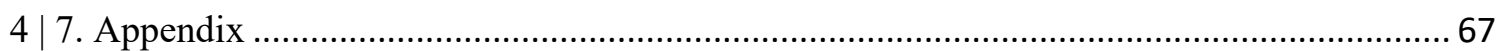

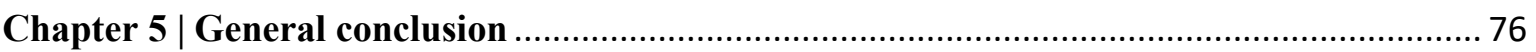

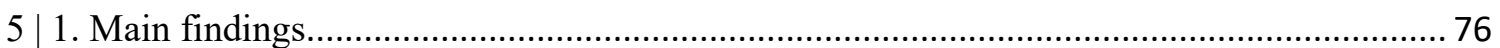

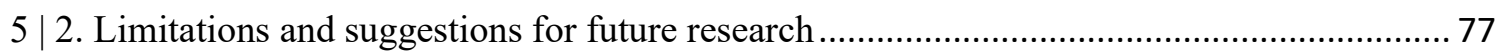

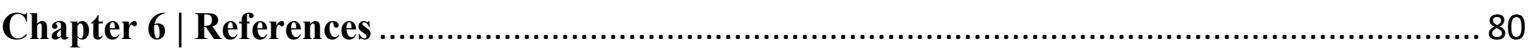

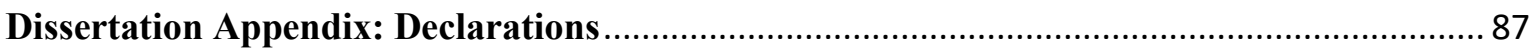




\section{List of figures}

Figure 1 | 1. Stylised representation of network layouts ---

Figure 2 1. Neighbourhood network in network and spatial layout --------o- 13

Figure 2 2. Sales structure network in network and spatial layout--------- 13

Figure 2 3. Dairy structure network in network and spatial layout ------------------------ 14

Figure $2 \mid$ 4. Public farm advisory service network in network and spatial layout------------------- 15

Figure $2 \mid$ 5. Organic farming association network in network and spatial layout --a--o--o- 16

Figure $2 \mid 6$. AMS adoption per year (left) and cumulative adoption over time (right) in Germany

Figure 2 7. Shares of components, 1997 - 2013 (with identical intercepts)------------------ 21

Figure 2 8. Results of random networks --- 22

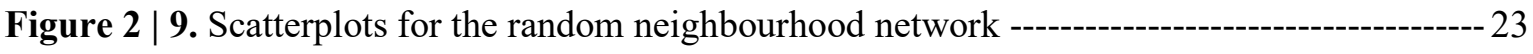

Figure 2 10. Scatterplots for the random neighbourhood network------------------- 24

Figure $2 \mid$ 11. Shares of components, $1997-2913$ (with random intercepts in the exogenous

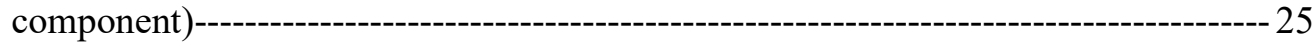

Figure 3 | 1. AMS adoption per year (left) and cumulative adoption over time (right) in Germany

Figure $3 \mid$ 2. Development of adoption of AMS per administrative district in Germany ------- 33

Figure 3 | 3. Network structures: neighbourhood network (left) and sales structure network (right)

Figure 3 4. Local Moran's I (left and right) for the number of dairy farms in 2013 --------------- 37

Figure 3 5. Local Moran's I (left and right) for the number of dairy cows in 2013

Figure 4 | 1. Schematic representation of the rubber and oil palm value chain in Jambi ----------- 48

Figure 4 | 2. Trading network 2012 (left: rubber, right: oil palm) ------------------------------ 56

Figure 4 | 3. Trading network 2015 (left: rubber, right: oil palm)----

Figure 4 | 4. Trading network 2018 (left: rubber, right: oil palm) ------------------------------ 58

Figure 4 | 5. Rubber trading network of the panel dataset --- 59

Figure 4 | 6. Oil palm trading network of the panel dataset --- 59 


\section{List of tables}

Table 2 | 1. Network characteristics --- 12

Table $2 \mid$ 2. p-values for the Knox and Mantel test -----o- 18

Table $2 \mid$ 3. Results for the model with identical intercepts ---------------------------- 20

Table $2 \mid$ 4. Results for the model with random intercepts in the exogenous component ------------ 24

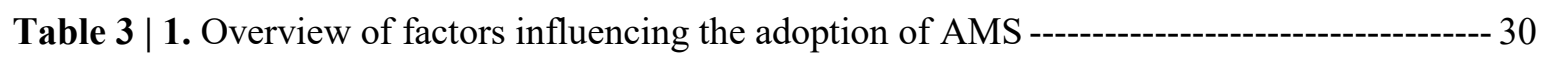

Table 3 | 2. Description of variables -----on

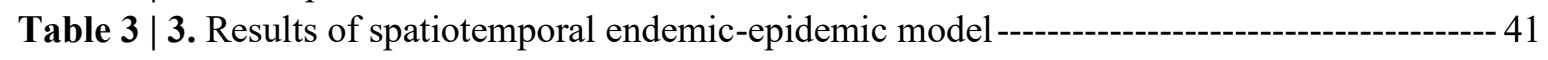

Table 4 | 1. Summary statistics of the cross-sectional dataset------------------------------------------- 51

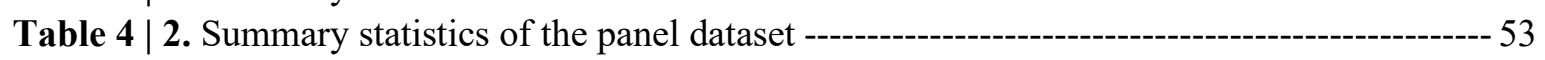

Table 4 | 3. Network summary statistics of the cross-sectional dataset------------------------- 58

Table 4 | 4. Network summary statistics of the panel dataset ---------- 60

Table 4 | 5. ERGM estimates of the cross-sectional dataset (standard errors in parentheses)------- 61

Table 4 | 6. ERGM estimates of the panel dataset (standard errors in parentheses) ------------------ 64

Table 4 | A1. Goodness of fit for rubber and cross-sectional dataset ---------------------------------- 67

Table 4 | A2. Goodness of fit model statistics for rubber and cross-sectional dataset---------------- 68

Table $4 \mid$ A3. Goodness of fit for oil palm and cross-sectional dataset -------------- 69

Table 4 | A4. Goodness of fit model statistics for oil palm and cross-sectional dataset------------ 71

Table 4 | A5. Goodness of fit for rubber and panel dataset----------------------------------------------- 72

Table 4 | A6. Goodness of fit model statistics for rubber and panel dataset ---------------------- 73

Table 4 | A7. Goodness of fit for oil palm and panel dataset-------------------------------- 74

Table 4 | A8. Goodness of fit model statistics for oil palm and panel dataset ------------------------- 75 


\section{List of abbreviations}

AIC

AMS

ERGM

FADN

FAO

GLM

NUTS

S.d.
Akaike's Information Criterion

Automatic milking system

Exponential random graph model

Farm Accountancy Data Network

Food and Agricultural Organization of the United Nations

General linear model

Nomenclature of territorial units for statistics

Standard deviation 



\section{Chapter 1 | General introduction}

\section{1 | 1. Background}

Psychologist Stanley Milgram published in 1967 his experiment about the transmission of a letter from person to person from a randomly chosen starting person to a predetermined target person in the US. His study made history in psychological and sociological research. Although starting and target individual did not know each other in person, one-third of the letters arrived within only six steps. The result is better known as the 'six degrees of separation' or the small world phenomenon, which was formalised by Watts and Strogatz in 1998 (Jackson 2008; Easley and Kleinberg 2010). Stanley's experiment proofs that people in a society are intimately connected even if they never met each other, which forms an important building component in the sociological concept of social network analysis.

Later, social network analysis was incorporated in economic research. Granovetter (1985; 2005) describes economic behaviour as being embedded in an individual's social environment and that the structure of the social setting shapes the economic outcome. Mainly exchange and transmission of information are in the focus of network analysists. Well studied is such an approach for the labour market and job search (Rees and Shultz 1970; Jackson 2008). Information about job vacancies and the employment of people is facilitated through social relations (Granovetter 1973; Corcoran et al. 1980; Ioannides and Datcher 2004).

Environmental economics and governance is another field of research where social networks can ease the understanding of underlying mechanisms regarding the coordination of collective actions (Robins et al. 2011) or how to manage natural resources (Bodin and Crona 2009). Barnes et al. (2016) apply networks to show how communication could reduce bycatch in Hawaii, while Sullivan and Xie (2009) observe the implications of networks on the internet on social movements of Chines environmental activists.

Besides, the visualisation of personal relationships and transmission of information, networks are suitable to display the flow of goods, as in international trade. De Benedictis and Tajoli (2010) examine the world trade flow of various products. In contrast, An et al. (2014) concentrate only on crude oil to find direct and indirect relationships in trade patterns. Reyes et al. (2010) place the integration of specific regions, East Asia and Latin America, in international trade in the centre of their work. Environmental implications of trade can be analysed using networks, as well. The virtual water flow of agricultural products is addressed 
in a study by Yang et al. (2015) and Prell and Feng (2016) elaborate on the carbon trade imbalance.

\section{2. Network components and characteristics}

Social networks are generally described as a set of agents in which some agents are connected by a specific linkage (Glückler 2007; Wasserman and Faust 2009; Easley and Kleinberg 2010). Depending on the setting, these agents can be individuals, households, companies, countries, or any other kind of research objective. Challenging in the formation of a network is the definition of the boundaries of a network. Natural borders can be membership of groups or geographic frontiers. However, communication and transport technologies accomplish social proximity between agents, despite the geographical distance (Glückler 2007). The linkage among them characterises the relationship between the agents (Glückler 2007) and should be defined by the research question and the context (Jackson 2008; Borgatti and Halgin 2011). Links be continuous, like kinship, or discrete, like the transaction of information or goods (Borgatti and Halgin 2011).

In the network visualisation and analysis, agents are referred to as nodes and the connection as links. The set $N=\{1, \ldots, n\}$ is the set of nodes involved in the network graph $(N, g)$, where $g_{i j}$ is the relation between two nodes $i$ and $j$. The link $g$ is undirected when $g_{i j}=$ $g_{j i}$ and directed when $g_{i j} \neq g_{j i}$. When all links are present, the network is called complete (Jackson 2008; Wasserman and Faust 2009).

Figure 1 1. Stylised representation of network layouts

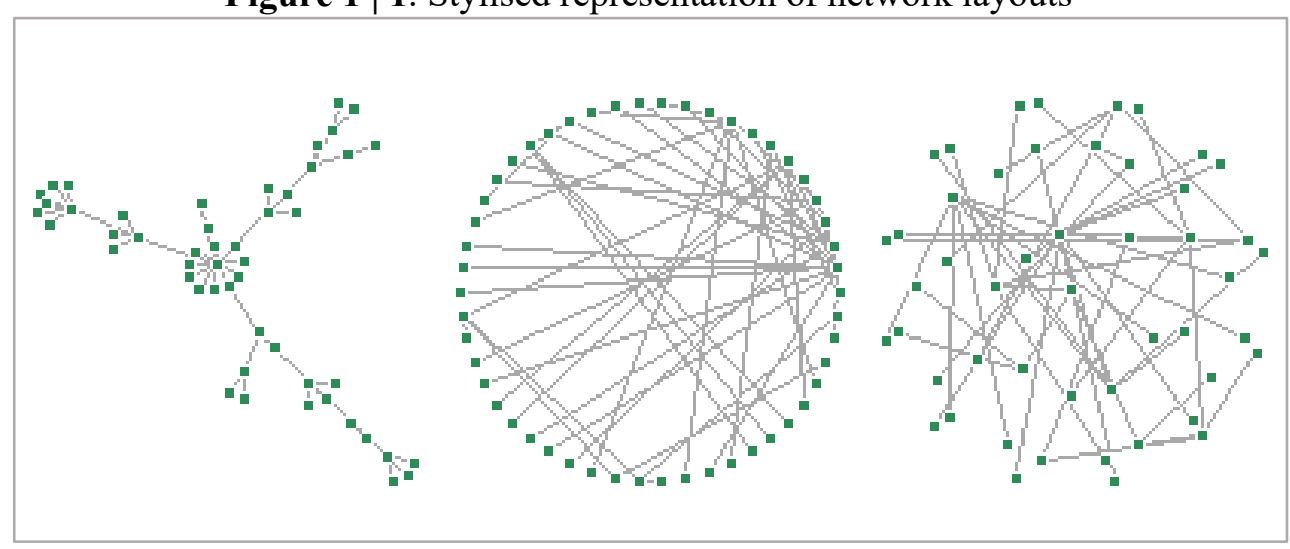

The figure displays three networks with 50 nodes and 49 links in three layouts.

On the left: scale-free model; in the centre: small-world model; on the right: random model 
All components together form the network structure. The network structure can give first impressions of the pattern of the relations and substantially influences the outcome, for example for transaction and diffusion networks (Glückler 2007; Jackson 2008; Easley and Kleinberg 2010; Borgatti and Halgin 2011). As shown in Figure 1|1, the same number of nodes and links can lead to several network structure and therefore to different possible outcomes. Analysing the network characteristics can support the understanding of the network structure and its implications on the research setting (van Duijn and Vermunt 2006).

Network characteristics, for example, are the size of the network, the degree, density, average shortest path, diameter or the transitivity ${ }^{1}$. The size of a defined by the number of nodes and links. The degree of a node is the number of links directly related to the node. It is calculated as:

$$
d_{i}(g)=N_{i}(g)
$$

In a directed network, the degree can be distinguished between in-degree and out-degree. The in-degree is the number of links towards the node, and the out-degree is the number of links away from the node.

The density describes the fraction of links that are present in relation to the number of possible links in the network:

$$
\Delta=\frac{2 L}{N(N-1)}
$$

with $L$ being the number of present links and $N$ being the number of nodes.

Average shortest path and diameter are related to the number of links between two particular nodes. The average shortest path indicates the shortest distance between two nodes, without repeating links. The diameter describes the longest distance between two nodes using the direct route. The transitivity or clustering coefficient measures the number of nodes linked to two nodes, which are already mutually linked, so-called triangles.

Measuring network characteristics can associate network structure and statistical modelling, in addition to the nodal attributes (Borgatti and Halgin 2011). Thus, in the focus of social network analysis is the influence of network properties on the outcome, the evolution of network characteristics over time, and the role of the social network on the behaviour and

\footnotetext{
${ }^{1}$ We refer to Jackson (2008), Wasserman and Faust (2009), and Easley and Kleinberg (2010) in the description of the network properties
} 
decisions of the considered agents and vice versa (Easley and Kleinberg 2010; Borgatti and Halgin 2011).

\section{3. Networks in agricultural economics}

In agricultural economics, social networks are mainly deployed in innovation and adoption research. Some studies focus on networks as drivers of adoption without specifying the considered technology (Diederen et al. 2003; Kondylis et al. 2014; Beaman et al. 2016; Läpple et al. 2016; 2017). Sampson and Perry (2019) study the influence of peers on the adoption of groundwater rights for irrigation technology in the US, while Genius et al. (2013) analyse the adoption of irrigation technology among olive growers in Crete. Both elaborate on the importance of peer effects in the adoption process. However, the influence of the social network of a farmer decreases with increasing distance between the peers.

Some authors conduct studies on specific management practices, like organic farming (Wollni and Anderson 2014) or conservation practices (Brown and Roper 2017). Wollni and Anderson (2014) report of neighbourhood and agglomeration effects as a factor in the implementation of organic farming in Honduras, which again is decreasing with increasing distance.

Other studies concentrate on the adoption of specific crops or improved seeds. In 1995 publish Foster and Rosenzweig their work about the adoption of high yield varieties in India. They distinguish between learning-by-doing and learning-from-others, affecting planting decisions and expectations. The study reveals that farmers with experienced and successful neighbours are more profitable and allocate more land to the cultivation of the new crop. This result can be widely confirmed by more recent studies (Baerenklau 2005; Matuschke and Qaim 2009; Conley and Udry 2010; Krishnan and Patnam 2013; Xiong et al. 2016; Maertens 2017). Those findings can be explained as farmers classify fellow farmers as their most reliable source of information (Just and Zilberman 2002; Brown et al. 2016), because they are working in similar conditions (Conley and Udry 2010). Further, access to information and knowledge is crucial to the successful adoption of technology and peers are an appropriate source of information in many settings (Feder and Slade 1984; Feder and Umali 1993).

However, the previously named studies analyse the influence of neighbourhood and peers on the decisions of individual farmers, only a few conduct data on relationships and sources 
of information of farmers to construct individual networks. In their widely recognised study on the adoption of pineapple in South Ghana, Conley and Udry (2010) evaluated data on individual farmers' networks obtained in regular survey rounds within two years. Also, Hoang et al. (2006) in their research on access to information and extension services in Vietnam, Diaz-José et al. (2016) in their work on conservation practices in Mexico and Maertens (2017) in her study on the adoption of Bt cotton in India, collected detailed individual network data.

Instead of obtaining relational data, proxies of networks are frequently used. Many surveys use spatial proximity to assume relationships between particular groups (Genius et al. 2013; Krishnan and Patnam 2013; Ward and Pede 2014; Wollni and Anderson 2014; Läpple et al. 2016; 2017; Sampson and Perry 2019). Other use membership in groups or the number of known farmers who adopted (Diederen et al. 2003; Baerenklau 2005; Pierpaoli et al. 2013; Ma et al. 2014).

Collecting individual network data can be an expensive and challenging thing to do, as for conclusive networks, the entire group of agents needs to be surveyed, and randomness is only possible to a limited extent. This contradicts most of the conventional sampling practices. Conley and Udry (2010) and Maertens (2017) use random-matching-withinsampling, while Diaz-José et al. (2016) apply snowball sampling to compile the networks. Hoang et al. (2006) concentrate their survey on one village and interviewed 73 out of 82 households. Thus, utilising network proxies is often less time consuming and reasonable.

In other areas of agricultural economics than technology adoption, networks are most underrepresented. Social network analyses have been conducted in the spread of livestock diseases using movement and trade networks (Ortiz-Pelaez et al. 2006; Nicolas et al. 2013; Lentz et al. 2016). Although trade flows are aforementioned as being extremely suitable for network analysis, agricultural trade on a regional level is mostly neglected in research.

\section{1 | 4. Research objectives and outline}

This dissertation contains three essays examining social networks in modern agriculture. In the first and second essay, we analyse the diffusion and adoption of automatic milking systems using networks structures as an explanatory factor. While many studies on the adoption of technology are confined to a short period of time covers our dataset a maximum of 17 years. Additional, while many studies on the relevance of networks in the adoption 
process are located in developing countries, concentrate our work on dairy farms in Germany. The third essay explores the local trade of rubber and oil palm in Indonesia. We specify trade networks to show differences in the value chain of both products over the time of three survey rounds.

In summary, this dissertation aims to answer the following research questions:

- Does agricultural technology spread through network structures over time?

- Do different network structures have a different impact on the distribution of technology and which network structure fits best?

- Are there regional differences in the adoption pattern of automatic milking systems in Germany?

- What kind of factors are shaping the adoption decision of automatic milking systems? Are agglomeration and network effects still relevant?

- How do the trading networks of rubber and oil palm in Jambi look like and do they change over time? Are there differences in the network patterns of both products?

- What aspects determine the formation of links between sellers and buyers?

The remainder of this dissertation is structured as follows: Chapter $\mathbf{2}$ discusses the application of several network structures in the process of diffusion and adoption of automatic milking systems in Germany. Chapter 3 tests the relevance of networks structures while controlling for other economic aspects affecting the adoption of automatic milking systems. Chapter 4 elaborates the explanatory power of social networks displaying and analysing local trade structures of rubber and oil palm in Indonesia. Chapter 5 discusses the main result of the essays and concludes this dissertation. 


\title{
Chapter 2 | Do networks matter? Diffusion through network structures $^{2}$
}

\begin{abstract}
As information about the availability and suitability of innovation is one of the critical factors in the diffusion and adoption process of agricultural technology, its transmission is of crucial importance. Farming neighbours are often mentioned as the most significant origin of knowledge. However, various sources, like extension services, technology providing companies, and downstream and upstream industries are significant stakeholders One instrument in displaying information patterns originated from different sources to farmers are social networks by linking various agents. We are applying those networks in case of adoption of automatic milking systems in Germany. Thus, we construct five different network structures to analyse their impact and relevance in the process of diffusion and adoption of technology: the neighbourhood network, the sales structure network, the dairy factory network, the public advisory network, and the organic farming association network. A spatiotemporal endemic-epidemic model for infectious disease spread is applied to capture the dynamic contagious process of diffusion. Different outcomes occur for distinctive networks. The neighbourhood network provides the best fit, as well as the most substantial impact on the diffusion. The public advisory network, in contrast, performs poorly and influences less than $1 \%$.
\end{abstract}

Keywords - technology adoption, networks, automatic milking systems, neighbourhood network, sales structure network

\footnotetext{
${ }^{2}$ This chapter is co-authored by Juliane Manitz (JM), Sebastian Meyer (SM) and Bernhard Brümmer (BB). $\mathrm{CH}, \mathrm{JM}$ and $\mathrm{BB}$ jointly developed the research idea. $\mathrm{CH}$ and JM designed the network structures. SM supported the statistical analysis. $\mathrm{CH}$ did the literature review, the data analysis, and wrote the essay. BB commented the various stages of the research and contributed to writing and revising the essay.
} 


\section{2 | 1. Introduction}

Adoption of technology is often accompanied by risk and uncertainty (Feder and Slade 1984, 1985; Sauer and Zilberman 2012; Xiong et al. 2016) for individual farmers. However, for a rapid diffusion, information about profitability and characteristics of the technology are crucial (Foster and Rosenzweig 2010) and costly. Uncertainty and costs can be reduced by free-riding on experience and information of other farmers (Foster and Rosenzweig 1995; Läpple et al. 2017). Studies report that the performance of farming neighbours can matter for the adoption decision, referred to as peer or spillover effects (Maertens and Barrett 2012; Wollni and Anderson 2014; Beaman et al. 2016; Xiong et al. 2016; Läpple et al. 2017). Foster and Rosenzweig (1995), for example, observe higher profitability of farmers with neighbours using the same technology. Delre et al. (2010), on the contrary, note that farmers do not adopt technology because their neighbours did not adopt either. An explanation for these observations could be similar production conditions (Ward and Pede 2014; Sumane et al. 2017) and the opportunity of practical demonstrations of suitability and operation (Brown et al. 2016; Xiong et al. 2016; Brown and Roper 2017). In summary, farmers are observing their neighbour's behaviour and much likely adopt their habits (Rogers 1995), because of the transferred information regarding the technology to adopt.

Peer effects are recognised widely as essential in the process of technology diffusion and adoption. However, this process can be shaped by a variety of additional stakeholders serving as the source of information. Läpple et al. (2015) promote the inclusion of policy, extension services, and the supply chain. Besides, Feder and Umali (1993) suggest that different sources of information can lead to differences in learning and thus to differences in the pattern of technology diffusion in agriculture. Others report variations in the importance of sources of information in different stages of the adoption process (Baptista 2000; Xiong et al. 2016). In this paper, we use social networks as an instrument to display various origins of information spread. Social networks enable to overcome close spatial proximity. We show the influence of five information sources in the adoption process - neighbouring farmers, sales structure of the manufacturer of the technology, downstream industry, public farm advisory services and farming associations. Each network is structured differently by linking the information sources with individual farmers to capture variations in the distribution pattern. The questions we address are: does agricultural technology spread through network structures over time? Do different network structures have a different impact on the distribution of technology? Which network structure fits best? 
We implement the theoretical considerations using a spatiotemporal endemic-epidemic model for infectious disease spread to explain the distribution of automatic milking systems (AMS) in Germany from 1997 to 2013. Most studies regard peer effects only during a minimum period and only over a short spatial distance or narrow social unit due to constraints in their research setting. In this paper, our analysis spans over 17 years and all 402 German administrative districts. The employed model allows us to address Manski's (1993) identification problem of social effects and to display the dynamic characteristics of technology adoption. Our results are in line with the literature. According to the Akaike's Information Criterion (AIC), the neighbourhood network is the best performing network among our considered networks. Nevertheless, exogenous factors are driving the spread of AMS in Germany.

The paper is structured as follows. In Section 2, we explain the theoretical design. Afterwards, we present a detailed description of the networks (Section 3) used in the empirical illustration (Section 4). In Section 5, we provide the results of the basic model and its specification. Section 6 concludes the paper.

\section{2. Theoretical background}

Previous studies concentrated on the influence of farming neighbours or personal relationships in informal networks on the adoption decision of individual farmers (Feder et al. 2004). However, various formal sources are conceivable because of different stakeholders in the agricultural value chain (Feder and Umali 1993; Läpple et al. 2015; Sumane et al. 2017). Just and Zilberman (2002) suggest incorporating extension services, public agencies, commodity groups or commercial firms. Studies investigating the impact of extension services, predominantly in developing countries (Feder et al. 2004; Krishnan and Patnam 2013; Ma et al. 2014; Wollni and Anderson 2014; Niu and Ragasa 2018), reveal that extension services are successful in raising awareness for the availability of innovations in early stages of the adoption process while becoming less relevant in later stages (Feder et al. 2004; Ma et al. 2014). Other stakeholders in upstream and downstream industries, for instance, input suppliers (Feder and Slade 1984; Ma et al. 2014), technology suppliers or experts (Feder et al. 2004; Sauer and Zilberman 2012), as well as research institutions or public administration (Fritsch and Kauffeld-Monz 2008; Sumane et al. 2017) can provide specific details on technology and operation. 
Social networks can serve as an instrument to link these different kinds of sources of information with the individual farmer over space and time by displaying the pattern of the information flow. The network structure determines the spreading pattern of information or technology (Easley and Kleinberg 2010). Rogers (1995) confirms that diffusion and adoption are facilitated or handicapped by the structure of the social environment. Hence, in the understanding of the social spillover effects on the adoption of technology the design of the social environment should be emphasised as network links can be predictors of the individual's adoption behaviour (Rogers 1995).

Using social network theory to explain the diffusion and adoption of technology requires the consideration of diverse aspects. Many studies report the impact of the decisions of neighbours and peers on the decision making of individual farmers but often cannot distinguish or separate between different underlying interconnections leading to the primary source of influence (Baerenklau 2005; Wollni and Anderson 2014; Sampson and Perry 2019). First discussed in 1993 by Manski as the reflection problem of social effects, this issue is frequently picked up in literature as identification problem (Bramoullé et al. 2009; Sauer and Zilberman 2012; Ward and Pede 2014). Manski (1993) differentiates between three types of effects: the endogenous effect, the exogenous or contextual effect, and the correlated effect. Endogenous effects represent the actual peer effects and group interactions, shaping the decision of an individual farmer. In general, these effects suggest that the tendency of a farmer to adopt varies with the adoption behaviour of his or her peer group (Baerenklau 2005; Sauer and Zilberman 2012). Conversely, exogenous or contextual effects address the exogenous characteristics of the farmer's peer group (Sauer and Zilberman 2012; Ward and Pede 2014). Correlated effects refer to similar behaviour of farmers due to similar production characteristics or constraints (Baerenklau 2005; Bramoullé et al. 2009; Ward and Pede 2014).

The identification problem must be taken into account when choosing a method for the analysis of network effects on adoption decisions as with linear models it is not possible to disentangle endo- and exogenous effects (Baerenklau 2005). Furthermore, diffusion of innovation and adoption of technology is described as being similar to the spread of an epidemic disease because of its dynamic contagious process (Beaman et al. 2016). Epidemiological threshold models like SIR (susceptible - infected - recovered) or SIS (susceptible - infected - susceptible) are often used illustrating technology adoption (Valente 1996; Watts and Dodds 2007; Beaman et al. 2016) which assumes the individual 
farmer adopts a technology as soon as a certain percentage of his or her neighbours adopted previously. We suggest taking advantage of the well-established spatiotemporal endemicepidemic modelling framework "hhh4" to address both the identification problem of social effects and the contagious nature of diffusion of innovation and technology adoption.

\section{2 | 3. Network design}

Networks are composed of nodes, each of them representing an agent in a social environment. Links connect the nodes, representing the relationships and interdependencies among these agents, both forming the shape of the network. Different shapes can picture differential flows of information originated by distinct sources and spreading patterns along with the links between nodes. We developed five network structures to capture various sources of information about AMS and to display different patterns of information flow. In our networks, the nodes reflect German administrative districts the farmers are located in. Therefore, all five networks share the same size with 402 nodes, according to the 402 administrative districts in Germany. The number of links depends on the supposed structure and differs among the presented networks from 412 to 1053 links.

The structure of the networks, thus the pattern of the information flow, can be described by various properties. We measure five network properties to characterise and differentiate our networks, following Wasserman and Faust (2009): density, average degree, average shortest path, diameter, and transitivity. We evaluate the networks according to their network characteristics listed in Table 2|1.

Density in the network context is understood as the proportion of the number of possible links to the number of the actual present links. It can take any value between 0 , equal to there are no links, and 1, equal to all links are present, and the graph is complete.

The density is measured as

$$
\Delta=\frac{2 L}{g(g-1)}
$$

with $L$ being the number of present links and $g$ being the number of nodes in the network. The degree of nodes is related to the density. The degree states the number of links occurring at an individual node and again ranges between 0 , the node is isolated, and $(g-1)$, the node is connected to all other nodes in the network. 
The expansion of a network can be indicated by two properties, the average shortest path, and the diameter. The shortest path describes the distance between two distinct nodes, with its length is specified as the number of non-repeated links between them (Easley and Kleinberg 2010). In contrast, the diameter reports the longest distance between two nodes by assuming the direct route. Information can spread from one node to another with the diameter giving the maximum number of links between both of them.

Table $2 \mid$ 1. Network characteristics

\begin{tabular}{lcccccc}
\hline Network structure & Links & Density & $\begin{array}{c}\text { Average } \\
\text { Degree }\end{array}$ & $\begin{array}{c}\text { Average } \\
\text { shortest } \\
\text { path }\end{array}$ & Diameter & Transitivity \\
\hline Neighbourhood & 1053 & 0.0131 & 5.24 & 8.81 & 22 & 0.3741 \\
Sales structure & 573 & 0.0071 & 2.85 & 2.83 & 3 & 0.2169 \\
Dairy structure & 582 & 0.0072 & 2.90 & 5.37 & 11 & 0.0113 \\
Advisory service & 492 & 0.0061 & 2.45 & 2.81 & 3 & 0.0852 \\
Organic association & 412 & 0.0051 & 2.05 & 3.49 & 6 & 0
\end{tabular}

Finally, transitivity is defined as the ratio of the number of triangles to the number of triples of actors in a graph. A triangle consists of three nodes with two links. For example, if node $\mathrm{x}$ is related to node $\mathrm{y}$, node $\mathrm{y}$ is related to node $\mathrm{z}$ a triangle arises. Additionally, if node $\mathrm{x}$ is related to node $\mathrm{z}$, a triple emerges. Transitivity can take values between 0 , there are no triangles in the network at all, and 1, there are only cliques in the network (Wasserman and Faust 2009; Easley and Kleinberg 2010). For this reason, transitivity is close related to the clustering coefficient, which gives the probability of a triple link.

\section{Neighbourhood network}

The first network displays the classical neighbourhood network (Figure 2|1). It contains links between adjacent districts. We assume that farmers in one administrative district $i_{1}$ know and talk to each other. Thus, information spreads along with the links to farmers in a neighbouring administrative district $i_{2}$. The network is constructed by connecting all districts sharing common borders, which leads to the spatial shape of Germany.

This network is the densest one with a value of 0.0131 and 1053 links (compare Table 2|1). On average each node is connected to 5 other nodes, with the average shortest path equal to 9 and the longest distance between two nodes is 22 . Again, the value of transitivity remains the highest at 0.374 . 
Figure 2 | 1. Neighbourhood network in network and spatial layout
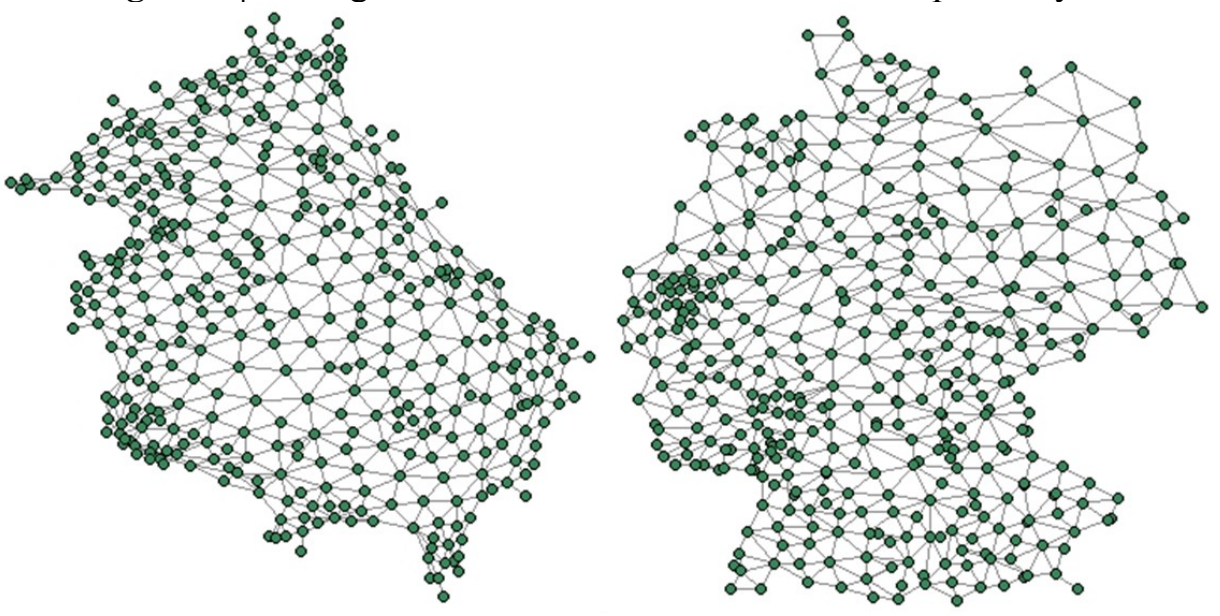

$\underline{\text { Sales structure network }}$

Network two exhibits the sales structure the AMS manufacturer is providing to promote and distribute the technology (Figure 2|2). In 2013, the company maintained 20 sales centres all over Germany, each one serving a specific area and number of administrative districts, which are not necessarily equal to the federal states. The information flows from the sales centre in one administrative district to the farmers in one of its serving districts. The network is constructed first by assigning each sales centre to the respective administrative district and second by linking them to the served area. Since all centres belong to the same company, they are linked to each other, as we are assuming a uniform information basis and communication policy. This leads to a network with 573 links and a density of 0.0071 , which is almost half the density of the neighbourhood network. With a value of 2.8 for the average shortest path and 3 for the diameter, this network is also much smaller than the neighbourhood network.

Figure $2 \mid$ 2. Sales structure network in network and spatial layout
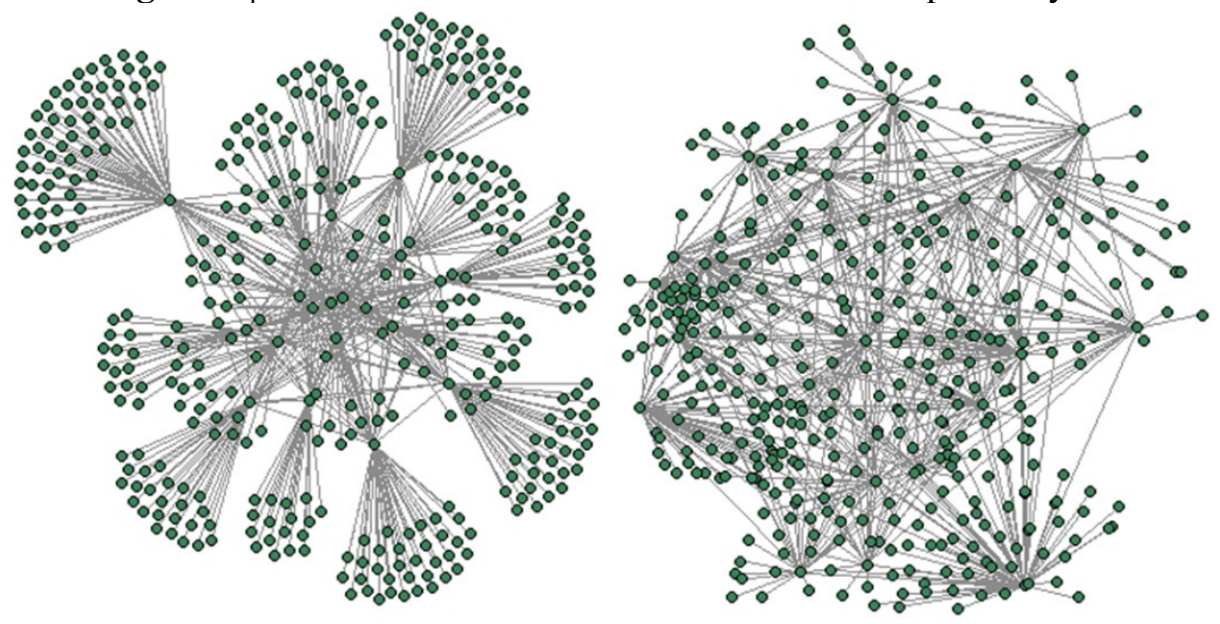


\section{Dairy structure network}

The third network shows all 117 dairies present in 2013. Most of them maintain only one plant, while some few have branches (in total 96 branches) located nearby or even in other parts of Germany (Figure 2|3). This network structure supposes that dairies provide their suppliers with some information about innovation in technology and management due to positive health and quality aspects achieved by automatic milking (Bergman and Rabinowicz 2013; Woodford et al. 2015). We assume further that each farmer is supplying only one dairy and that they are choosing the geographically closest one, as the dataset does not contain any information about the actual dairy the farmer supplies to. First, the dairies are assigned to the respective administrative district, and afterwards, the farmer is linked to his or her closest dairy. If there are two or more dairies in the same geographically distance, the farmer is allocated randomly to one of them. Figure 2/3 displays the network with links between the closest three dairies, additional to the links between headquarters and branches. The dairy structure network is the second-largest network according to the average shortest path (5.37), diameter (11), and density (0.0072) (compare Table 2|1).

Figure 2 | 3. Dairy structure network in network and spatial layout
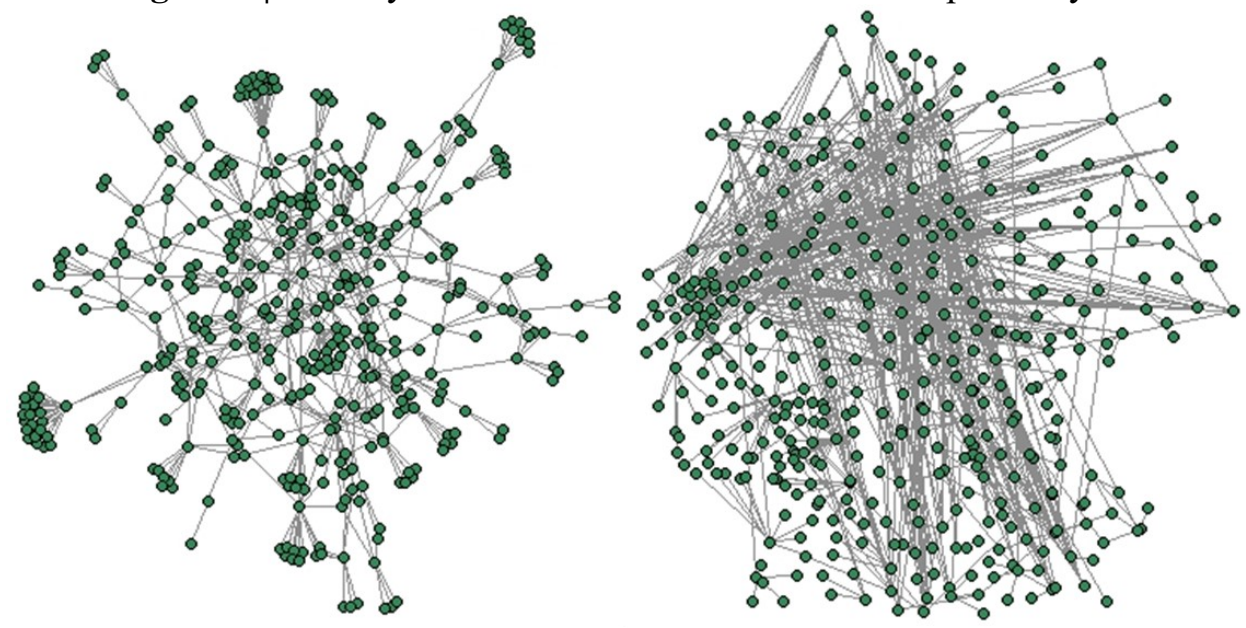

$\underline{\text { Public farm advisory service network }}$

Network four illustrates the 212 German public advisory centres for agricultural matters (Figure 2|4). Affiliated to the Ministry of Agriculture of each German federal state, institutions like the so-called agricultural chambers (Landwirtschaftskammer) and boards of agriculture (Landwirtschaftsamt) offer advisory services. The number is varying in each federal state, and the facilities serve only farmers in the respective federal state. Private counsellors are explicitly disregarded in the development of the network. Advice seeking 
farmers can turn to the agricultural chamber in his or her federal state to gather information about milking systems. Again, each advisory service is allocated to its administrative district. Then, the remaining administrative districts in each federal state are linked. The farmers are assigned to the geographically closest service centre. According to its network characteristics, the advisory service network has 492 links with 2.45 links at each node on average. It is rather small, compared to the other introduced networks, according to the average shortest path of 2.81 and diameter of 3. Density and transitivity are a lot smaller than the values of the neighbourhood network.

Figure 2 4. Public farm advisory service network in network and spatial layout

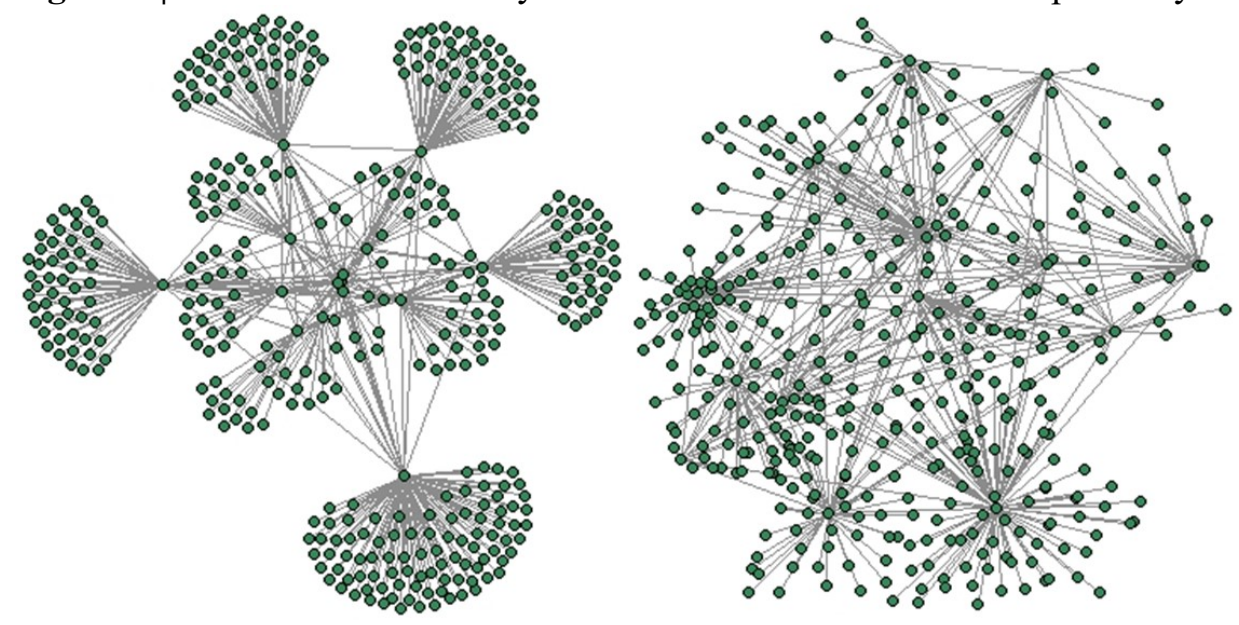

Organic farming association network

The last network views the seven organic farming associations in Germany: Biokreis, Bioland, Ecoland, Biopark, Demeter, Gäa, Naturland (Figure 2|5). Some of them work only in individual administrative districts; others operate nationwide with branches in different locations. We assume the organic farming associations to share information with the farmers about AMS as the systems are promoted to be appropriate for organic milk production (Sauer and Zilberman 2012). As before, we presume farmers, who are interested in organic production, to join the closest organic farming association. However, this is a very restrictive assumption, as organic production is often accompanied by a particular production philosophy, which can differ among the various associations. For this reason, the organic farming association network has the fewest links (412), and the lowest average degree of 2 (compare Table 2|1). The value for the average shortest path (3.49) and the diameter (6), in contrast, lies in between the results of the previous networks. 
Figure $2 \mid$ 5. Organic farming association network in network and spatial layout
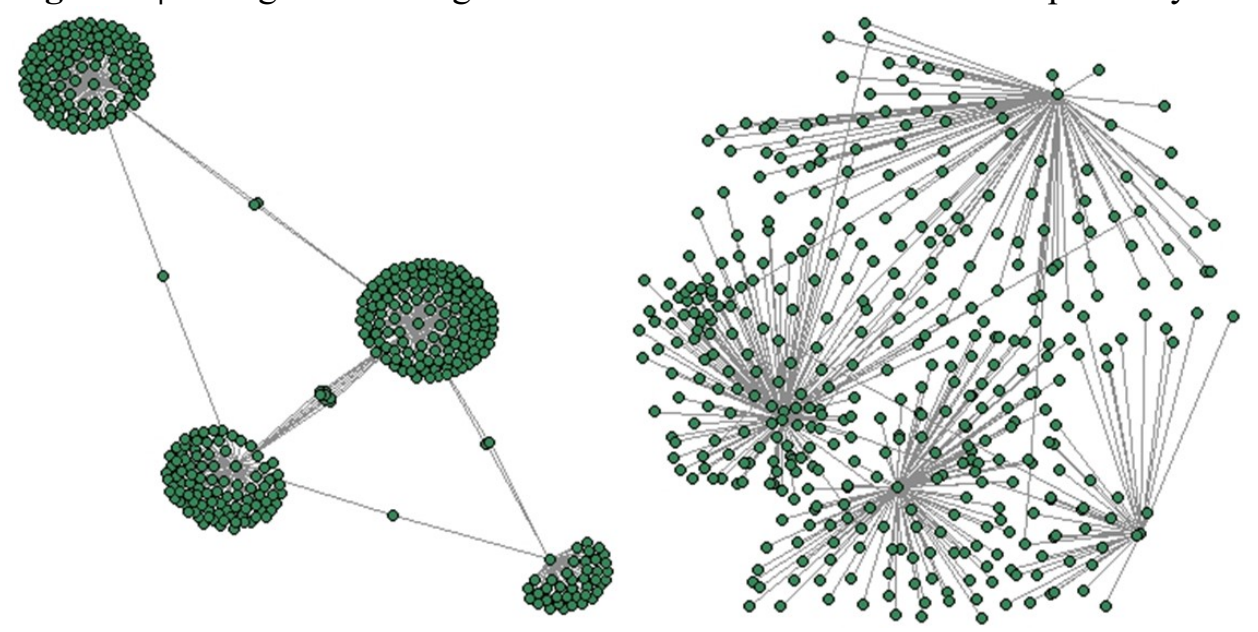

\section{2 | 4. Empirical illustration}

\subsection{Data}

The application is based on a dataset of installed AMS in Germany by one manufacturer. The data provides the postal codes and dates of each installation; in total, 2,531 AMS have been installed between July 1997 and November 2013. As the analysis is based on administrative district levels in Germany per year, the postal codes are assigned to the respective administrative districts and aggregated to a yearly basis.

Figure $2 \mid$ 6. AMS adoption per year (left) and cumulative adoption over time (right) in Germany
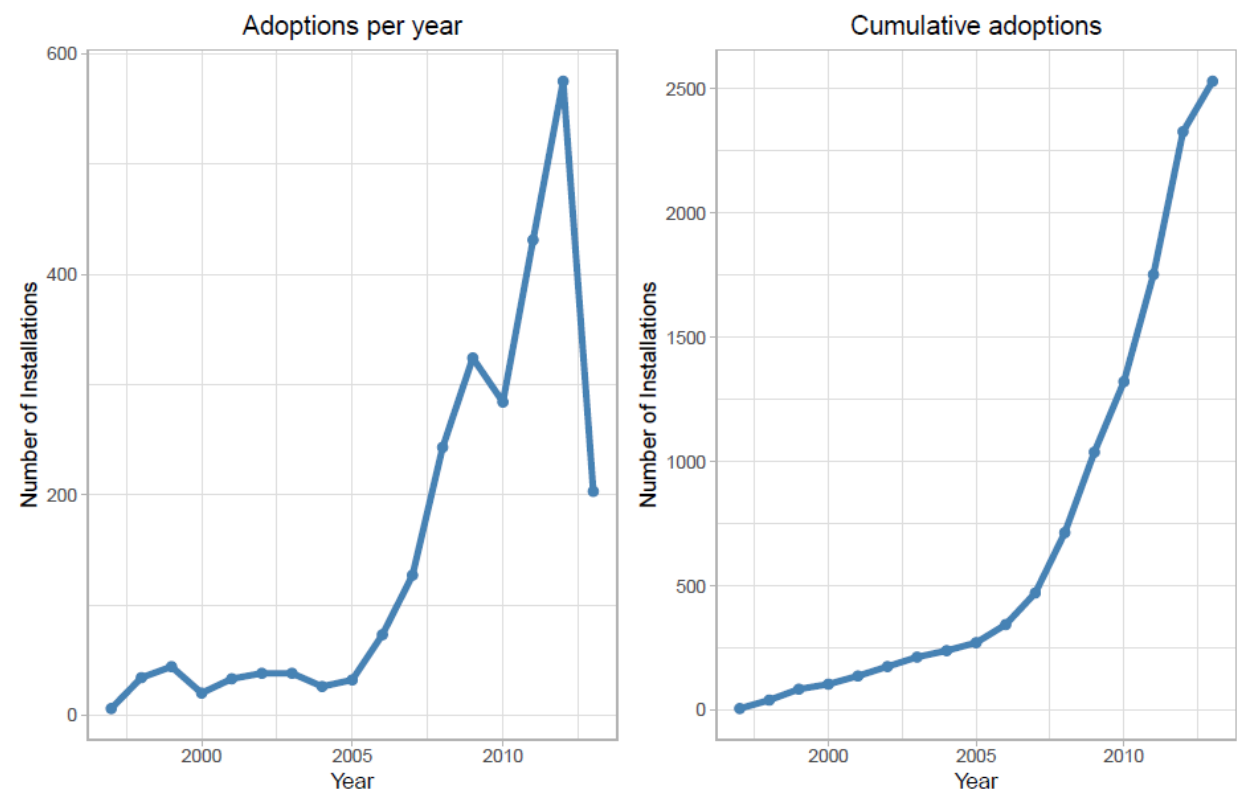

Figure $2 \mid 6$ shows on the left side the absolute number of AMS installations of this manufacturer per year, on the right side, in comparison, the cumulative number of AMS over 
the full period. While in 1997 only six systems were installed, there are 127 installed in 2007, with its peak in 2012 with 575 systems. Furthermore, the graph shows that the rate of diffusion remains low until 2005 (almost a linear trend in Figure 2|6) and then speeds up. The low number of AMS in 2013 could emerge as not the whole year is contained in the dataset. This explanation is strengthened, as considered monthly, AMS installations primarily take place in the winter months. However, it is also conceivable that the adoption of AMS by this manufacturer decreases, for instance, because of increasing competition. Such a trend is incomprehensible by this dataset.

Due to the structure of the available dataset, we cannot control for self-selection, as we are using the number of installed milking system by one company. Besides, our research area exclusively concentrates on Germany and our networks, as well, display the national territory. This can lead to an underrating of influences in the administrative districts at the German border. The adoption behaviour of dairy farmers in the border regions of neighbouring countries could have an impact on German farmers, of course, but is not considered in our network structures. That is also because we do not have information on the sources of information or communication patterns of the farmers in the used dataset.

\subsection{Knox and Mantel test for spatiotemporal interaction}

Before modelling the spatiotemporal endemic-epidemic model, interaction in the dataset needs to be verified to assess evidence for spatiotemporal dependence. It has to be tested in advance if AMS installations tend to cluster in time and space. Classical approaches for testing interaction of a given point pattern $\left\{\left(s_{i}, t_{i}\right): \mathrm{i}=1, \ldots, \mathrm{n}\right\}$ with spatial coordinates $S_{i}$ and time points $t_{i}$ observed in region $\mathrm{W}$ during a period $(0, \mathrm{~T}]$, are the Mantel test and the Knox test (Meyer et al. 2016b). Both measures test against the null hypothesis that cases do not appear in spatiotemporal clusters and use a function of respective Euclidean distances to define space $\left(d_{i j}^{S}=\left\|s_{i}-s_{j}\right\|\right)$ and time $\left(d_{i j}^{t}=\left\|t_{i}-t_{j}\right\|\right)$ for a pair of events $\mathrm{i}$ and $\mathrm{j}$ (Meyer et al. 2016b).

The standardised Mantel test statistic as a Pearson correlation (Mantel 1967; Meyer et al. 2016b):

$$
T_{\text {Mantel }}=\frac{1}{n(n-1)-2} \sum_{i=1}^{n} \sum_{j \neq i} \frac{d_{i j}^{s}-\overline{d_{s}}}{\widehat{\sigma}_{d^{s}}} \frac{d_{i j}^{t}-\overline{d_{t}}}{\widehat{\sigma}_{d^{t}}},
$$

with $\bar{d}=$ sample means and $\hat{\sigma}_{d}=$ standard deviations of the pairwise distances. 
For the Knox test, it is critical to predefine closeness in space and in time (Meyer et al. 2016). In the case of AMS in Germany, close in time installations are implemented within one year ( $\tau=365$ days) or within half a year ( $\tau=182$ days), respectively. Close in distance are installations within the same administrative district $(\delta=0)$ or in adjacent districts $(\delta=1)$, respectively. Knox test statistic (Knox and Bartlett 1964; Meyer et al. 2016):

$$
T_{\text {Knox }}=\frac{1}{2} \sum_{i=1}^{n} \sum_{j \neq i} \mathbb{1}\left(d_{i j}^{S} \leq \delta\right) \mathbb{1}\left(d_{i j}^{t} \leq \tau\right)
$$

with $\delta=$ closeness in space and $\tau=$ closeness in time.

Both the Mantel and the Knox test reject the null hypothesis with a p-value of 0.019 for the Mantel test and a p-value of 0.001 for all Knox test specifications (compare Table 2|2). This suggests that there is an interaction of space and time in the dataset and the spatiotemporal hhh4 models for the different network structures can be measured.

Table $2 \mid$ 2. p-values for the Knox and Mantel test

$\begin{array}{lll}\text { Mantel test } & & \text { p-value }=0.019 \\ & \tau=182, \delta=0 & \text { p-value }=0.001 \\ \text { Knox test } & \tau=182, \delta=1 & \text { p-value }=0.001 \\ & \tau=365, \delta=0 & \text { p-value }=0.001 \\ \tau=365, \delta=1 & \text { p-value }=0.001\end{array}$

\subsection{Spatiotemporal endemic-epidemic $\operatorname{model}^{3}$}

The spatiotemporal endemic-epidemic modelling framework "hhh4", initially developed for infectious disease surveillance data by Held et al. (2005) can be applied to the adoption of technology due to various extensions (Paul et al. 2008; Paul and Held 2011; Meyer et al. 2017) using the R package surveillance (Meyer et al. 2016a). The advantage of the model resides in its decomposition into an endemic and epidemic component, capturing different aspects of the diffusion process and revealing the three effects of the identification problem. In detail, the hhh4 model assumes that the counts $Y_{i t}$ from unit $i=1, \ldots, I$ during periods $t=$ $1, \ldots, T$ are negative binomial distributed with mean

$$
\mu_{i t}=e_{i t} v_{i t}+\lambda_{i t} Y_{i, t-1}+\phi_{i t} \sum_{j \neq i} \omega_{j i} Y_{j, t-1}
$$

conditional on past observations. In our application, counts $Y_{i t}$ equal the number of installations of AMS in the German administrative districts $i$ during the calendar year $t$. We assume a time lag of one year between the first information about the availability and

\footnotetext{
${ }^{3}$ The description of the model follows Held et al. (2005), Paul and Held (2011), and Meyer et al. (2017)
} 
suitability of AMS and the practical implementation, as have to concede time for decision making to the farmers. AMS is a rather cost-intensive investment. Besides, AMS is not only changing the milking procedure on a dairy farm but is often accompanied by a new feeding and management regime (Sauer and Zilberman 2012; Eastwood et al. 2017). A negative binomial distribution is preferred over a simple Poisson model to allow for overdispersion.

The mean comprises of an endemic and an epidemic component. The parameter-driven endemic component $e_{i t} v_{i t}$ is estimated proportional to a region-specific and time-dependent offset $e_{i t}$. In our analysis, the offset represents the time-variant number of dairy cows in each administrative district. The endemic component captures all exogenous factors determining the diffusion process, which are not attributed to the previous number of cases. It is henceforth called exogenous effects because it constitutes the exogenous or contextual effect of the identification problem of social effects.

The observation-driven epidemic component measures the influence of past cases and establishes temporal and spatial dependence. It consists of the autoregressive effect $\lambda_{i t} Y_{i, t-1}$ moreover, the spatiotemporal effect $\phi_{i t} \sum_{j \neq i} \omega_{j i} Y_{j, t-1}$. The first depicts the autoregression of adopted cases within the same administrative district $i$ and refers to the correlated effect in the identification problem. The second captures the influences of cases in another district $j$. The weights $\omega_{j i}$ specify the diffusion flow of AMS and derive from the previously introduced network structures. $\omega_{j i}$ equals 1 , if there is a link between two administrative districts, thus the districts share a common border. If $\omega_{j i}$ equals 0 , there is no link. Hence, this component identifies the peer spillovers and equals the endogenous effect in the identification problem.

In our analysis, we presume identical intercepts across all districts for the three log-linear predictors $v_{i t}, \lambda_{i t}$ and $\phi_{i t}$ as a first step. In a robustness check, we consider the intercepts in the endemic component to be random across all units to account for unobserved heterogeneity among the administrative districts.

The relative performance of the different network structures is assessed by Akaike's Information Criterion (AIC). However, as soon as random intercepts are included in the model, the AIC can no longer be employed. Instead, we use the log-likelihood to compare both specifications. 


\section{2 | 5. Results and discussion}

\subsection{Model with identical intercepts}

The spatiotemporal endemic-epidemic model provides the results for the mean $\mu_{i t}$ and its shares of the three components, respectively. In Table $2 \mid 3$, we express each component with its share in percentages. According to the AIC without a network component ( $\mathrm{AIC}=7656)$, the model performance is improved when including a network structure as explaining component. The neighbourhood network shows the highest share of the network component with $28 \%$. The AIC of 7436 confirms the best fit of the neighbourhood structure among the considered networks. Thus, our result acknowledges the literature for the neighbourhood network as the most significant in the diffusion of technology (Just and Zilberman 2002; Conley and Udry 2010; Maertens and Barrett 2012; Wollni and Anderson 2014).

Table $2 \mid$ 3. Results for the model with identical intercepts

\begin{tabular}{lcccccc}
\hline Network structure & $\begin{array}{c}\text { Mean } \\
\mu_{i t}\end{array}$ & $\begin{array}{c}\text { Shoges of the mean } \mu_{i t} \text { (in percentage) } \\
\text { effect }\end{array}$ & $\begin{array}{c}\text { Autoregressive } \\
\text { effect }\end{array}$ & $\begin{array}{c}\text { Network } \\
\text { effect }\end{array}$ & AIC & $\begin{array}{c}\text { log- } \\
\text { likelihood }\end{array}$ \\
\hline Without network & 2589 & 63.31 & 36.69 & & 7656 & -3825 \\
effect & 2428 & 37.50 & 34.23 & 28.27 & 7436 & -3715 \\
Neighbourhood & 2526 & 54.99 & 36.52 & 8.48 & 7567 & -3780 \\
Sales structure & 2526 & 58.43 & 36.66 & 4.91 & 7640 & -3816 \\
Dairy structure & 2582 & 62.33 & 37.09 & 0.58 & 7646 & -3819 \\
Advisory service & 2580 & 61.31 & 37.05 & 1.64 & 7651 & -3821 \\
$\begin{array}{l}\text { Organic } \\
\text { association }\end{array}$ & & & & & &
\end{tabular}

The neighbourhood network is followed by the network describing the sales structure of the manufacturer considered (network effect $=8.48 \%$, AIC $=7567$ ). A general nationwide pattern characterises the sales structure. Therefore, the company offers large numbers of contact points each farmer can turn to. This reduces the cost of information seeking before and during the technology adoption process. Interestingly, the network capturing the public advisory service in Germany is performing second worst with the lowest network effect among the analysed networks (network effect $=0.58 \%$, AIC $=7646$ ). We expected this network to have a better explanatory power in the AMS diffusion process, as farm advisory is often seen as an essential source of information in the adoption process. However, we only considered public facilities, no private consulting services. An installation of AMS changes fundamentally the structure of a dairy farm but requires a specific herd size and farm facilities beforehand. Thus, public advisory services may be somewhat cautious in their 
advice. The poor performance of the organic farming association network may be owed to the underlying assumptions. Due to the lack of information about the share of organic farmers and the membership of farmers in one of the organic farming associations in our sample, each farmer was assigned to the geographically closest association. This assignment may contradict to the philosophy going along with organic farming.

Assessing the two other effects in the model both show a higher share of the mean $\mu_{i t}$. Notably, the exogenous effect is driving the adoption process in all network specifications. Including covariates in the model could increase the content of information and validity of the model. Besides, the autoregressive effect has a more considerable influence than the network component. This component includes the number of installed AMS in the same administrative district in previous periods. Thus, the autoregressive effect can capture spillover effects within the administrative districts, such as agglomeration effects described in the economic geography.

Figure 2 7. Shares of components, 1997 - 2013 (with identical intercepts)
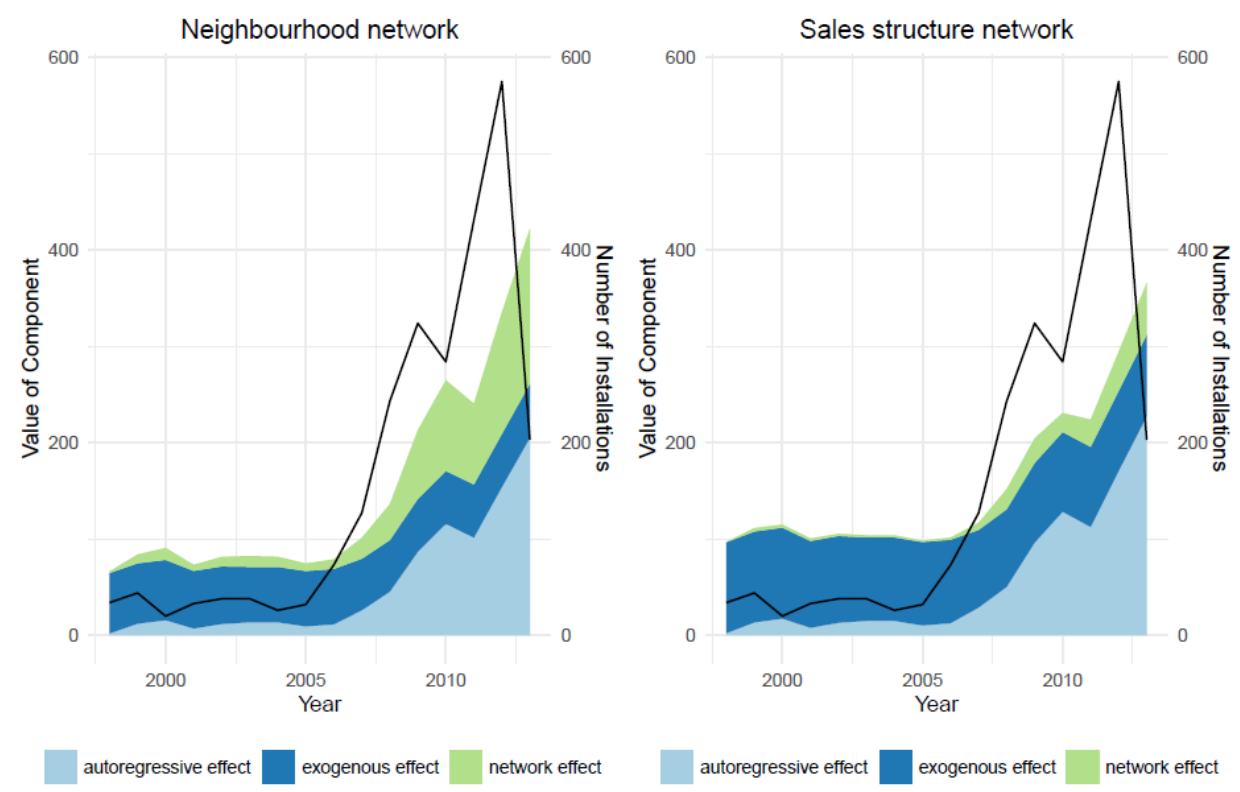

Figure $2 \mid 7$ shows the development 1997 to 2013, with the neighbourhood network on the left and the sales structure network on the right side. The thin black line represents the accumulated number of AMS installations for each year (compare Figure 2|6). The influence of each component changes over time. Exogenous factors drive the adoption of AMS in the beginning. Over time, the network and the autoregressive effect gain in importance. This finding confirms previous studies, which suggest a change in the importance of various factors in the adoption process (Baptista 2000; Xiong et al. 2016). The share of network and 
autoregressive component increases from 2006 onwards along with the number of installations per year. The growing impact of both components leads to an acceleration in the diffusion of AMS in Germany.

\subsection{Network effects and network characteristics}

The question arises if the network characteristics presented in Table 2|1 foster the results. As the pattern of a network is supposed to impact the diffusion of technology (Rogers 1995; Easley and Kleinberg 2010), it is conceivable, that our outcomes are determined due to the networks' construction assumptions. To test for interdependence, we construct two random networks. One is based on the properties of the neighbourhood network; the other is the sales structure network, as both are performing best according to the AIC. Both random networks have the same size, with 402 nodes, as the structured ones. However, the links are established randomly without a given order. The random neighbourhood network exhibits the same number of links (1053), the identical density of 0.0131 and the identical average degree of 5.24. The same holds for the random sales network with 573 links, a density of 0.0071 and an average degree of 2.85 . We are running 200 iterations of the model with identical intercepts, including the random networks. The results are shown in Figure $2 \mid 8$.

Figure $2 \mid$ 8. Results of random networks

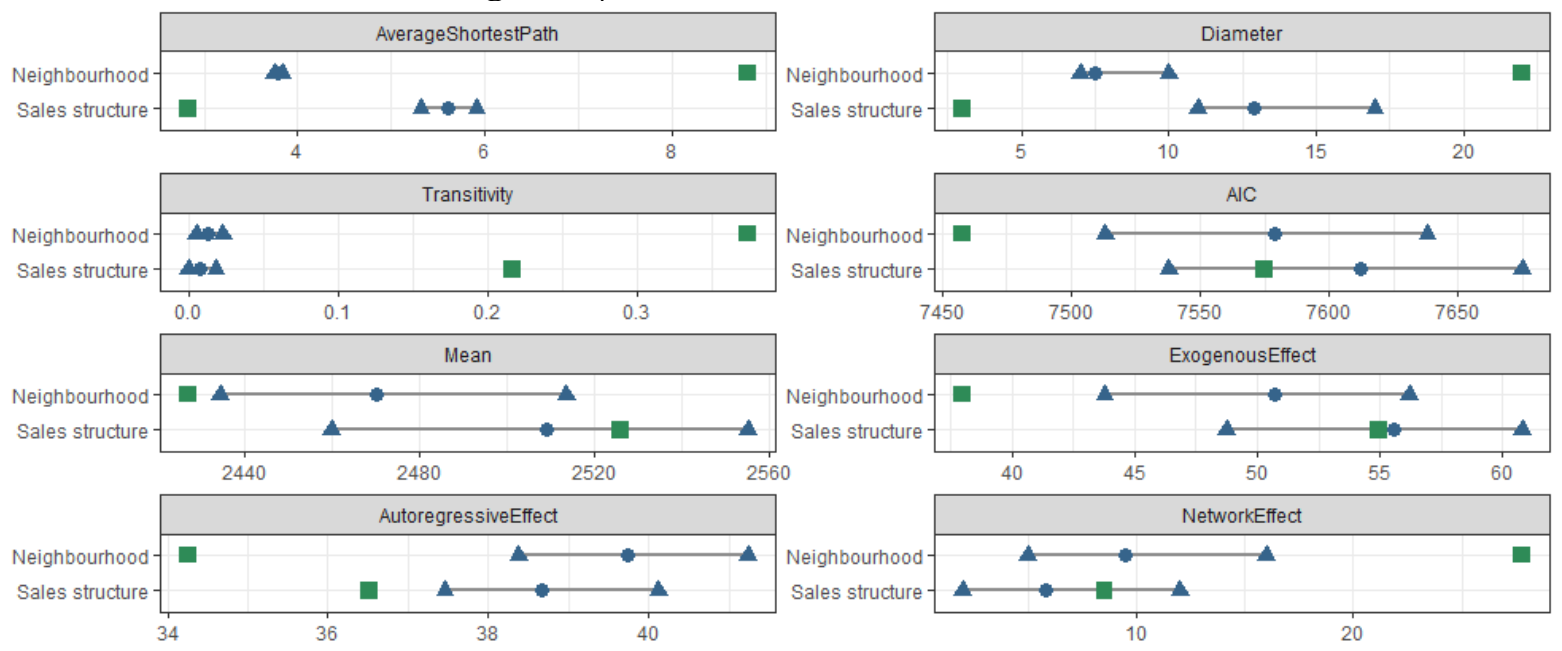

The figure shows the results for 200 iterations of the spatiotemporal endemic-epidemic model with identical intercepts, including the random neighbourhood and random sales structure network, respectively. The ranges of each variable, from minimum to maximum, are labelled with a (blue) triangle. The (blue) points mark the mean value of each variable. The (green) rectangle gives the value of the structured neighbourhood and structured sales structure network for the respective variable.

The remaining network characteristics have much higher values for the structured neighbourhood network than for the random neighbourhood network. The results of the analysis, especially the share of the network effect of the mean 
$\mu_{i t}$, is much higher for the structured neighbourhood, as well as the structured network exhibits a better fit. In summary, the structured neighbourhood network gives a better result for each parameter, which leads to the finding that the structured links of the neighbourhood are to be preferred over the random links.

Figure $2 \mid$ 9. Scatterplots for the random neighbourhood network
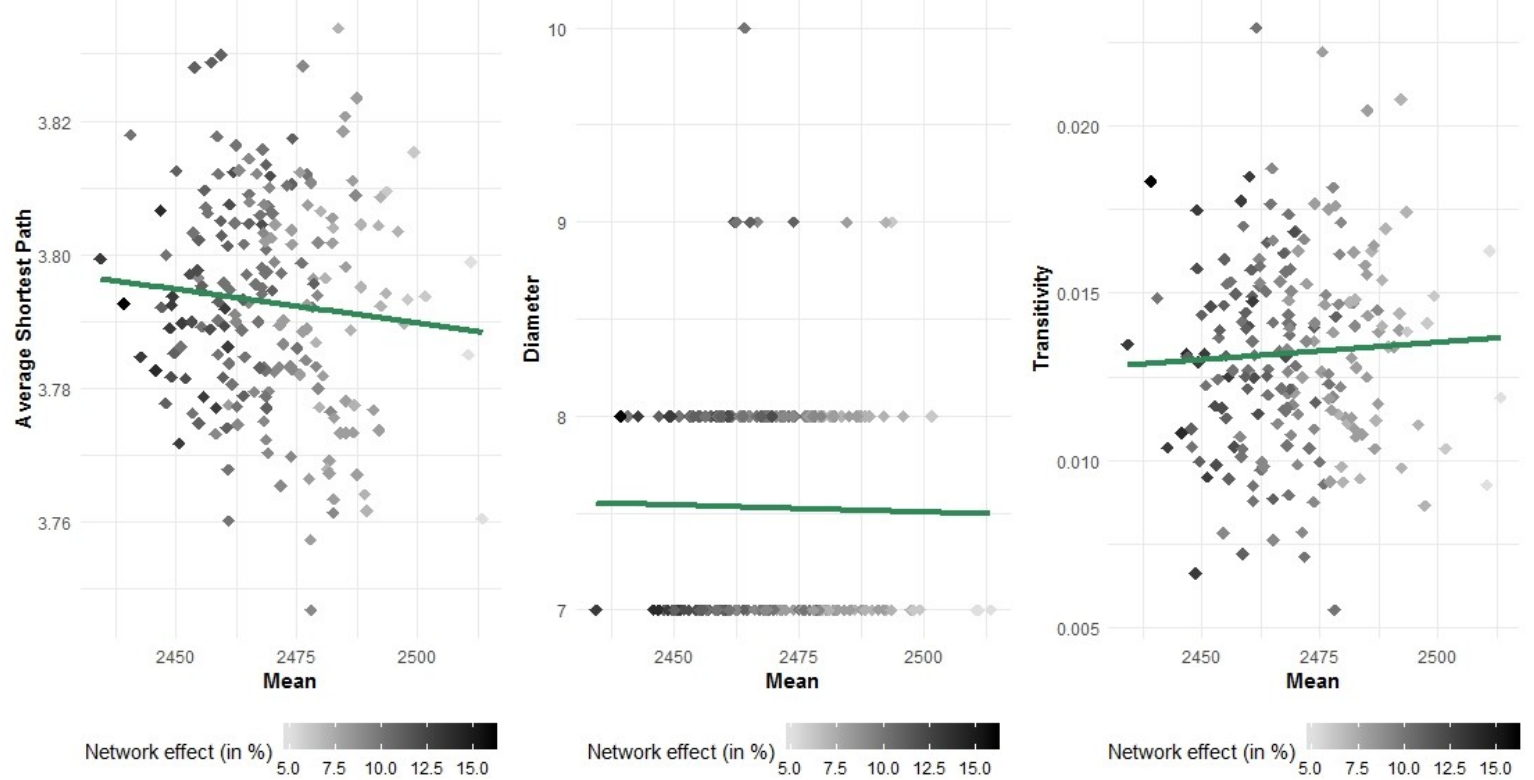

For the random and structured sales structure network, the evaluation is not straightforward. While diameter and average shortest path are smaller for the structured network, the transitivity is a lot higher than the maximum value. In contrast, the values of the model results of the structured network are in the range of the random sales network, except for the autoregressive effect, which has a little smaller than the minimum limit. Consequently, the structured sales network does not yield distinct results compared to the random sales structure network.

Still, it is conceivable that specific network characteristics affect these outcomes. Therefore, we use scatterplots to control for the dependence between certain variables. Figure2|9 shows scatterplots for the random neighbourhood network classified for different shares of the network component. The scatterplots show the relationship between the network characteristics average shortest path, diameter and transitivity, and the mean $\mu_{i t}$. However, we are not able to identify a clear trend here. 
Figure $2 \mid$ 10. Scatterplots for the random sales network
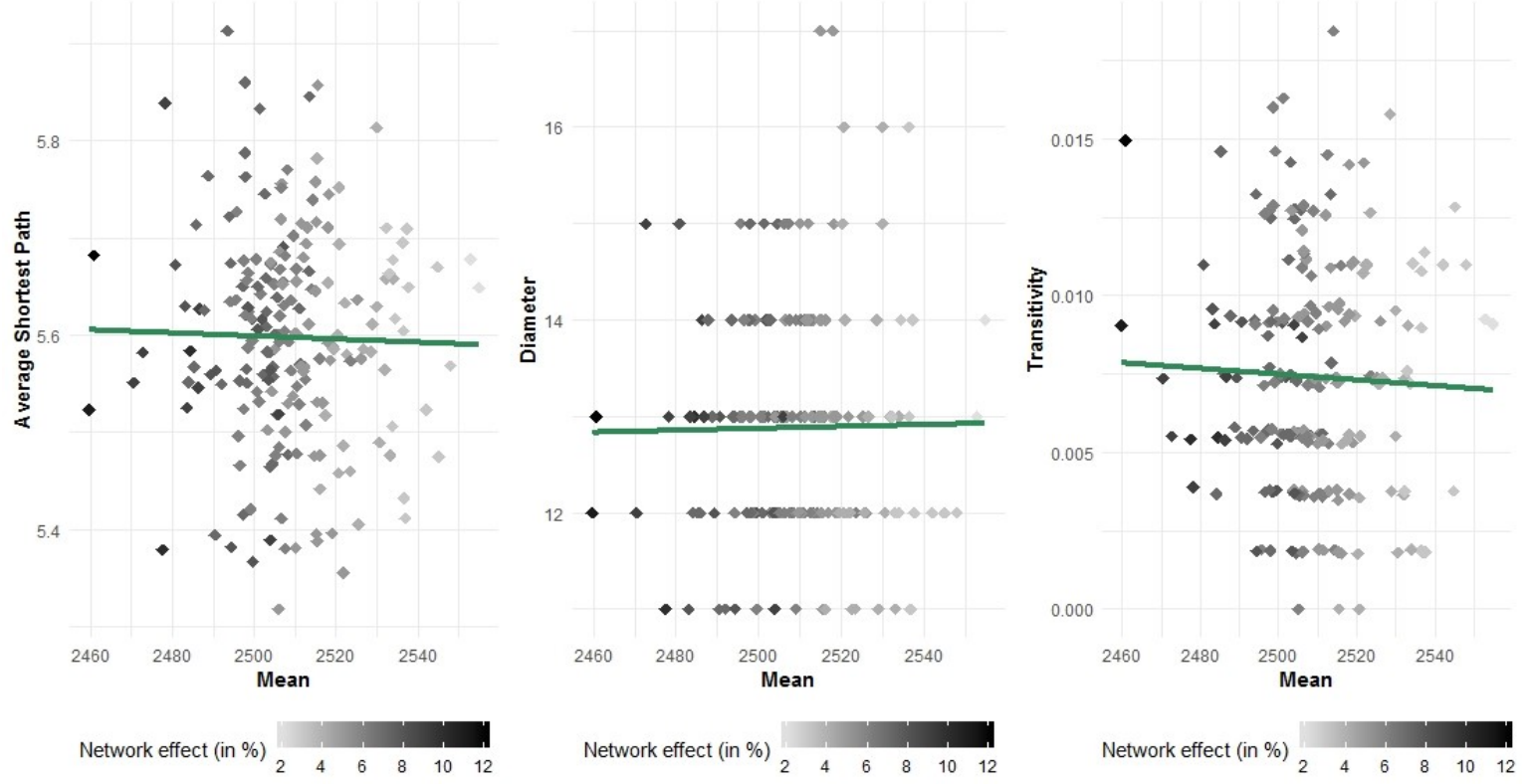

Similar results are shown in the scatterplots for the random sales structure network (Figure $2 \mid 10)$. This indicates that the networks are not influencing the results only by construction, but that there is a real network effect in the diffusion and adoption of AMS in Germany.

\subsection{Robustness validation}

To check the robustness of our results, we relax the assumption about the intercepts of the log-linear predictors in the model and allow for random intercepts in the exogenous component while keeping identical intercepts in the other two components. In Table $2 \mid 4$, we show the results for two best performing networks in the model with identical intercepts.

Table $2 \mid$ 4. Results for the model with random intercepts in the exogenous component

\begin{tabular}{lccccc}
\hline \multirow{2}{*}{ Network structure } & Mean & Shares of the mean $\mu_{i t}$ (in percentage) & Exens \\
& $\mu_{i t}$ & effect & Autoregressive & Network & log- \\
& 2345 & 31.81 & 40.43 & 27.76 & -3636 \\
Neighbourhood & 2360 & 46.33 & 48.35 & 5.31 & -3706
\end{tabular}

The values for the mean $\mu_{i t}$ with random intercepts are in general lower than for the basic model. Both, the exogenous and network effect loose in share, but more slightly for the neighbourhood network (27.76\%) compared to the basic model. The effect of the network component remains highest for this network, while the sales structure decreases a lot more $(5.31 \%)$ than for the structured networks. Furthermore, the autoregressive effect is the primary driver of the adoption process, yet. As AIC can no longer be used as an instrument 
for the evaluation of the model when allowing for random intercepts, we use the loglikelihood values, also in comparison to the model with identical intercepts. In both model specifications, the neighbourhood network (log-likelihood $=-3715$ and -3636 ) provides a better fit compared to the sales structure network (log-likelihood $=-3780$ and -3706$)$. The model with random intercepts in the exogenous component performs better in general, which should come as no surprise. When assuming identical intercepts across all German administrative districts, we suppose all districts to be identical in all factors influencing AMS adoption. Though there are varying concentrations of dairy farms in Germany and considerable differences in social and economic aspects, identical units reflect reality to a limited extent.

Figure 2 | 11. Shares of components, $1997-2013$ (with random intercepts in the exogenous

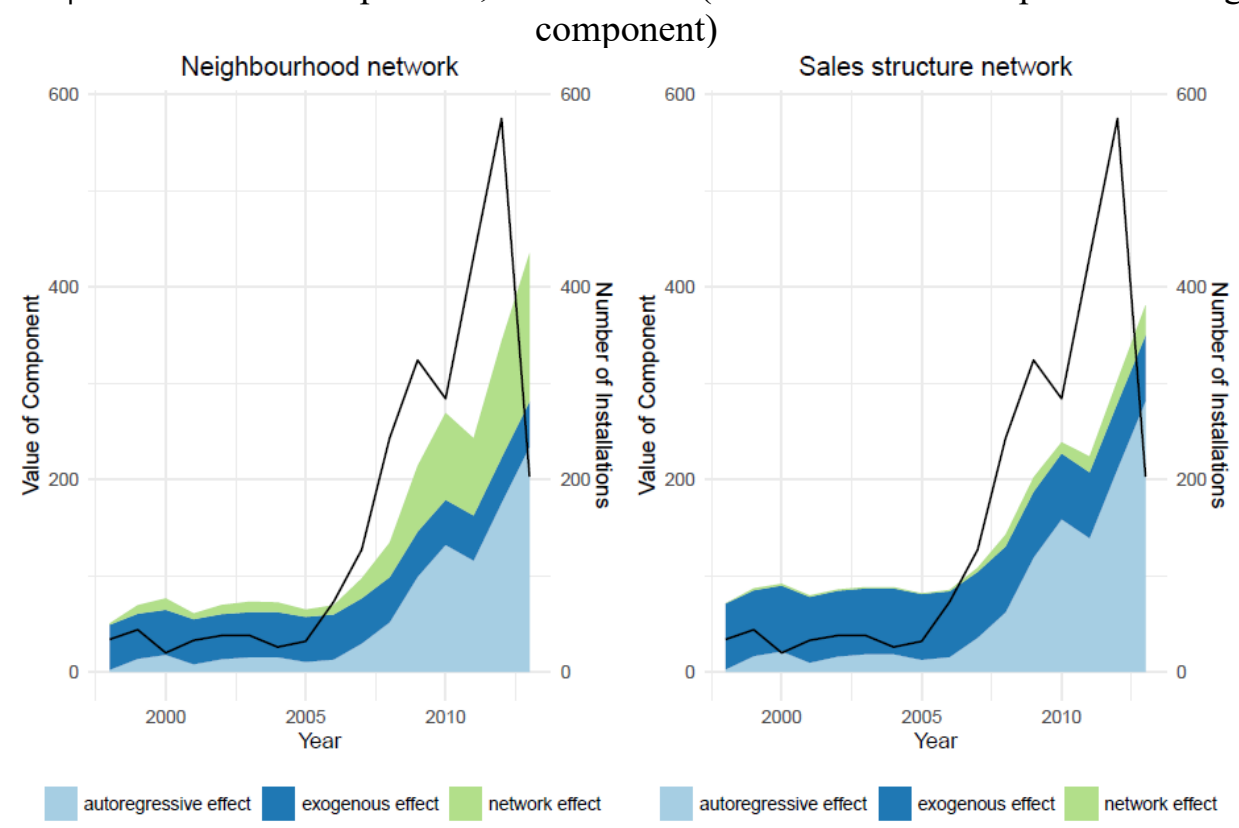

Figure 2|11 confirms the findings of Section 5.1 for the model with random intercepts. While the exogenous effect is forcing the initial adoption process, both autoregressive and the network effect are taking over the adoption from the year 2006 onwards.

Despite slight differences in values, the overall results of the model with identical intercepts are confirmed when allowing for random intercepts in the exogenous component. The neighbourhood network, still, explains best the diffusion and adoption of AMS in Germany among the considered network structures. However, exogenous and autoregressive effects are decisive for the process. 


\section{$2 \mid 6$. Concluding remarks}

The social environment of a farmer gains in importance explaining diffusion and adoption of technology. Individual farmers rely on the information and experience of various stakeholders to reduce both uncertainties towards the outcomes of innovation and the costs of gathering information. Fellow farmers are often treated as the primary and most reliable source of information. In this paper, we propose four more sources influencing the diffusion and adoption of AMS in Germany: the manufacturer of the technology, the downstream industry, public farm advisory services and farming associations. We use networks to connect the farmers with the source of information. Therefore, each of the five network structures is built on different assumptions according to the difference in the spread of information and the adoption of technology and exhibits specific network characteristics. We prove that these network characteristics are not forcing the outcome of the spatiotemporal endemic-epidemic model, which is used to examine the importance of the networks in the diffusion process.

Our estimations show that the inclusion of network structures improves the performance of the spatiotemporal endemic-epidemic model. As implied in literature, the neighbourhood network shows the best performance and the most considerable influence on the adoption in both model specifications, followed by the sales structure network. The public advisory service network, in literature, acknowledged as an essential element in the diffusion of technology, performs unexpectedly weak with a network effect of less than $1 \%$.

The highest value for the network effect constitutes the neighbourhood network with more than $28 \%$. However, the exogenous and the autoregressive component are the main forces driving technology adoption. Including various exogenous variables, as the milk price, the number of labour forces or the size of the herd could expand the explanatory power of the model. Thus, it remains to be seen in future research, whether the outcome for the network effects holds. According to the autoregressive component, agglomeration effects should be considered due to a varying concentration and a spatial clustering in German milk production. Furthermore, as agglomeration effects display a type of spillover effects, the consideration of it could further increase the impact of network effects. 


\title{
Chapter 3 | Social networks, agglomeration effects, and labour Drivers in the adoption process of automatic milking systems in Germany ${ }^{4}$
}

\begin{abstract}
One major innovation modifying the milking process on dairy farms are automatic milking systems (AMS). Besides several non-economic aspects, like a higher level of flexibility and more leisure time, the installation of AMS is often determined by labour costs and labour scarcity as well as the characteristics of the milk production. However, peer effects are also named as one driver in the adoption process. In the dataset, containing adopted AMS in Germany between 1997 and 2003, the technology is clustered in specific regions. Therefore, we aim to identify regional variation in the adoption pattern, factors determining the adoption and the relevance of network and agglomeration effects in the adoption process of AMS. Local Moran's I is applied to measure the spatial variation in the adoption and a spatiotemporal endemic-epidemic model, embracing two network specifications, is executed to capture network and agglomeration effects. The AMS in our sample are increasingly adopted in areas with a concentration in milk production. Further, our estimates show that AMS are used to substitute dwindling labour forces and increasing labour costs. Agglomeration and network effects are of substantial importance in the diffusion of AMS. Thus, dense adoption within the areas.
\end{abstract}

Keywords - technology adoption, network effects, agglomeration effects, automatic milking systems

\footnotetext{
${ }^{4}$ This chapter is co-authored by Juliane Manitz (JM), Sebastian Meyer (SM) and Bernhard Brümmer (BB). $\mathrm{CH}$, JM, and $\mathrm{BB}$ jointly developed the research idea. $\mathrm{CH}$ and JM designed the network structures. $\mathrm{SM}$ supported the statistical analysis. $\mathrm{CH}$ did the literature review, the data analysis, and wrote the essay. BB commented the various stages of the research and contributed to writing and revising the essay.
}

Acknowledgment - The authors are grateful to Heiko Hansen and the Thünen-Institut, Braunschweig for the support in accessing the FADN dataset. 


\section{3 | 1. Introduction}

Milk in industrialised countries is, for the most parts, produced under the use of complex technologies. One innovation in the last decades related to the milking process itself are automatic milking systems (AMS). The first AMS was installed in 1992 on a dairy farm in the Netherlands (Sauer and Zilberman 2012; Eastwood et al. 2017). Since then, AMS spread mainly in north-western Europe (Heikkilä et al. 2012; Sauer and Zilberman 2012; Schewe and Stuart 2015), in the US (Schewe and Stuart 2015) and New Zealand (Woodford et al. 2015).

Contrary to its name, AMS do not only involve the milking process on a dairy farm but the management systems, the work structure and often the feeding system (Sauer and Zilberman 2012; Woodford et al. 2015; Eastwood et al. 2017). Due to substantial investment costs and high technological requirements, AMS are considered by farmers as rather risky to adopt (Bewley and Russell 2010; Hein 2011; Bergman and Rabinowicz 2013; Floridi et al. 2013; Eastwood et al. 2017). The advantages of AMS are the reduction of labour while increasing milk production. Sauer and Zilberman (2012), as well as Floridi et al. (2013) and Hansen (2015), agree on an increase in milk production by $10-15 \%$ on average under the use of AMS. Schewe and Stuart (2015) report a rise of $6-35 \%$ in milk yield per cow. The same studies document an average reduction of labour by about $20-30 \%$, although the cows are milked more frequently. Also, AMS are associated with positive effects on the health of the animals and the milk quality (Woodford et al. 2015).

In the literature, AMS adoption is often related to high labour costs, highly intensive production systems and peer effects as well as non-economic factors, like the gain of more flexibility and time for social contacts (Heikkilä et al. 2012; Sauer and Zilberman 2012; Gillespie et al. 2014; Hansen 2015; Eastwood et al. 2017). However, even, when we consider all economic aspects, there can be still regional differences in the adoption of a technology (Baptista 2000; Läpple et al. 2016).

In this paper, we analyse the adoption of AMS in Germany between 1997 and 2013. First, we associate the distribution of AMS in our sample with the concentration of milk production in Germany, using local Moran's I as a measurement of spatial autocorrelation. Afterwards, we are applying a spatiotemporal endemic-epidemic model to identify three effects fostering the diffusion of technology to the adoption. The exogenous effect captures the influence of farm characteristics on the adoption decision, while the autoregressive effect 
involves agglomeration effects in a specific spatial unit. The network effect describes the influence of the adoption decisions of farmers in adjacent spatial units. We contribute to the literature by addressing the following questions: are there regional differences in the adoption pattern of AMS in Germany? What kind of factors are shaping the adoption decision of AMS? Are agglomeration and network effects relevant to the adoption and diffusion?

The paper is structured as follows: In Section 2, we give an overview of the background of the adoption of AMS, as well as on network and agglomeration effects. Section 3 introduces the dataset and the applied network structures. Additionally, insights into milk production in Germany are provided before describing the econometric model (Section 3). We present the results in Section 4 and conclude the paper by discussing them in section 5.

\section{3 | 2. Background}

\subsection{Adoption of automatic milking systems}

Farmers install AMS in order to have more time for family and friends, more time for offfarm work or more flexibility in their daily routine (Bergman and Rabinowicz 2013; Hansen 2015). Woodford et al. (2015) emphasise strongly that profit maximisation is no explicit driver for the adoption decision. In contrast, as a reason for non-adoption, farmers often claim profit-related factors (Bergman and Rabinowicz 2013). Nevertheless, socio-economic, economic and production-related aspects have a role in the decision-making process.

Table 3|1 states the results of four studies examining the adoption of AMS in three European countries (Denmark, Finland, Sweden) as well as in the US. Three out of the four surveys consider hired labour. Milk production in industrialised countries is often characterised by high, and still rising, labour costs (Sauer and Zilberman 2012; Hansen 2015) and decreasing labour availability. Thus, AMS are used to substitute labour expenses. Besides, farmers consider aspects as labour flexibility (Hansen 2015; Schewe and Stuart 2015) and improvement of the work atmosphere (Bergman and Rabinowicz 2013). The structure of milk production itself is decisive as well. The number of dairy cows and the herd size has positive effects on the adoption decision (Bergman and Rabinowicz 2013; Hansen 2015). According to the manufactures, AMS become cost-effective from an average herd size of 60 dairy cows onwards. Highly specialised and intensively producing farms have a higher probability of adopting (Heikkilä et al. 2012; Gillespie et al. 2014; Schewe and Stuart 2015). 
Additional, various studies mention that adoption decisions of fellow farmers are shaping the AMS installation of individual farmers (Sauer and Zilberman 2012; Bergman and Rabinowicz 2013; Floridi et al. 2013; Hansen 2015).

Table $3 \mid 1$. Overview of factors influencing the adoption of AMS

\begin{tabular}{|c|c|c|c|c|}
\hline & $\begin{array}{l}\text { Heikkilä et al. } \\
\text { (2012) }\end{array}$ & $\begin{array}{c}\text { Sauer \& } \\
\text { Zilberman } \\
(\mathbf{2 0 1 2})\end{array}$ & $\begin{array}{l}\text { Bergman \& } \\
\text { Rabinowicz } \\
\quad(\mathbf{2 0 1 3})\end{array}$ & $\begin{array}{c}\text { Gillspie et al. } \\
\text { (2014) }\end{array}$ \\
\hline \multicolumn{5}{|c|}{ Farmer characteristics: } \\
\hline Age & & & $-/ *$ & $+/ *$ \\
\hline Education & & & $-/ *$ & $+/ *$ \\
\hline Experience & & $+/ *$ & $-/ *$ & \\
\hline \multicolumn{5}{|l|}{ Labour: } \\
\hline Hired labour (share) & + & $+/ *$ & $+/-$ & \\
\hline Labour per cow & $-/ *$ & + & & \\
\hline \multicolumn{5}{|l|}{ Milk production: } \\
\hline Number of cows & & & $+/ *$ & + \\
\hline Herd size & $+/-$ & & $+/ *$ & $+/ *$ \\
\hline Milk yield & $+/ *$ & $+/ *$ & & \\
\hline Milk quota & & $+/ *$ & & \\
\hline Specialisation & & & & $+/ *$ \\
\hline Organic & & $+/ *$ & $+/ *$ & $-/ *$ \\
\hline Pasture & & & & - \\
\hline \multicolumn{5}{|l|}{ Finances: } \\
\hline Capital & $+/ *$ & & & \\
\hline $\begin{array}{l}\text { Investment support/ } \\
\text { subsidies }\end{array}$ & $+/ *$ & $+/ *$ & $+/ *$ & \\
\hline Off-farm income & & & + & \\
\hline \multicolumn{5}{|l|}{ Peer effects: } \\
\hline Peer effects & & $+/ *$ & $+/ *$ & \\
\hline Technology density & & $+/ *$ & & \\
\hline $\begin{array}{l}+ \text { the coefficient is po } \\
+/ * \text { the coefficient is } p \\
+/- \text { both effects are ob }\end{array}$ & $\begin{array}{l}\text { ve and significant } \\
\text { ble }\end{array}$ & $\begin{array}{l}- \text { the coe } \\
-/ * \text { the } \mathrm{c}\end{array}$ & $\begin{array}{l}\text { ent is negative } \\
\text { cient is negati }\end{array}$ & nd significant \\
\hline
\end{tabular}

Although Sunding and Zilberman (2001) describe adoption as the attitude of an individual towards new technology, the exchange with peers or other sources of knowledge supports the broader diffusion of a considered technology (Mansfield 1963). This requires communication between potential adopters over various distances. First, the individual requires information about the pure availability of an innovation (Rogers 1995). Second, adoption is often associated with uncertainty (Rogers 1995; Xiong et al. 2016). It can be described as a change of established procedures in production (Rogers 1995; Granovetter 2005), as the farmer has no or only little knowledge about use and profitability of the new 
technology (Sunding and Zilberman 2001; Foster and Rosenzweig 2010; Lewis et al. 2011; Xiong et al. 2016). Thus, costs for the farmers arise, while seeking information and gaining knowledge. Farmers can cope with these costs by utilising experiences and knowledge of fellow farmers, who are already using the considered technology (Foster and Rosenzweig 2010; Lewis et al. 2011; Xiong et al. 2016).

Studies confirm that farmers are more likely to adopt in the way prosperous neighbours do, as they demonstrate how to use new technologies under similar conditions and share their impressions (Sumane et al. 2017). Information is more valuable and useful when it is shared by a person of trust (Granovetter 1985; 2005). Just and Zilberman (2002) and Brown et al. (2016) prove that farmers trust other farmers most and use them as the primary source of information (Feder et al. 2004). The second source of information can be the manufacturer of the AMS (Sauer and Zilberman 2012; Bergman and Rabinowicz 2013), by providing and promoting the technology. In developing a comprehensive sales structure, the manufacturer can spread information and knowledge about the technology and its operation to the individual farmers.

\subsection{Network and agglomeration effect}

Several theoretical approaches can be employed, depicting information and technology diffusion. Adoptions often tend to accumulate in regional clusters (Malmberg 1997; Lakner et al. 2011; Läpple et al. 2015) and to differ geographically (Baptista 2000; Läpple et al. 2016); hence, the theory of agglomeration effects can be applied to explain those concentrations of technology.

Agglomeration effects, first described by Marshall in 1920, are caused through the spatial accumulation of companies, active in the same sector (Marshall 1938; Krugman 1993). Consequently, such an accumulation can lead to a concentration of specialised labour, improvements in input supply, increasing returns to scale and to spillovers of knowledge and information through facilitation of communication (Krugman 1993; Larue and Latruffe 2009; Wollni and Anderson 2014; Schmidtner et al. 2015). Krugman (1993) explains that spillovers also emerge, because of specialisation in knowledge, cooperation and exchange of information. Hailu and Deaton (2015) indicate that dairy farms in areas with a high density of dairy farms are more efficient than in areas with a low number of dairy farms. Richards 
(2018) addresses the decisive role of agglomeration effects in the expansion of agricultural land.

Thus, agglomeration effects provide some insights into the dispersion of a specific technology in a limited spatial area, where companies are clustered. Diffusion of technology across long distances and several spatial units can be displayed and explained by network effects. Networks compose of nodes and links (Wasserman and Faust 2009; Easley and Kleinberg 2010). Nodes are agents like farmers, companies, or spatial units, which relate to each other through links. Links are understood as any kind of relationship between two agents, e.g. friendship, the transaction of goods or the diffusion of information. Due to their flexible definition, networks can be applied in multiple ways and a variety of settings (Granovetter 1985; Bodin and Crona 2009; Conley and Udry 2010; Valente et al. 2015; Zhou et al. 2016; Maertens 2017). One function of networks is that they allow agents to share information about technologies, although they are not located in the same area. Furthermore, different structures of networks can lead to different outcomes in the diffusion process (Rogers 1995; Valente 1996; Maertens 2017; Grassi 2010).

In this paper, we distinguish between both effects by using spatial units. We define spillover effects within the same spatial unit as agglomeration effects and between various spatial units as network effects. Here, spatial units are the administrative districts in Germany.

\section{3 | 3. Context and model specification}

\subsection{Data}

The dataset for our analysis contains 2,531 installed AMS in Germany between July 1997 and November 2013, by one manufacturer. We aggregate the data to the respective administrative district (NUTS 3 ) and on a yearly basis. We cannot control for self-selection, as we have access to the data of solely one manufacturer. However, this manufacturer has a unique market position. It was the only supplier in 1997 and is still the leading company in 2013 with a market share of more than 50\%. As shown in Figure 3|1, the adoption of AMS per year developed slowly until 2005. The peak is reached in 2012 with 575 installations. A look at the cumulative adoptions offers a continuous growth of AMS in Germany, which accelerates from 2006 onwards. 
Figure 3 | 1. AMS adoption per year (left) and cumulative adoption over time (right) in Germany
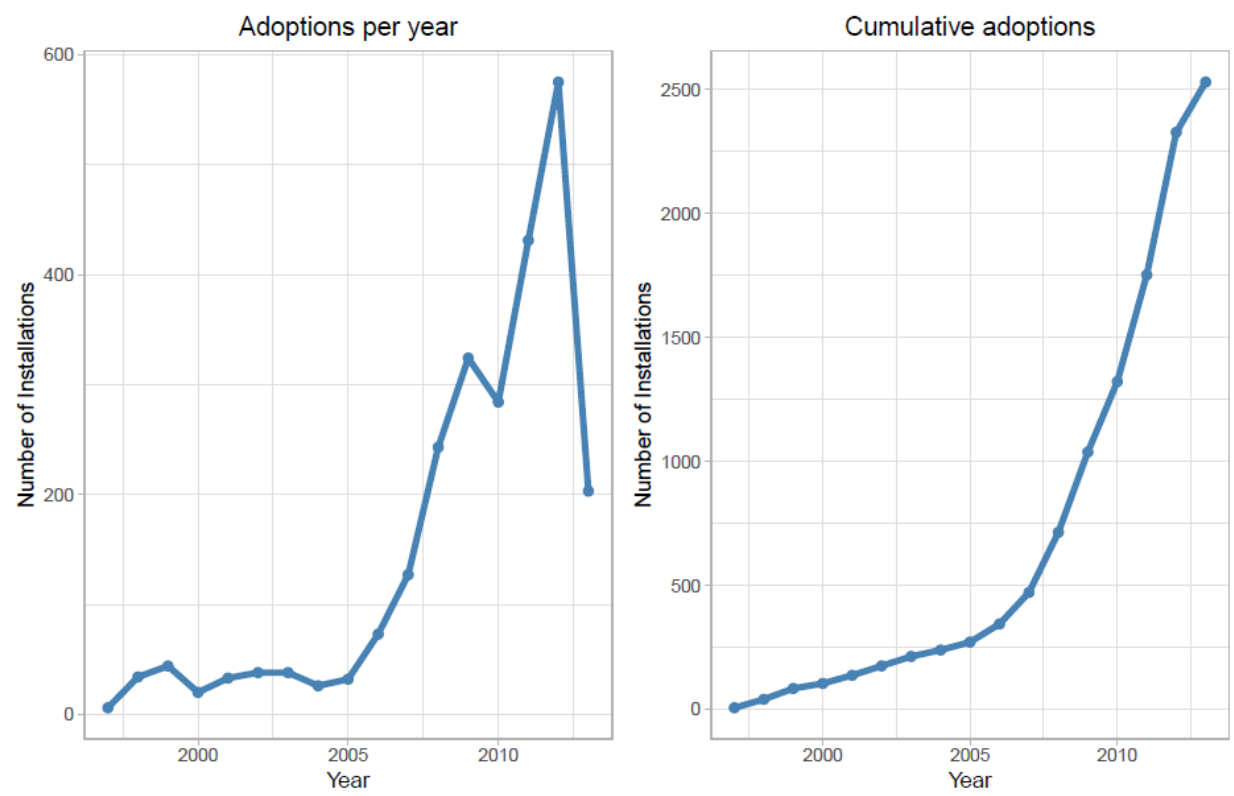

Considering the spatial dispersion of AMS, differences occur. Figure $3 \mid 2$ shows the development between 1997 and 2013 in the 402 German administrative districts based on eight selected maps. In 1997, six AMS were installed by farmers in five administrative districts located all over Germany. Over the years, the adoption enhances in particular in the northern and north-western, as well as in the southern and south-eastern districts. In 2013, 260 of the 402 administrative districts record at least one AMS (grey coloured). Eleven districts (green coloured) have more than 40 installed systems and two (red coloured) list more than 70 AMS (Kleve $=77$, Ravensburg $=76$ ).

The dataset does not provide any information about the farms or the farmers' reasons to adopt. Therefore, we use secondary data offered by the German Federal Statistical Office and the German Farm Accountancy Data Network (FADN) of the European Commission. The dataset offered by the German Federal Statistical Office provides limited census data on a NUTS 3 level. The used FADN dataset contains 6,070 dairy farms in 1997. Over time, the number of dairy farms in the sample decreases to 4,359 farms in 2013. Table $3 \mid 2$ lists the variables analysed in the statistical model. We use the variable unemployment rate as a proxy for labour availability in the respective district, although the qualification of the unemployed labour may not fit the requirements on a dairy farm. 
Figure $3 \mid$ 2. Development of adoption of AMS per administrative district in Germany

2003
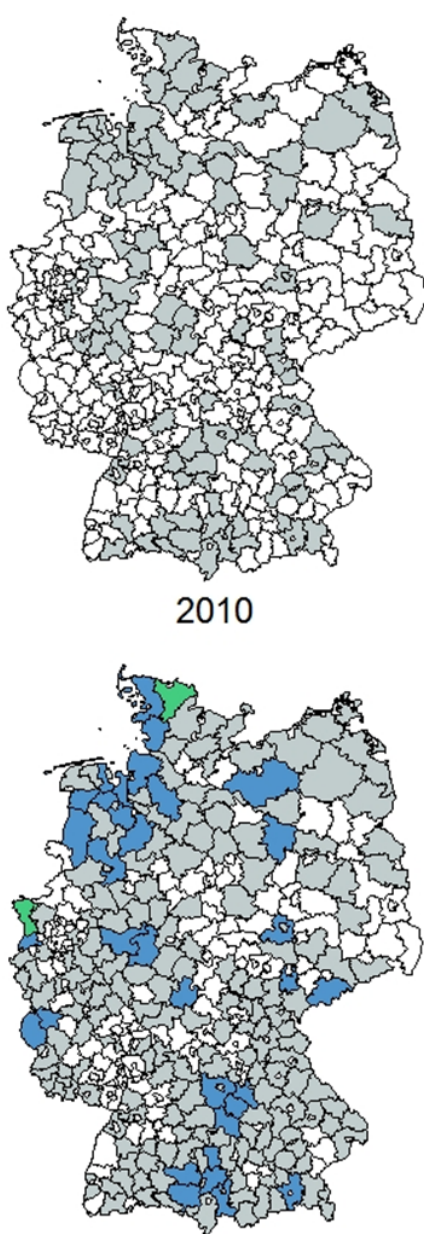

$>=70$ AMS

11-39 AMS

$\square$ 1-10 AMS

$\square$ OAMS
1997
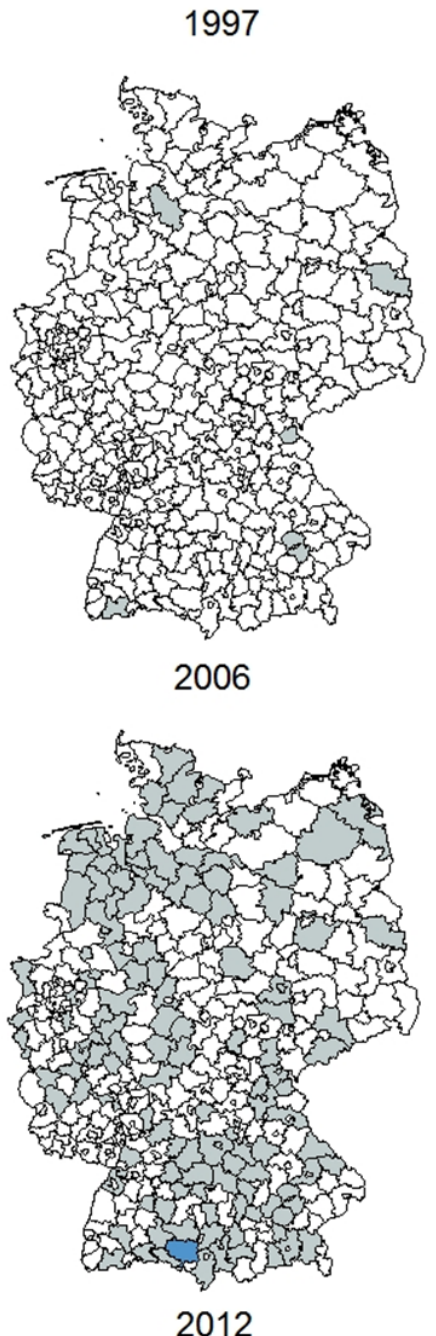

2012

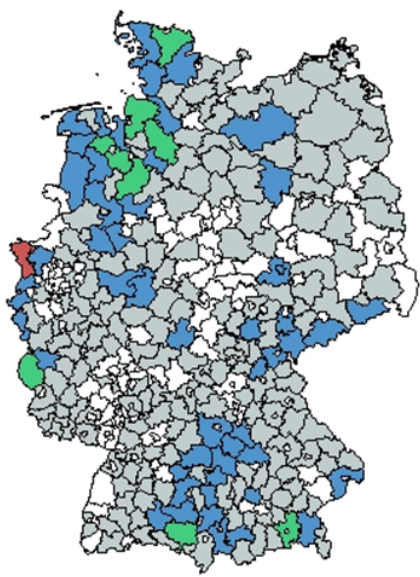

2000

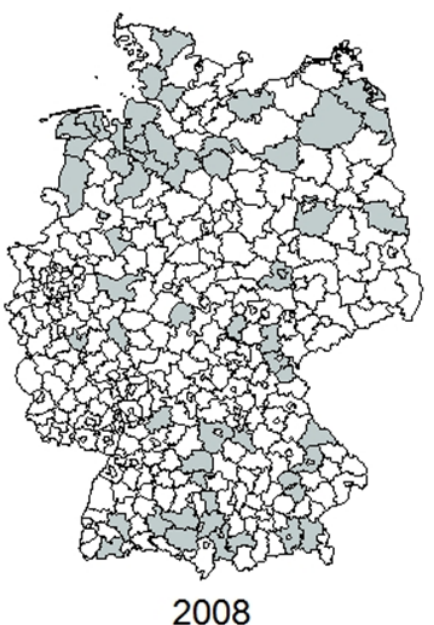

2008

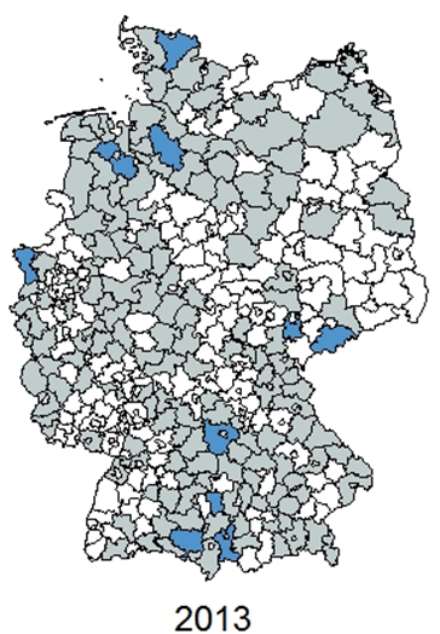

2013

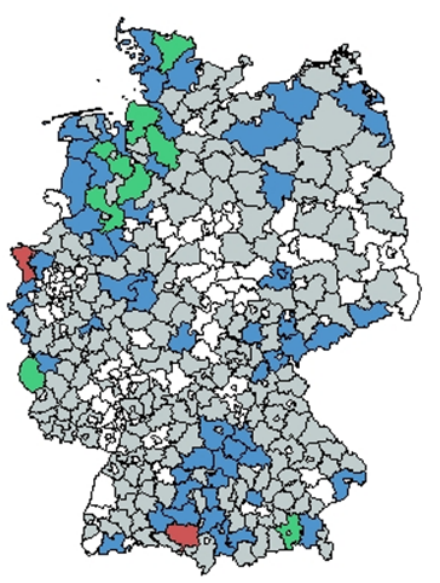

The unemployment rate and the number of farms are available at the NUTS 3 (administrative districts), the other ten variables are solely available at NUTS 2 (administrative division). As we perform the analysis at the level of the administrative districts, we use the average of each variable and regional unit. We z-standardise all variables, except for the variables measuring shares. 
Table 3 2. Description of variables

\begin{tabular}{|c|c|c|c|}
\hline Variable & Source & Regional level & Description \\
\hline Family labour & German FADN & NUTS 2 & Average number of family labour force \\
\hline Farm operation & German FADN & NUTS 2 & Share of farms operated full-time \\
\hline Herd size & German FADN & NUTS 2 & Average number of dairy cows \\
\hline Hired labour & German FADN & NUTS 2 & Average number of hired labour force \\
\hline Legal form & German FADN & NUTS 2 & $\begin{array}{l}\text { Share of farms operated as a partnership } \\
\text { (non-corporate legal entity) }\end{array}$ \\
\hline Milk price & German FADN & NUTS 2 & Average milk price, in $€ / \mathrm{dt}$ \\
\hline Milk yield per cow & German FADN & NUTS 2 & Average milk yield per dairy cow, in $\mathrm{kg}$ \\
\hline Number of farms & $\begin{array}{l}\text { German Federal } \\
\text { Statistical Office }\end{array}$ & NUTS 3 & $\begin{array}{l}\text { Total number of dairy farms in the } \\
\text { respective districts }\end{array}$ \\
\hline Personnel expenses & German FADN & NUTS 2 & Average personnel expenses, in $€$ \\
\hline Profit & German FADN & NUTS 2 & Average profit, in $€$ \\
\hline Specialisation & German FADN & NUTS 2 & Share of milk production in total revenue \\
\hline Unemployment rate & $\begin{array}{l}\text { German Federal } \\
\text { Statistical Office }\end{array}$ & NUTS 3 & Rate of unemployment \\
\hline
\end{tabular}

\subsection{Network structures}

We consider two network structures to analyse the diffusion of AMS in Germany: the neighbourhood network and the sales structure network. Due to data constraints on the relationships of the farmers in our sample, we constructed both networks built on various assumptions. The nodes in the networks reflect the 402 German districts. The neighbourhood network (Figure 3|3, left) contains 1,053 links; the sales structure network (Figure 3|3, right) consists of 573 links. In both networks, information can spread along with the links from one administrative district $i_{1}$ to the farmers in another administrative district $i_{2}$, and is captured as a network effect.

The neighbourhood network displays the classical peer network. We assume farmers in one administrative district to share information with fellow farmers in the adjacent districts. In the second network, we use the sales structure of the manufacture producing the AMS in our sample, for construction. The company operates 20 sales centres to extend advisory services on its technologies. Each sale centre serves a certain number of administrative districts, which is represented by the connected nodes in Figure $3 \mid 3$ (right side). Additionally, we relate all sales centres to each other, to allow for information exchange within the company. 
Figure 3 | 3. Network structures: neighbourhood network (left) and sales structure network (right)
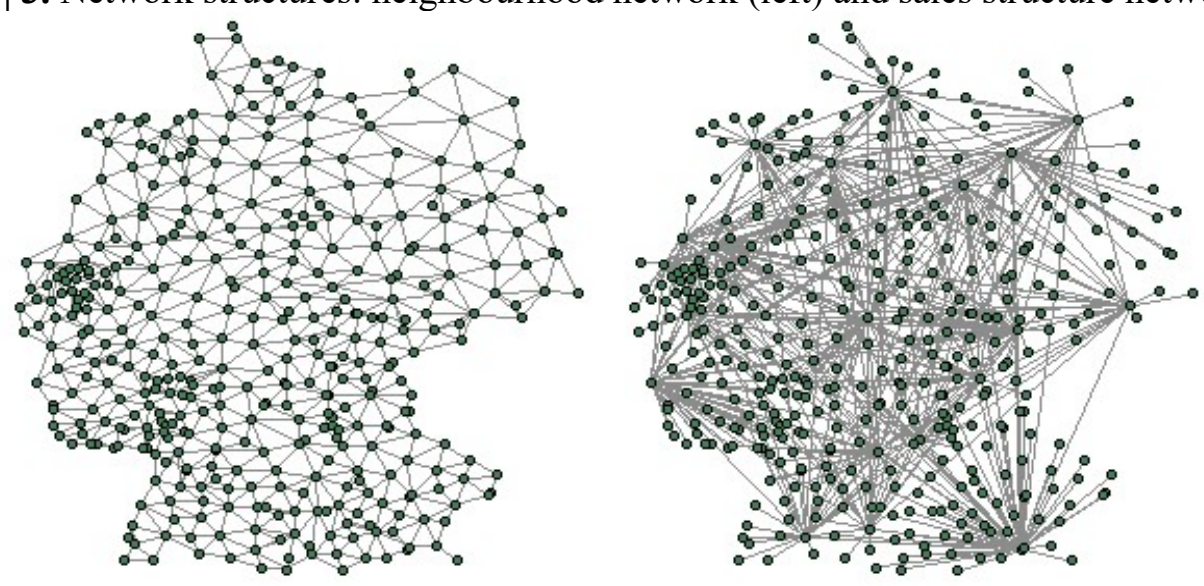

\subsection{Milk production in Germany}

The distribution of AMS (compare Figure 3|2) suggests a cluster of technology in the northwest and south and leads to the assumption that milk production in Germany might be concentrated in these areas. Larue and Latruffe (2009) use the local Moran's I in the analysis of technical efficiency of pig production in France. Schmidtner et al. (2012) identify concentrations of organic farming or the role of neighbourhood effects in the spatial distribution of organic farming in Germany (Schmidtner et al. 2015) through local Moran's I.

Local Moran's I is a measure to identify patterns in spatial distributions of considered events, which are related to a specific spatial weight matrix. We estimate the local Moran's I to analyse the regional clustering of the dairy production in Germany. Hence with using the number of dairy farms and dairy cows per administrative districts as events. As spatial weight matrix we use both networks.

Local Moran's I is defined as:

$$
\mathrm{I}_{i}=\frac{x_{i}-\bar{x}}{\sigma^{2}} \sum_{j \neq i}^{n} \omega_{j i}\left(x_{j}-\bar{x}\right)
$$

with $x_{i}$ and $x_{j}$ being the observations in unit $i$ and $j, \bar{x}$ being the mean, $\sigma^{2}$ the variance and $\omega_{j i}$ being the spatial weight matrix (Anselin 1995; E. Schmidtner et al. 2012). As a spatial unit, we use the German administrative districts.

The indicator estimates spatial autocorrelation and outliers by assigning spatial units into four categories according to the number of events occurring in the spatial unit $i$ and its 
adjacent unit $j$ (Kelley and Helper 1999; Lakner et al. 2011; Schmidtner et al. 2012). The four categories are:

- high-high: high number of events in both unit $i$ and its adjacent units; spatial clusters are formed

- low-low: low number of events in both unit $i$ and its adjacent units

- high-low: high number of events in unit $i$ and low number of events in surrounding units

- low-high: low number of events in unit $i$ and high number of events in surrounding units

Figure $3 \mid 4$ shows the local Moran's I estimated for the number of dairy farms per district using the neighbourhood network (left) and the sales structure network (right) as the spatial weight matrix. In the centre is the map of 2013 (compare Figure 3|2), illustrating the distribution of AMS. For illustration purpose, we expose the high-low and low-high outliers, although only the high-high clusters are statistically significant at the $10 \%$-level.

Figure 3 | 4. Local Moran's I (left and right) for the number of dairy farms in 2013
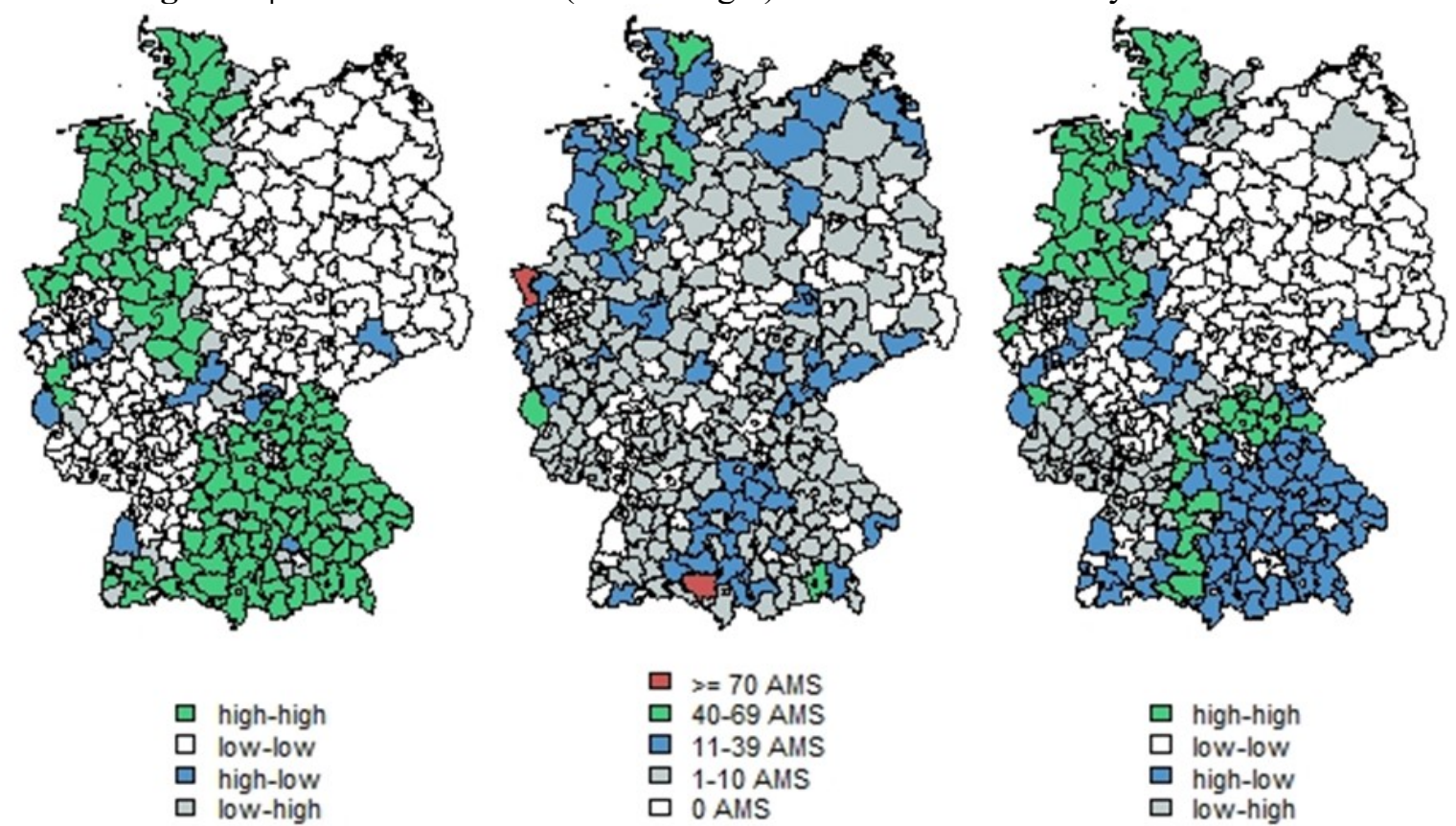

The neighbourhood network (left) and the sales structure network (right) are used as spatial weight matrix to compute the local Moran's I respectively

Applying both networks as spatial weight matrix results in slightly different maps for the Moran's I. While the neighbourhood network provides one massive cluster in the northnorthwest and one in the south-southeast with only a few outliers on the margins, do these 
clusters shrink in the sales structure network. Almost all administrative districts in South and South-East Germany are classified as high-low outliers. Furthermore, the sales structure network as weight matrix results in more low-high outliers in the southwest of Germany. As it appears, milk production is highly concentrated in both specifications. This corresponds with the map of AMS. However, the high numbers of adoption in the north-eastern and eastern districts are not reflected by analysing the spatial distribution of dairy farms.

Figure 3 | 5. Local Moran's I (left and right) for the number of dairy cows in 2013
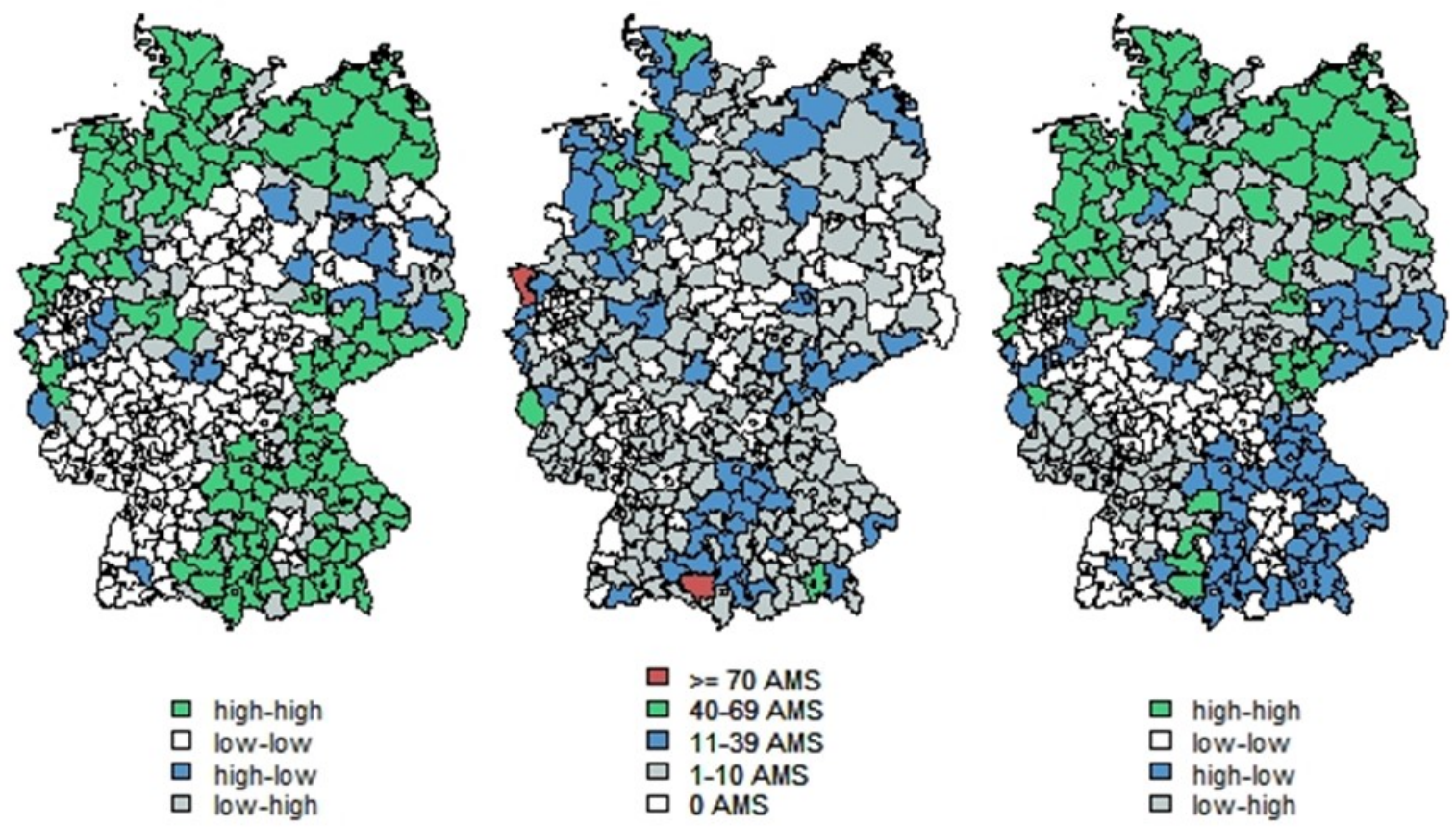

The neighbourhood network (left) and the sales structure network (right) are used as spatial weight matrix to compute the local Moran's I respectively

To get a robust overview, we estimate a second local Moran's I for the distribution of dairy cows per district with both network specifications (Figure 3|5). While the number of dairy farms in the north-eastern and eastern districts is lower than in the western and southern parts of Germany, the number of dairy cows per farm is considerably higher. The northern cluster of milk production expands to the north-east. The same applies to the eastern districts. Using the sales structure of the manufacturer as weight specification, again, shows a different result in the categorisation of the districts than the neighbourhood network. With some few exceptions all districts in the south, southeast and east are categorised as high-low outliers. Additionally, fewer districts are assigned to the low-low cluster. 


\subsection{Spatiotemporal endemic-epidemic $\operatorname{model}^{5}$}

We use the spatiotemporal endemic-epidemic modelling framework "hhh4" for the analysis of the distribution of AMS in Germany. The model was developed by Held et al. (2005) and extended by Paul et al. (2008), Paul and Held (2011) and Meyer et al. (2017), for the study of contagious disease data. The framework enables us to relate the network structure directly to a dynamic model, including past observations (Paul and Held 2011; Schrödle et al. 2012).

In the model, we assume that conditional on past observations, counts $Y_{i t}$ from unit $i=1, \ldots$, $I$ during periods $t=1, \ldots, T$ are negative binomial distributed with mean

$$
\mu_{i t}=e_{i t} v_{i t}+\lambda_{i t} Y_{i, t-1}+\phi_{i t} \sum_{j \neq i} \omega_{j i} Y_{j, t-1}
$$

To allow for overdispersion, we prefer a negative binomial distribution instead of a Poisson model. $Y_{i t}$ describes the adopted AMS in the administrative district $i$ in the calendar year $t$. As AMS are associated with a high investment, we assume a time lag of one year between taking note about the technology and the application on the farm.

The mean includes three components, describing three effects in the diffusion and adoption of technology. The first is the parameter-driven endemic component $v_{i t}$, which is measured proportional to an offset $e_{i t}$. As the offset is region-specific and time-dependent, we use the number of dairy cows in each administrative district and year. We interpret the endemic component as exogenous effect shaping the adoption process.

The other two, the autoregressive and network component, are observation-driven and depend on past cases $Y_{i, t-1}$. The autoregressive component $\lambda_{i t} Y_{i, t-1}$ can be referred to as agglomeration effects, as it describes the autoregression of installed AMS within the same administrative district. The network effect $\phi_{i t} \sum_{j \neq i} \omega_{j i} Y_{j, t-1}$ incorporates the spatiotemporal effects of a network structure, by using a spatial weight matrix $\omega_{j i}$. We use the neighbourhood and the sales structure network as a spatial weight matrix to capture the network effect and thus, estimate two model specifications.

Both the exogenous and the autoregressive effect can be described in detail, including additional variables. The coefficients estimated for the factors can be interpreted similarly to a negative binomial GLM model. We must emphasise that the covariables do not directly determine the outcome, but the overall effect of the component, which the variables are

\footnotetext{
${ }^{5}$ The description of the model follows Held et al. (2005), Paul and Held (2011), Meyer et al. (2017)
} 
assigned to. The assignment of the single variables to the exogenous or autoregressive component follows an economic assessment and the results of the Akaike's Information Criterion (AIC). The performance of the model as well is evaluated using the AIC.

\section{3 | 4. Results}

First, we show the results of the model specifications and the considered variables explaining the adoption of AMS in Germany. Table $3 \mid 3$ provides the estimated coefficients and the corresponding confidence intervals. Additionally, the mean and, where appropriate, the standard deviation of each variable is listed. Both refer to the regional level of the variable (compare Table $3 \mid 2$ ). As the coefficients must be interpreted as in a negative binomial GLM model, the variables do not affect the adoption of AMS directly, but indirectly through the associated effects. Furthermore, those variables, which are not indicated as shares, are z standardised. This implies that an increase by one standard deviation of a variable with a value below 1 represents a reduction by $(1$ - coefficient $) \%$. Contrary, a value above 1 leads to an increase by (coefficient -1$) \%$.

The covariables can be assigned to the autoregressive or the exogenous effect. The network effect is captured by the application of the two network structures. We allocate the two variables considering the particular situation and development in the administrative districts, the number of dairy farms and the unemployment rate, to the autoregressive effect. The remaining variables are related to the individual farm; hence, we use them to describe the exogenous effect more detailed.

The direction of the effects is similar in both model specifications. The number of dairy farms in the same district has a positive impact on the autoregressive effect. An increase of one standard deviation (441 farms per district) leads to an increase in the autoregressive effect by $19.17 \%$ with the neighbourhood network, and by $12.37 \%$ with the sales structure network. The unemployment rate has a negative effect on the autoregressive component. A rise in the unemployment rate in the district results in a decrease in the effect of $-11.99 \%$ with the neighbourhood network and $-16.34 \%$ with the sales structure network. 
$\underline{\text { Table } 3 \mid \text { 3. Results of spatiotemporal endemic-epidemic model }}$

\begin{tabular}{|c|c|c|c|c|c|c|c|c|}
\hline \multirow{3}{*}{ Variable } & \multirow{3}{*}{ Coefficient } & urhood & & \multirow{3}{*}{ Coefficient } & ucture $n$ & & \multirow{3}{*}{ Mean } & \multirow{3}{*}{ S.d. } \\
\hline & & \multicolumn{2}{|c|}{ Confidence interval } & & \multicolumn{2}{|c|}{ Confidence interval } & & \\
\hline & & $2.5 \%$ & $97.5 \%$ & & $2.5 \%$ & $97.5 \%$ & & \\
\hline Autoregressive effect: & $29.68 \%$ & & & $27.79 \%$ & & & & \\
\hline Number of farms & 1.1917 & 0.9921 & 1.3912 & 1.1237 & 0.9236 & 1.3239 & 324 & 441 \\
\hline Unemployment rate & 0.8801 & 0.8037 & 0.9566 & 0.8366 & 0.7551 & 0.9181 & $9.5 \%$ & \\
\hline Exogenous effect: & $51.74 \%$ & & & $66.35 \%$ & & & & \\
\hline Family labour & 1.4541 & 1.2242 & 1.6840 & 1.3748 & 1.1786 & 1.5710 & 1.6 & 0.2 \\
\hline Hired labour & 0.3048 & 0.0763 & 0.5332 & 0.2746 & 0.0812 & 0.4679 & 4.5 & 8.6 \\
\hline Personnel expenses & 4.9090 & 0.7018 & 9.1163 & 4.5187 & 0.8074 & 8.2300 & 83,775 & 171,234 \\
\hline Herd size & 1.2297 & 0.3195 & 2.1399 & 1.1742 & 0.3869 & 1.9615 & 81 & 83 \\
\hline Milk yield per cow & 1.4783 & 1.2231 & 1.7334 & 1.5778 & 1.3449 & 1.8106 & 6,466 & 853 \\
\hline Specialisation & 0.9871 & 0.9708 & 1.0035 & 0.9954 & 0.9820 & 1.0089 & $60.3 \%$ & \\
\hline Milk price & 1.3377 & 1.1841 & 1.4914 & 1.3006 & 1.1791 & 1.4221 & 31.8 & 2.8 \\
\hline Profit & 1.2731 & 1.0693 & 1.4769 & 1.2704 & 1.0800 & 1.4609 & 40085 & 36738 \\
\hline Full-time farming & 0.3269 & 0.0074 & 0.6463 & 0.3301 & 0.0432 & 0.6171 & $93.9 \%$ & \\
\hline Partnership & 1.0679 & 1.0390 & 1.0968 & 1.0593 & 1.0335 & 1.0851 & $91.5 \%$ & \\
\hline Network effect: & $18.58 \%$ & & & $5.86 \%$ & & & & \\
\hline AIC: & 7255 & & & 7312 & & & & \\
\hline
\end{tabular}


We assigned ten factors to the exogenous component, capturing characteristics of the dairy farms. The primary focus is on the amount of labour used on the farms and the associated costs. Considering family and hired labour results in opposite effects on the component. While an increase in the amount of family labour will increase the use of AMS (neighbourhood network: $+45.41 \%$, sales structure network: $+37.48 \%$ ), will additional hired labour decrease the probability of the adoption of AMS (neighbourhood network: $-69.52 \%$, sales structure network: $-72.54 \%$ ). The personnel expenses associated with hired labour have the most considerable impact on the exogenous effect. This factor increases the exogenous effect by $+390.90 \%$ (neighbourhood network) and $+451.87 \%$ (sales structure network), respectively; thus, determines the adoption of AMS on the farm strongly.

According to the factors of milk production, the average herd size, the milk yield per cow and the milk price have a positive impact on the exogenous effect. One increase in the standard deviation (S.d. $=83$ ) of herd size in the administrative division, would raise the exogenous effect by $+22.97 \%$ for the neighbourhood network and by $+17.42 \%$ for the sales structure network. The milk yield per cow has an even more substantial positive effect on its component $(+47.83 \%$ for the neighbourhood network, $+57.78 \%$ for the sales structure network), as well as the milk price $(+33.77 \%$ for the neighbourhood network, $+30.06 \%$ for the sales structure network). Unexpected in this context is the result of the specialisation. The specialisation of a farm was calculated using the share of milk production to the total revenue. The influence estimated in both model specifications is slightly negative, with a value of $-1.29 \%$ for the neighbourhood network and $-0.45 \%$ for the sales structure network. As expected, the profit provides a positive influence on the exogenous component. An increase by one standard deviation of the farm profit affects the associated component by $+27.31 \%$ (neighbourhood network) and $+27.04 \%$ (sales structure network), respectively. Farms operated as a partnership (as a non-corporate legal entity) according to their legal status have a higher probability of adopting AMS (neighbourhood network: $+6.79 \%$, sales structure network: $+5.93 \%$ ). Additionally, farms operated full-time decrease in the exogenous component by $-67.31 \%$ for the neighbourhood network and $-66.99 \%$ for the sales structure network.

However, the directions are similar, and values differ at most marginal for most of the single variables (exceptions are the personnel expenses and the milk yield per cow), the implications vary, especially for the network component. The autoregressive effect in the 
model specification with the neighbourhood network explains almost $30 \%$ of the mean, with the sales structure network around $28 \%$. For both networks, the exogenous effect constitutes the main driver of the adoption. The network component explains 18.59\% (neighbourhood network) and 5.86\% (sales structure network). Despite the inclusion of economic factors, the influence of the neighbourhood network holds almost $19 \%$ of the explanatory power in the adoption process of AMS

Finally, we assess the models using the AIC criterion. The AIC for the model specification applying the neighbourhood network is 7255 ; the sales structure network, the AIC is 7312 . Thus, the neighbourhood network is to prefer over the sales structure network.

\section{3 | 5. Discussion and conclusion}

AMS fundamentally change the operating procedures on dairy farms entailing significant investments. In this paper, we use the dataset of 2,531 adopted AMS of one manufacturer in Germany over 17 years to analyse the factors shaping its diffusion and adoption using a spatiotemporal endemic-epidemic model. Based on the results of our model, we find evidence for the substitutional character of AMS. Considering the outcomes of the unemployment rate in a particular district, the number of family and hired labour on the farm in combination with the personnel expenses allows us to cover multiple situations. Farms with a high number of hired workers are less likely to adopt AMS as they have sufficient people at hand to cope with the work. Similar, a low unemployment rate implies a low availability of labour force and a high competition for workforce between several economic sectors. Farmers can meet these challenges by investing in automation of specific work processes, like milking, which grants the farmers independence from the fluctuations on the labour market. Still, the adoption of AMS is associated with a high investment, but it replaces the personnel expenses. In summary, our results confirm the hypothesis that AMS are adopted to substitute increasing labour costs and decreasing labour availability in Germany.

The amount of family labour as a driver for the adoption seems contradictory at first. Clearly, instead of investing in expensive technology, farmers can employ family members to approach their lack and cost of hired labour. However, research revealed that farmers name non-economic factors as the basis of their decision-making (Sauer and Zilberman 2012; Bergman and Rabinowicz 2013; Hansen 2015; Schewe and Stuart 2015). Potentially, this 
applies not only to farmers themselves but also for their kin. Family members not engaged on the farm are available to generate a second, off-farm income.

As addressed in the literature, the strategic orientation of milk production substantially influences the adoption probability of farmers. Farms with large herd size and high milk yields per cow are more likely to adopt AMS. However, this result is slightly weakened by the marginally negative outcome of the variable specialisation. AMS are featured to improve the milk production per dairy cow and the overall milk yield (Sauer and Zilberman 2012; Hansen 2015). Thus, farms intending to intensify the milk production are predestined to adopt AMS.

The importance of the number of dairy farms located in the same spatial unit complies with the theory that agglomeration effects, emerging through the accumulation of farms engaged in the same production area, shape the diffusion of technology. As the autoregressive component captures effect within one administrative unit, it can be described as a measure of agglomeration effects, which is strengthened by the involvement of explaining variables. The calculation of local Moran's I (Figure 3|4 and Figure 3|5) confirms the assumption of clusters of AMS technology in areas of concentrated milk production. Both, the local Moran's I and the autoregressive effect emphasise the relevance of agglomeration effects in the distribution of technology.

Nonetheless, agglomeration effects only account for spillover effects in a limited spatial area. For accomplishing a comprehensive rate of adoption, networks effects are essential. Despite the inclusion of economic factors, the influence of the neighbourhood network holds almost $19 \%$ of the explanatory power in the adoption process of AMS. In contrast, considering the sales structure of the manufacturer leads to a network effect of $6 \%$, which is almost 13 percentage points lower than the neighbourhood network. When incorporating social networks in the adoption process, the structure of the network is an integral part of the prosperity of the implementation.

Summing the network and the agglomeration effect, capturing related elements of the adoption process in different spatial units, both constitute for almost 50\% for the neighbourhood network and almost $34 \%$ for the sales structure network. Future strategies of dissemination of technology can exploit the benefits of a stronger integration of the social environment of a farmer. 


\title{
Chapter 4 | A network analysis of local rubber and oil palm trade in Jambi, Indonesia ${ }^{6}$
}

\begin{abstract}
Intermediaries play a crucial role in the local rubber and oil palm trade, which are the main crops produced in the province of Jambi in Indonesia. They connect producers and processors within the region. Intermediaries can select several paths to directly or indirectly trade the crops to the factories. Social networks are suitable to illustrate trading patterns and to show marketing choices. Network properties like the size or the in- and out-degree reveal whether there are differences in the trade of rubber and oil palm and if there are changes over time. Therefore, we use a cross-sectional and a panel dataset to examine the local trade. Besides network visualisation, exponential random graph $\left(\mathrm{p}^{*}\right)$ models are estimated to evaluate the parameters influencing the link formation in the networks displaying rubber and oil palm trading. We include various node attributes, edge attributes and homophily aspects. Results confirm that the average crop price and the provision of loan by the buyer are driving the trade relations. The trading experience and the total traded quantity of the seller are insignificant. However, previous trading links impact the choice of buyers.
\end{abstract}

Keywords - trade networks, network formation, ERGM, rubber, oil palm

\footnotetext{
${ }^{6}$ This chapter is co-authored by Rakhma Sujarwo (RS), Thomas Kopp (TK) and Bernhard Brümmer (BB). CH and BB jointly developed the research idea. RS and TK, as members of the CRC 990 provided the data and supported the analysis with detailed background information. $\mathrm{CH}$ did the literature review, the data analysis, and wrote the essay. BB commented the various stages of the research and contributed to writing and revising the essay.
}

Acknowledgement - The authors are grateful to the Collaborative Research Centre (CRC 990) in Ecological and Socioeconomic Functions of Tropical Lowland Rainforest Transformation Systems in Sumatra, Indonesia at the University of Göttingen, to provide the data. 


\section{4 | 1. Introduction}

Indonesia is the worldwide largest producer of rubber and oil palm in 2017 with a production area 3,659,129 ha and 3,146,330 ha, respectively (FAO 2019). In Indonesia, the province of Jambi is ranked number three in rubber and number four in oil palm production in 2016. Special about Jambi is that $99 \%$ of the rubber and $62 \%$ of the oil palm production area is cultivated by smallholders (Directorate General of Estate Crops 2017a; 2017b). Thus, the production of both crops makes a significant contribution to the improvement of the living conditions of the farming households (Kubitza et al. 2018).

Initial analyses of the value chain in Jambi, conducted by Kopp et al. (2014), Kopp and Brümmer (2017), and Sujarwo et al. (2014) show that the smallholders sell their products to intermediaries, who either sell directly to crumb rubber factories or oil palm mills or other middlemen. In the local rubber trade other platforms, like warehouses or auction markets can be additionally used by the intermediaries to distribute the crops. However, several mechanisms underlying the local trade in Jambi are very much unknown, yet. We use social network analysis to gain an overview of the pattern of local rubber and oil palm trade in Jambi (Easley and Kleinberg 2010; Jackson 2008). In our application the trade networks consist of intermediaries and buyers, connected through the transaction of products.

With this paper, we would like to address the subsequent research questions: How do the trading networks of rubber and oil palm in Jambi look like and do they change over time? Are there differences in the network patterns of both products? What aspects determine the formation of links between sellers and buyers?

As part of the CRC 990 Ecological and Socioeconomic Functions of Tropical Lowland Rainforest Transformation Systems in Sumatra, Indonesia, information on intermediaries and their buyers was collected, which enables us to disentangle the trading structures of rubber and oil palm. The dataset composes of three survey rounds in 2012, 2015 and 2018. Thus, a cross-sectional sample of in total 886 traders and a panel sample of 83 traders can be analysed. To ease the differentiation between intermediaries, traders, sellers and buyers, we define the following: respondents in our sample, who are trading rubber and oil palm are going to be called sellers, institutions, which are named as purchasing rubber and oil palm in our sample are going to be called buyers throughout the empirical parts of the paper.

For the statistical analysis, we apply an exponential random graph (p*) model as introduced by Robins et al. (2007a). This type of models allows us to estimate influences on the 
formation of links while using the network structure as a baseline. Various attributes of the agents and the links can be exploited to explain the reasons for traders to sell to specific buyers. Estimations show that the average price per $\mathrm{kg}$ rubber respective oil palm and the provision of loan by the buyer are driving the formation of trading connections. Besides, we recognise differences in the rubber and oil palm trade in the panel sample. Disparities are also evident in the network structures of both crops.

The paper is structured as follows: In Section 2, we provide an overview of the rubber and oil palm trade in Jambi. The data and the applied model are introduced in Section 3. In Section 4, we display and discuss the rubber and oil palm trading network. Before we conclude the paper in Section 6, we present and discuss the results of the statistical model in Section 5 .

\section{4| 2. Background}

Markets in developing countries are often described as inefficient, not perfect, and interlocked (Blume et al. 2009; Subramanian and Qaim 2011). If markets were functioning perfectly, the product price would be the most relevant variable explaining trade (Blume et al. 2009; Subramanian and Qaim 2011). In interlocked markets, other aspects drive the decision to whom to sell the product. Location, granting of a loan, or the availability of a transporting vehicle are just a few aspects that need to be considered (Fafchamps and Minten 2002; Kopp and Salecker 2018).

Furthermore, when analysing local markets and trading chains, buyers and sellers are often treated as anonymous to each other (Kranton and Minehart 2001; Fafchamps and Minten 2002). However, repeated interactions between sellers and buyers instead indicate a relationship between both agents (Fafchamps and Minten 2002; Kopp and Salecker 2018). This assumption can be even reinforced in interlocked markets. Therefore, a non-inclusion of a relationship between agents can lead to a misunderstanding and misinterpretation of the market function.

Social networks can be applied to illustrate the trading chains of traders and buyers. Networks comprise of links between agents in a social environment (Kranton and Minehart 2001; Jackson 2008; Easley and Kleinberg 2010). The kind of links depends on the setting of the study and can be personal relationships or the transactions of goods (Glückler 2007; Robins 2015). Using network visualisations can consolidate the understanding of trading 
patterns and changes over time (Jackson 2008; Borgatti and Halgin 2011). Network properties, node and link attributes add further information.

Additionally, homophily can be measured. Homophily describes the behaviour of people to form connections to people who have similar characteristics like themselves (Jackson 2008; Easley and Kleinberg 2010). Typical examples for homophily are age, ethnicity or gender. In other settings homophily can refer to the same employer, being located in the same area or trade the same goods. Various studies use network analysis to evaluate international trade of goods and the integration of specific regions in global transactions (De Benedictis and Tajoli 2010; Reyes et al. 2010; An et al. 2014). Trade networks on a regional level in agricultural settings are scarce.

In the international production of rubber and oil palm Indonesia is the market leader. The province of Jambi is the third-largest producer of rubber and the fourth-largest producer of oil palm in Indonesia. In 2016, smallholders produced 2,427,749 tons of rubber and $1,013,114$ tons of oil palm, which equals $98 \%$ and $62 \%$ of the provincial volume (Directorate General of Estate Crops 2017a; 2017b). Rubber has a long tradition of being grown in Jambi (Schwarze et al. 2015), and the majority of farmers produces rubber (Kubitza et al. 2018). Besides, rubber is more cost-effective per unit of land (Kubitza et al. 2018).

Figure $4 \mid$ 1. Schematic representation of the rubber and oil palm value chain in Jambi

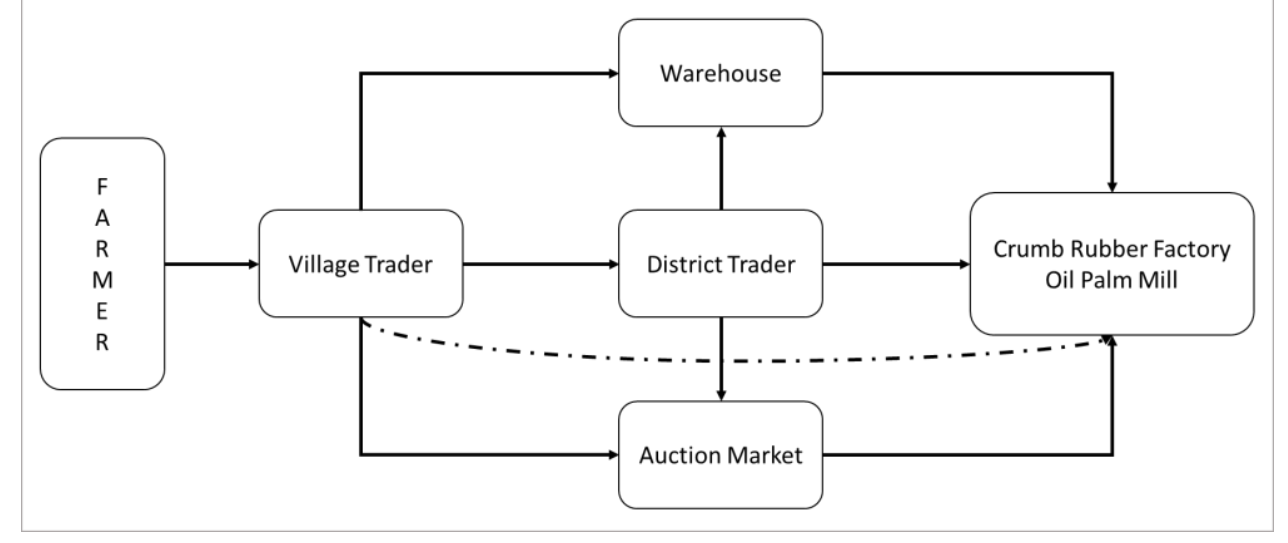

Figure $4 \mid 1$ shows the value chain of rubber and oil palm in Jambi. Typically, farmers do not transport the crops to the processor themselves but sell their harvest to intermediaries (Kopp et al. 2014; Sujarwo et al. 2014; Kopp and Brümmer 2017). Nakajima et al. (2010) argue that existing structure developed due to constraints in infrastructure, the requirement by many factories to meet a minimum quantity, and, in the case of oil palm, the perishable nature of the crop. This leads to the situation that middlemen are in charge of distributing 
the crops by connecting farmers and processors (Coughlan et al. 2006). Therefore, intermediaries are a crucial element in the local value chain.

These intermediaries can be traders located in the same villages as their suppliers or district traders, who visit the farmers regularly (Nakajima et al. 2010; Kopp and Brümmer 2017). In the case of rubber, two other selling platforms, auction markets and warehouses, are available (compare Figure 4|1). Consequently, many paths exist, how rubber and oil palm can be market in Jambi.

Many aspects can influence the path choice. For oil palm trade in North Sumatra, Nakajima et al. (2010) emphasise the quantity and quality of the product, the offered price by the factory, the distance between trader and factory and the availability of a transportation vehicle to determine the buyer's decision. Sujarwo et al. (2014) add the preference of the same ethnicity of trader and buyer, as well as the provision of a loan.

Further, access to information about prices on the local and world level play a role in the choice of the channel. Traders with a high informational grade, choose buyers without any obligations to be more flexible in the future. Kopp and Salecker (2018) apply agent-based modelling to analyse the buyer-seller interactions in rubber trader in Jambi. Their approach results in the outcome that sales are influenced by the distance between both agents, credit obligations, ethnicity and the price.

\section{3. Data and methodology}

\subsection{Data}

The data was collected as part of the project of the Collaborative Research Centre (CRC 990) in Ecological and Socioeconomic Functions of Tropical Lowland Rainforest Transformation Systems in Sumatra, Indonesia. Five regencies were chosen, which are representative for low land forests in the Jambi province in Indonesia: Sarolangun, Butang Hari, Muero Jambi, Tebo and Bungo. Within the regencies, in total, 22 districts and 37 villages were selected using stratified random sampling techniques. In each village, all active sellers, trading rubber or oil palm, were surveyed employing a standardised questionnaire. Besides questions about the sellers themselves and their businesses, the respondents were asked to name up to three buyers. Depending on the traded crop, buyers can be other traders, factories (oil palm mills or crumb rubber factories), warehouses, or auction markets. The 
buyers were not surveyed, and all the information about the individual buyers was collected through the sellers.

Altogether, three survey rounds in 2012, 2015 and 2018 were executed. This leads to a sample of 271 sellers in 2012, 295 sellers in 2015, and 320 sellers in 2018. However, some sellers were active throughout the time so we can form a panel of 83 traders. Thus, we can analyse both the cross-sectional and the panel dataset to compare differences in the results.

To analyse the trading networks in Jambi, we include numerous variables. Besides factors characterising the seller, like age, education, if the seller has an additional function in the village, we use indicators that could determine the wealth of the seller: the value of the house, value of the owned land, and the land size. An additional function in the village can be for example village head, village official or official of an organisation located in the village. We further consider access to information about international and national policies on rubber and oil palm, information on harvests, and the access to the internet as information source. Aspects describing the business are the total traded quantity, the experience in trade, crop storage possibilities and the total capacity of transport vehicles. To represent the trade relationship, we use the average obtained crop price and the provision of loan by the buyer. Finally, to capture homophily between seller and buyer, we include location and ethnicity. Homophily in location means that both seller and buyer are located in the same regency in Jambi; homophily in ethnicity means that both belong to the same ethnical group.

\section{$\underline{\text { Cross-sectional dataset }}$}

In Table 4|1, we compile the summary statistics for the cross-sectional dataset, distinguishing rubber and oil palm sellers in the respective years. The number of people trading rubber and oil palm suggests a more substantial increase in oil palm sellers and a decline of rubber sellers over time, though the sum of active sellers increases in the research area. Both groups are similar in age and education, though, in terms of experience, rubber sellers are active for more years than oil palm sellers. This can be confirmed by Schwarze et al. (2015), who describe that rubber is cultivated for a longer time than oil palm in Jambi. Remarkable is the development of the traded quantities of rubber throughout the years. Although the number of rubber sellers in our sample declines, the quantity raises from an average of 12 tons to an average of 95 tons. This leads to the conclusion that the rubber sellers expand their businesses and that the rubber market is highly more concentrated than before. 
Table $4 \mid$ 1. Summary statistics of the cross-sectional dataset

\begin{tabular}{|c|c|c|c|c|c|c|c|c|}
\hline & \multicolumn{4}{|c|}{ Rubber } & \multicolumn{4}{|c|}{ Oil palm } \\
\hline & Mean & S.d. & Max & Min & Mean & S.d. & Max & Min \\
\hline 2012 & \multicolumn{4}{|c|}{216 sellers } & \multicolumn{4}{|c|}{55 sellers } \\
\hline Age & 42.51 & 9.90 & 62 & 21 & 40.65 & 8.99 & 60 & 20 \\
\hline Education & 3.33 & 1.52 & 5 & 1 & 3.20 & 1.54 & 5 & 1 \\
\hline Experience & 9.42 & 8.50 & 18 & 0.25 & 5.80 & 3.74 & 17 & 0.83 \\
\hline Quantity & 12 & 20.75 & 32 & 0.30 & 296.74 & 853.61 & 6000 & 300 \\
\hline Average price & 10.92 & 4.32 & 14 & 0.64 & 2.88 & 4.43 & 16.30 & 0.50 \\
\hline Storage & 10.01 & 19.63 & 12 & 0 & 19.26 & 37.17 & 200 & 0 \\
\hline Capacity & 3.42 & 6.34 & 12 & 0 & 9.88 & 10.03 & 40 & 0 \\
\hline Value house & 171.83 & 189.07 & 500 & 0 & 161.09 & 184.85 & 1000 & 0 \\
\hline Value land & 94.02 & 176.53 & 200 & 0 & 96.02 & 158.99 & 1000 & 0 \\
\hline Land size & 16.17 & 33.44 & 375 & 0 & 12.95 & 21.00 & 107 & 0 \\
\hline 2015 & \multicolumn{4}{|c|}{202 sellers } & \multicolumn{4}{|c|}{93 sellers } \\
\hline Age & 44.72 & 9.68 & 70 & 24 & 43.83 & 11.39 & 80 & 24 \\
\hline Education & 2.94 & 1.09 & 5 & 1 & 2.78 & 1.13 & 5 & 1 \\
\hline Experience & 11.78 & 7.87 & 39 & 1 & 6.88 & 4.77 & 20 & 1 \\
\hline Quantity & 9.90 & 14.60 & 100.00 & 0.25 & 87.39 & 132.04 & 800 & 0.36 \\
\hline Average price & 6.72 & 1 & 8.75 & 1.15 & 1.21 & 0.83 & 7.40 & 0.62 \\
\hline Storage & 5.53 & 8.12 & 50 & 0 & 12.87 & 39.44 & 300 & 0 \\
\hline Capacity & 0.55 & 1.47 & 11.50 & 0 & 1.06 & 3.41 & 25.50 & 0 \\
\hline Value house & 167.83 & 135.92 & 500 & 0 & 231.84 & 720.20 & 7000 & 0 \\
\hline Value land & 61.43 & 116.31 & 1000 & 0 & 45.75 & 76.73 & 500 & 0 \\
\hline Land size & 9.99 & 12.39 & 100 & 0 & 11.35 & 15.65 & 115 & 0 \\
\hline 2018 & \multicolumn{4}{|c|}{185 sellers } & \multicolumn{4}{|c|}{135 sellers } \\
\hline Age & 43.75 & 10.35 & 76 & 21 & 41.94 & 12.46 & 99 & 22 \\
\hline Education & 2.97 & 1.03 & 5 & 1 & 3.05 & 1.18 & 5 & 1 \\
\hline Experience & 12.40 & 7.41 & 42 & 1 & 7.63 & 6.02 & 38 & 1 \\
\hline Quantity & 95.45 & 792.24 & 9000 & 0 & 227.26 & 1299.82 & 15000 & 2 \\
\hline Average price & 9.08 & 5.71 & 85 & 3 & 1.14 & 0.14 & 1.72 & 0.83 \\
\hline Storage & 7.18 & 20.47 & 220 & 0 & 3.75 & 12.84 & 100 & 0 \\
\hline Capacity & 4.69 & 9.04 & 11 & 0 & 11.34 & 11.24 & 61.50 & 0 \\
\hline Value house & 119.81 & 177.10 & 1200 & 0 & 118.94 & 173.01 & 1000 & 0 \\
\hline Value land & 57.68 & 112.17 & 800 & 0 & 88.41 & 189.81 & 1320 & 0 \\
\hline Land size & 9.93 & 10.58 & 70 & 0 & 10.89 & 13.69 & 70 & 0 \\
\hline $\begin{array}{l}\text { Age and experi } \\
\text { Education: } 1= \\
\text { secondary scho } \\
\text { Quantity, storas } \\
\text { Capacity is the } \\
\text { Land size in he } \\
\text { Average price i } \\
\text { Value house an }\end{array}$ & $\begin{array}{l}\text { ears } \\
\text { school no } \\
\text { eted, } 5= \\
\text { ity in ton } \\
\text { e transpe } \\
\text { ad Indone }\end{array}$ & $\begin{array}{l}\text { pleted, } 2 \\
\text { se/univer } \\
\text { acities o } \\
\text { Rupiah p }\end{array}$ & $\begin{array}{l}\text { primary s } \\
1 \text { vehicle } \\
\text { g, averas }\end{array}$ & ol com & $\mathrm{ed}, 3=\mathrm{se}$ & dary scho & ot compl & ed, $4=$ \\
\hline
\end{tabular}

As Table $4 \mid 1$ shows, the price per kg rubber is higher than the price for kg oil palm, but oil palm is traded in higher quantities. Both products record a decline in price and quantity in 
2015 due to developments in the world market. While the average price for rubber in our sample nearly recovers in 2018 , the average price for oil palm continues to fall.

Regarding the land size, it is apparent that for both groups the average land size shrinks. We interpret this as sellers focus on trading the crops instead of producing it. The capacity of storage reduces among oil palm sellers from an average of 19 tons to 3 tons. As oil palm needs to be processed within 24 hours to ensure quality, storage capacities for oil palm sellers are less necessary than for rubber sellers. The reduction of storage capacity can be interpreted as the sellers switched from rubber to oil palm trade, which can be directly linked to the rising number of oil palm traders in the time period.

\section{$\underline{\text { Panel dataset }}$}

In Table $4 \mid 2$, we list the summary statistics of the panel dataset in our sample. In total, 83 sellers are present in 2012, 2015, and 2018. Similar to the cross-sectional sample, the number of people selling oil palm increases, while the number of rubber sellers declines slightly. However, the number of sellers trading both crops rises from two in 2012 to five in 2015 and eight in 2018.

Although we can recognise similar developments of price and quantity for rubber, the sellers present in the panel obtain higher average prices per kg rubber at any time and increase the traded quantity much more on average. The average price per $\mathrm{kg}$ oil palm for 2015 and 2018 in the panel is slightly above the price in the cross-sectional sample. Thus, the traded quantity continues to decrease, and a little more than one-third of the average quantity in the crosssectional sample for 2018. Regarding the storage and transport capacity, the rubber sellers in the panel exhibit higher values for both.

In summary, sellers trading rubber in the panel dataset are more experienced, trade higher quantities to higher prices can store and transport larger volumes than the rubber sellers in the cross-sectional dataset. In contrast, for oil palm sellers, the results of the comparison are far from clear. 
Table $4 \mid$ 2. Summary statistics of the panel dataset

\begin{tabular}{|c|c|c|c|c|c|c|c|c|}
\hline & \multicolumn{4}{|c|}{ Rubber } & \multicolumn{4}{|c|}{ Oil palm } \\
\hline & Mean & S.d. & Max & Min & Mean & S.d. & Max & Min \\
\hline 2012 & \multicolumn{4}{|c|}{72 sellers } & \multicolumn{4}{|c|}{13 sellers } \\
\hline Age & 41.04 & 8.23 & 62.00 & 27.00 & 41.67 & 8.17 & 57.00 & 29.00 \\
\hline Education & 3.30 & 1.52 & 5.00 & 1.00 & 3.23 & 1.37 & 5.00 & 1.00 \\
\hline Experience & 8.03 & 5.11 & 22.00 & 0.83 & 7.55 & 5.33 & 17.00 & 1.00 \\
\hline Quantity & 10.9 & 15.14 & 100 & 0.6 & 248.66 & 290.18 & 1000 & 0.3 \\
\hline Average price & 11.64 & 4.31 & 23.5 & 0.75 & 2.5 & 4.13 & 14.8 & 0.5 \\
\hline Storage & 6.48 & 13.33 & 100 & 0 & 17.77 & 27.69 & 100 & 0 \\
\hline Capacity & 4.19 & 8.07 & 48.8 & 0 & 16.08 & 13.54 & 40 & 0 \\
\hline Value house & 146.99 & 145.47 & 1000 & 0 & 194.62 & 264.35 & 1000 & 0.1 \\
\hline Value land & 107.14 & 194.66 & 1000 & 0 & 14.354 & 255.8 & 1000 & 0.05 \\
\hline Land size & 17 & 44.456 & 375 & 0 & 12.31 & 18.69 & 75 & 1 \\
\hline 2015 & \multicolumn{4}{|c|}{66 sellers } & \multicolumn{4}{|c|}{22 sellers } \\
\hline Age & 45.23 & 9.44 & 65 & 31 & 44.18 & 10.25 & 63 & 27 \\
\hline Education & 2.91 & 1.09 & 5 & 1 & 2.80 & 1.03 & 5 & 1 \\
\hline Experience & 12.11 & 6.20 & 35 & 1 & 7.75 & 4.33 & 15 & 2 \\
\hline Quantity & 13.09 & 17.41 & 100 & 0.5 & 124.74 & 168.14 & 800 & 15 \\
\hline Average price & 6.78 & 0.8 & 8.1 & 5 & 1.32 & 0.96 & 5.7 & 0.8 \\
\hline Storage & 6.32 & 8.91 & 50 & 0 & 18.5 & 62.35 & 300 & 0 \\
\hline Capacity & 0.82 & 1.98 & 11.5 & 0 & 1.92 & 5.69 & 25.5 & 0 \\
\hline Value house & 194.32 & 132.35 & 500 & 0 & 183.64 & 142.75 & 500 & 0 \\
\hline Value land & 61.14 & 101.81 & 400 & 0 & 66.45 & 84.9 & 350 & 0 \\
\hline Land size & 8.63 & 7.09 & 31 & 0 & 37.27 & 123.21 & 600 & 0 \\
\hline 2018 & \multicolumn{4}{|c|}{67 sellers } & \multicolumn{4}{|c|}{24 sellers } \\
\hline Age & 45.09 & 10.18 & 76 & 21 & 41.83 & 9.94 & 62 & 26 \\
\hline Education & 2.89 & 0.99 & 5 & 1 & 2.65 & 1.05 & 4 & 1 \\
\hline Experience & 14.66 & 7.07 & 42 & 1 & 9.41 & 4.37 & 18 & 2 \\
\hline Quantity & 150.76 & 1089.67 & 9000 & 0.3 & 82.7 & 70.57 & 300 & 2.1 \\
\hline Average price & 9.78 & 9.33 & 85 & 6 & 1.15 & 0.16 & 1.71 & 0.86 \\
\hline Storage & 12.04 & 32.17 & 220 & 0 & 4.54 & 19.96 & 100 & 0 \\
\hline Capacity & 4.71 & 4.78 & 20 & 0 & 13.2 & 12.5 & 56.5 & 0 \\
\hline Value house & 142.61 & 205.56 & 1200 & 0 & 160.83 & 211.32 & 750 & 0 \\
\hline Value land & 61.96 & 117.72 & 700 & 0 & 82.82 & 164.55 & 750 & 0 \\
\hline Land size & 10.6 & 8.78 & 40 & 0 & 11.21 & 13.1 & 60 & 0 \\
\hline
\end{tabular}

Age and experience in years

Education: 1 = primary school not completed, 2 = primary school completed, $3=$ secondary school not completed, 4 = secondary school completed, 5 = college/university

Quantity, storage, capacity in tons

Capacity is the sum of the transport capacities of all vehicles

Land size in hectare

Average price in thousand Indonesian Rupiah per kg, average price per seller for three months

Value house and value land in million Indonesian Rupiah 


\subsection{Methodology}

Besides the visualisation and description, we analyse the rubber and oil palm trading networks using an exponential random graph p* model (ERGM). ERGM can be summarised as a class of probability models for social networks (Robins et al. 2007a). We assume that the links present in the networks are independent of one another (Robins et al. 2007b). The connection between one seller and one buyer is not determined by the connection of a second seller to the same buyer or the connection of the same seller to a second buyer.

The links are indicated to be random and for each pair of nodes $i$ and $j$ there is a random variable $Y_{i j} . Y_{i j}$ is equal to 1 , when there is a link between both nodes and equal to 0 when there is no link (Robins et al. 2007a). We define our networks to be directed, thus $Y_{i j}$ is no equal to $Y_{j i} \cdot y_{i j}$ represents the observed value of $Y_{i j}$.

ERG models estimate parameters, which maximise the probability that the simulated network, based on configurations of the observed network, is identical to the observed network. (Robins et al. 2007a; Hunter et al. 2008; Broekel and Hartog 2013). The configuration is specified by the network statistics and its structural characteristics and represented by the attributes at the nodes, dyad and network level (Robins et al. 2007b; Broekel and Hartog 2013; Levy and Lubell 2018). As summed up by Levy and Lubell (2018), the outcome variable of an ERGM is the observed network.

Robins et al. (2007a) and Broekel and Hartog (2013) express the basic model as

$$
\operatorname{Pr}(Y=y)=\left(\frac{1}{\kappa}\right) \exp \left\{\sum_{A} \eta A g A(y)\right\}
$$

$\operatorname{Pr}(Y=y)$ is the probability that $Y$ is identical to the observed network $y . \kappa$ is the normalising constant to assure that the equation is a proper probability distribution. The summation is over the configuration of type $A$, with $\eta A$ describing the parameter corresponding to the configuration $A$ and $g A(y)$ to be the network statistic.

The goodness of fit of the model can be evaluated comparing the structure of the simulated networks to the structure of the observed network (Hunter et al. 2008; Broekel and Hartog 2013). We do this by testing the goodness of fit of the in- and out-degree, of the edgewise shared partners, of the geodesic distance and the model statistics. The in- and out-degree indicates the number of links towards a node or away from a node, respectively. The edgewise shared partners reveal the number of nodes which have the same node in common. 
The geodesic distance can be understood as the path distance between two nodes. The decisive factor is the p-value. A p-value of less than 0.05 identifies a poor fit.

\section{4 | 4. Rubber and oil palm trading network}

In the first step of the analysis, we construct the trading networks separately per year and product. It is essential to mention that the networks are not complete, as we only have complete data on the sellers in the 37 villages, not for the respective districts, regencies or the whole region.

As we distinguish between two categories of nodes -sellers and buyers - we form directed bipartite network graphs. Bipartite means that the nodes establish links between the categories but not within the same category (Easley and Kleinberg 2010; Robins 2015). In our example, we have links between sellers and buyers, but not amongst sellers or buyers. In the networks, we differentiate the two categories by using different shapes of the nodes.

Displayed in the networks are two different kinds of directed links between sellers and buyers. Links from sellers to buyers represent the transaction of rubber or oil palm. Links from buyers to sellers illustrate the provision of loan from the specific buyer to his or her client. We determine both by using two colours in the graphs. It should be mentioned that the credits displayed in the networks do not have to be the only credits sellers obtain but highlights when sellers receive credit from the same source they are selling to. Additionally, the category of buyers can be more specified by the kind of buyer: auction markets, factories, traders, and warehouses. We classify the four types by using different colours.

Besides the elements of visualisation, we use the size of the networks, the in- and out-degree to add further explanatory power to the networks. The number of nodes and links describes the size of the network. Both, in- and out-degree, describe the links of the buyers. The average in-degree reveals the average number of links towards the buyer (here: transaction of crops) and the average out-degree indicates the average number of links directed away from the buyer (here: provision of loan) (Scott 2013; Robins 2015). The highest in- and outdegree expresses the buyer with the highest number of links directed towards or away from him or her, respectively. 


\section{$\underline{\text { Cross-sectional dataset }}$}

For the cross-sectional dataset, we must emphasise that the networks cannot be easily compared between the years. The networks contain differences in the number of nodes and links and thus do not have the same size. We listed the summary statistics of all networks for the cross-sectional dataset in Table $4 \mid 3$. The respective networks are displayed in Figure $4 \mid 2$, Figure 4|3, and Figure 4|4.

Figure 4 | 2. Trading network 2012 (left: rubber, right: oil palm)
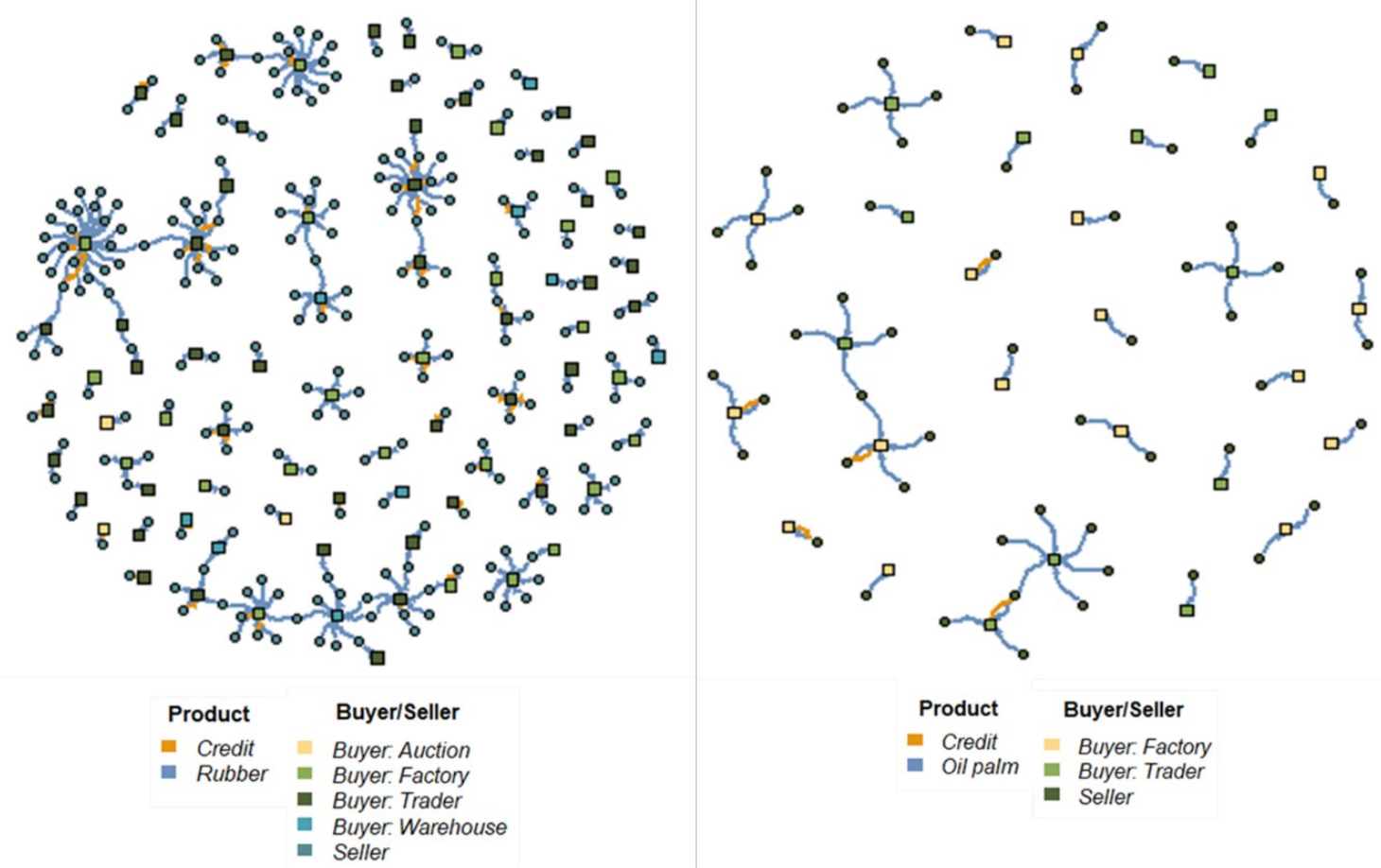

Although the number of nodes in the rubber trading networks remains almost the same due to an increase in buyers, the number of links declines. Considering the oil palm trading networks, the number of nodes more than doubles and the number of links almost increases four times as much between 2012 and 2018. Nevertheless, some more prominent buyers with more crop transactions seem to crystallise. It is striking that especially in the case of rubber trade, credits are not only provided by larger sellers, but also by smaller ones with fewer links in our sample.

As shown in Table $4 \mid 3$, oil palm sellers trade only to other traders and factories. The share of factories extends (2012: 58.62\%, 2015: 78.57\%, 2018: 73.24\%) over time with a slight decrease in 2018. Rubber sellers maintain relations to all four types of traders. In 2012, $55.52 \%$ of crop transactions were established to other traders. The share shrinks over time to $36.6 \%$ in 2018 , and the crumb rubber factories account for the most substantial portion of sales. 
Figure 4 | 3. Trading network 2015 (left: rubber, right: oil palm)
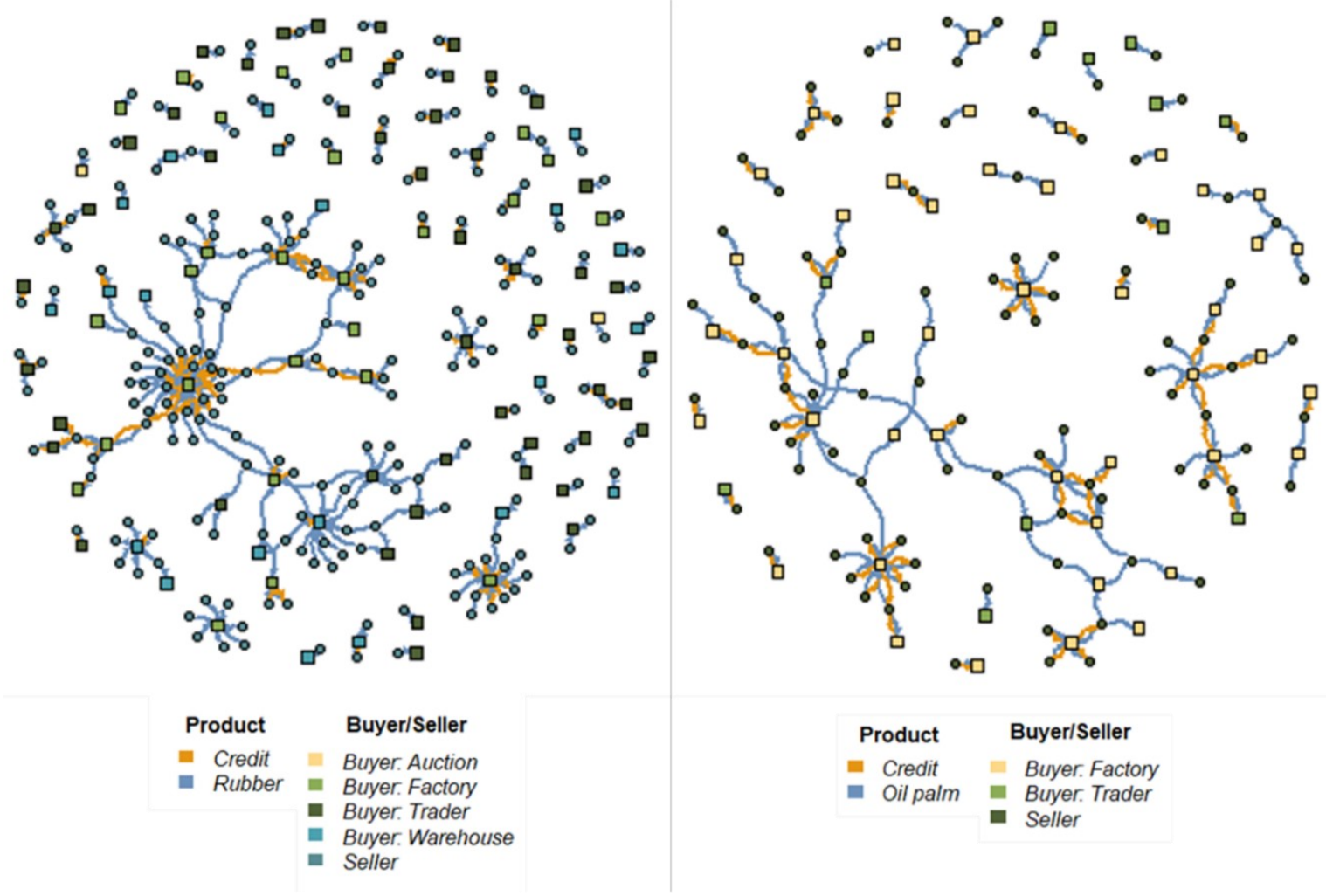

It appears regarding the links constituting crop transaction that the average in-degree among rubber buyers decreases over time. Although some big players with a high value for the outdegree evolve (compare Figure $4 \mid 2$, Figure $4 \mid 3$, Figure $4 \mid 4$, and Table $4 \mid 3$ ), it seems that there are more actors on the rubber market in the five regencies in 2018 than had been the case in 2012. Another explanation can be that buyers in other regencies or provinces have become better accessible due to improved infrastructure or investment in vehicles. The average outdegree, representing the provision of loan, increases with the total number of links over the period. The comparatively wide range of the highest out-degree with 19 provided loans by one single buyer in 2015 suggests high volatility on the market for credit. Reasons might be the development of the world market of rubber and the decline of the prices.

Additionally, the number of buyers on the market seems to rise, so, possible mutual dependencies on the credit and crop market can be diversified. Another possibility can be an increase in credit provision by other institutions like banks. Further research is needed to analyse the underlying processes. 
Figure 4 | 4. Trading network 2018 (left: rubber, right: oil palm)
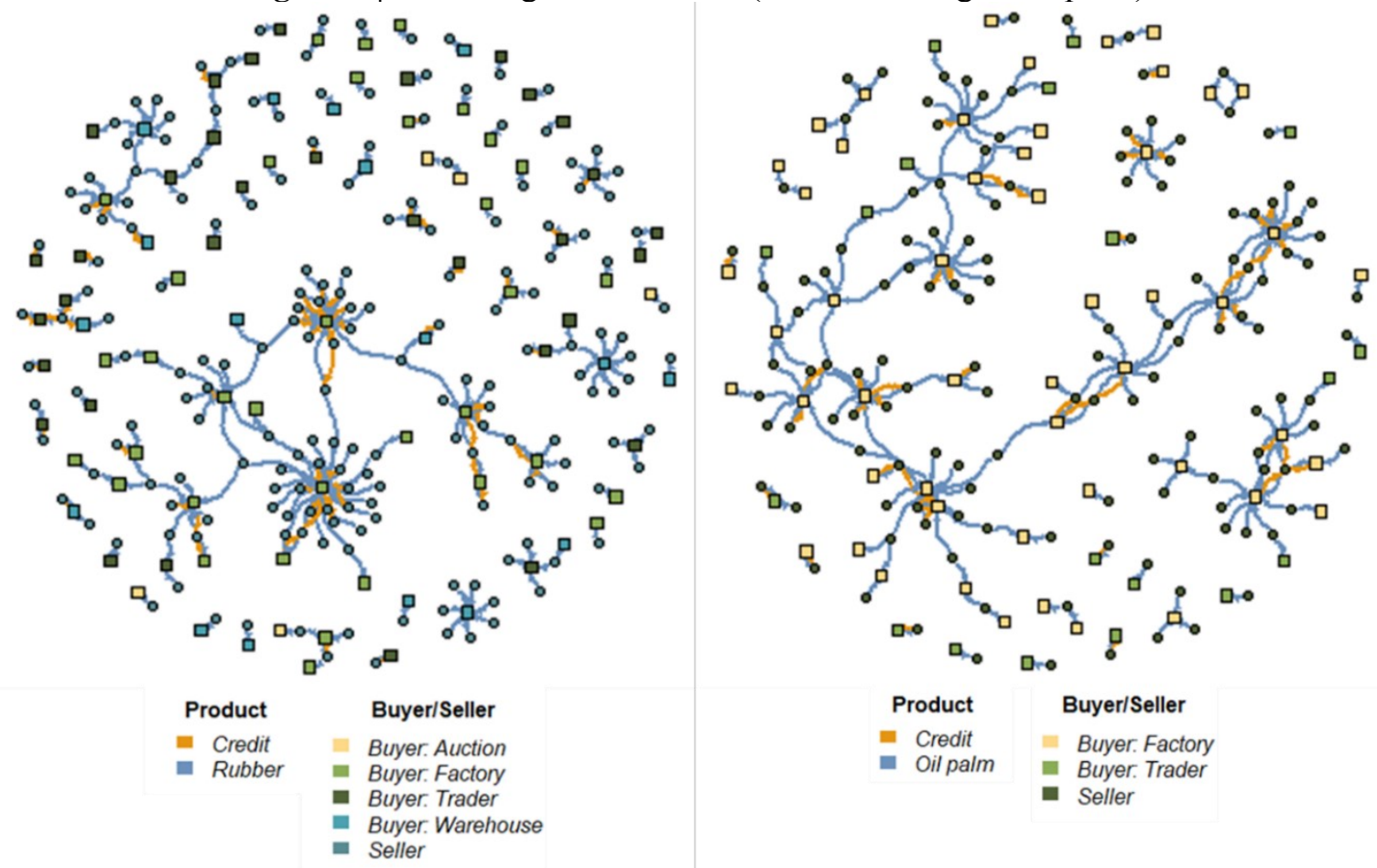

The size of the oil palm networks increases in the number of sellers and buyers as well as for links. The average in-degree varies, but the highest in-degree doubles over time from six links in 2012 to twelve links in 2018. This could be an indicator that the oil palm trade is somewhat stronger concentrated over the years with larger factories. The number of credits provided by oil palm buyers extends, but the highest out-degree remains low.

Table $4 \mid 3$. Network summary statistics of the cross-sectional dataset

\begin{tabular}{l|cc|ccc|cc}
\hline & \multicolumn{3}{c}{$\mathbf{2 0 1 2}$} & \multicolumn{2}{c}{$\mathbf{2 0 1 5}$} & \multicolumn{2}{c}{$\mathbf{2 0 1 8}$} \\
& Rubber & Oil palm & Rubber & Oil palm & \multicolumn{1}{c}{ Rubber } & Oil palm \\
\hline Number sellers & 216 & 55 & 202 & 93 & 185 & 135 \\
Number buyers & 83 & 29 & 97 & 56 & 90 & 71 \\
$\quad$ Auction & 3 & & 2 & & 5 & 52 \\
$\quad$ Factory & 25 & 17 & 26 & 44 & 35 & 19 \\
$\quad$ Trader & 46 & 12 & 48 & 12 & 33 & 17 & \\
$\quad$ Warehouse & 9 & & 21 & & 126 & 233 & 2.66 \\
Links crop & 239 & 57 & 243 & 2.25 & 2.42 & 12 \\
$\quad$ Average in-degree & 2.88 & 2.8 & 2.45 & 9 & 29 & 43 \\
$\quad$ Highest in-degree & 23 & 6 & 33 & 58 & 58 & 2.74 \\
Links credit & 45 & 5 & 88 & 58 & 1.74 & 11 & 52
\end{tabular}




\section{$\underline{\text { Panel dataset }}$}

Figures $4 \mid 5$ and $4 \mid 6$ display the rubber and oil palm network using the panel dataset for construction. The associated summary statistics are shown in Table $4 \mid 4$.

Figure $4 \mid$ 5. Rubber trading network of the panel dataset
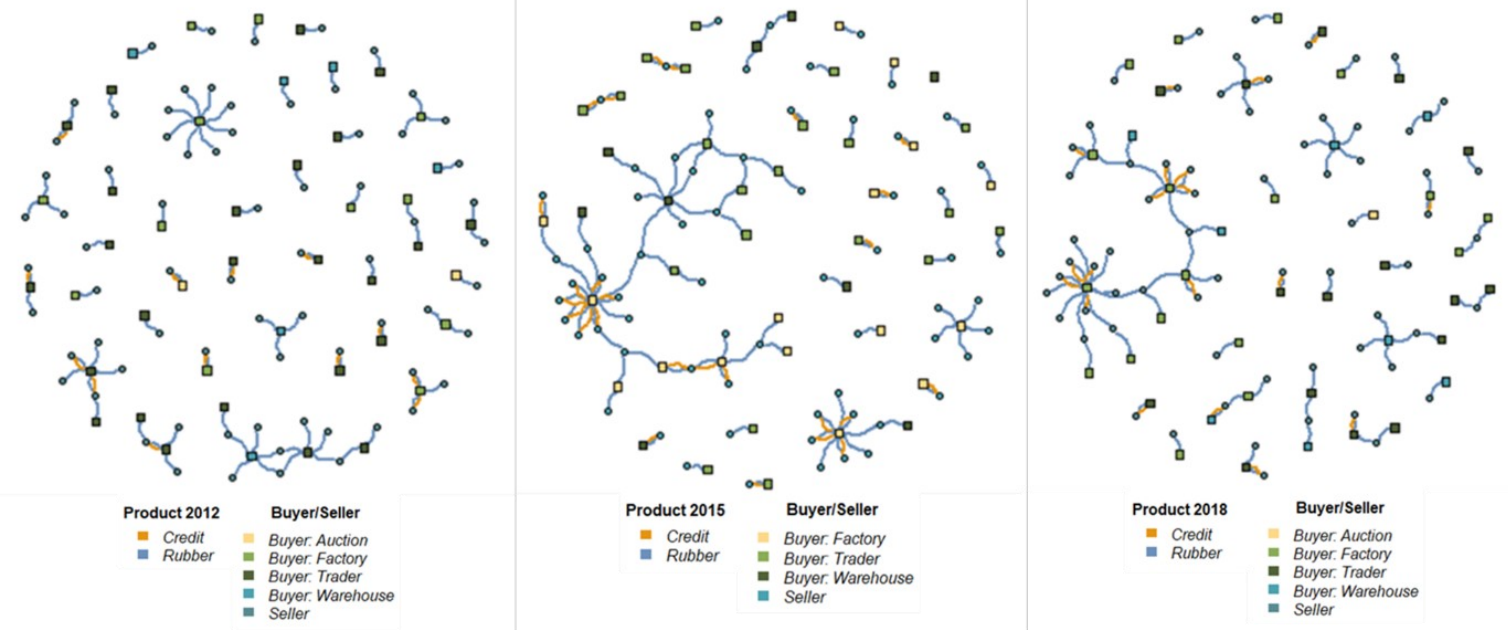

In the rubber panel, the number of nodes decreases slightly from 117 nodes in 2012 to 110 nodes in 2018, primarily because of a decline in sellers. The oil palm network increases sharply between 2012 and 2015 but remains almost constant between 2015 and 218 . According to the shares of the various buyers, the portion of links to other traders diminishing (2012: 55.56\%, 2015: 45.65\%, 2018: 37.21\%), while the share of factories in the sample rises $(2012: 26.67 \%, 2015: 34.78 \%, 2018: 41.86 \%)$ in the rubber trade. The oil palm mills extended the portion of sales from $70 \%$ in 2012 to $78.95 \%$ in 2018 .

Figure 4 | 6. Oil palm trading network of the panel dataset
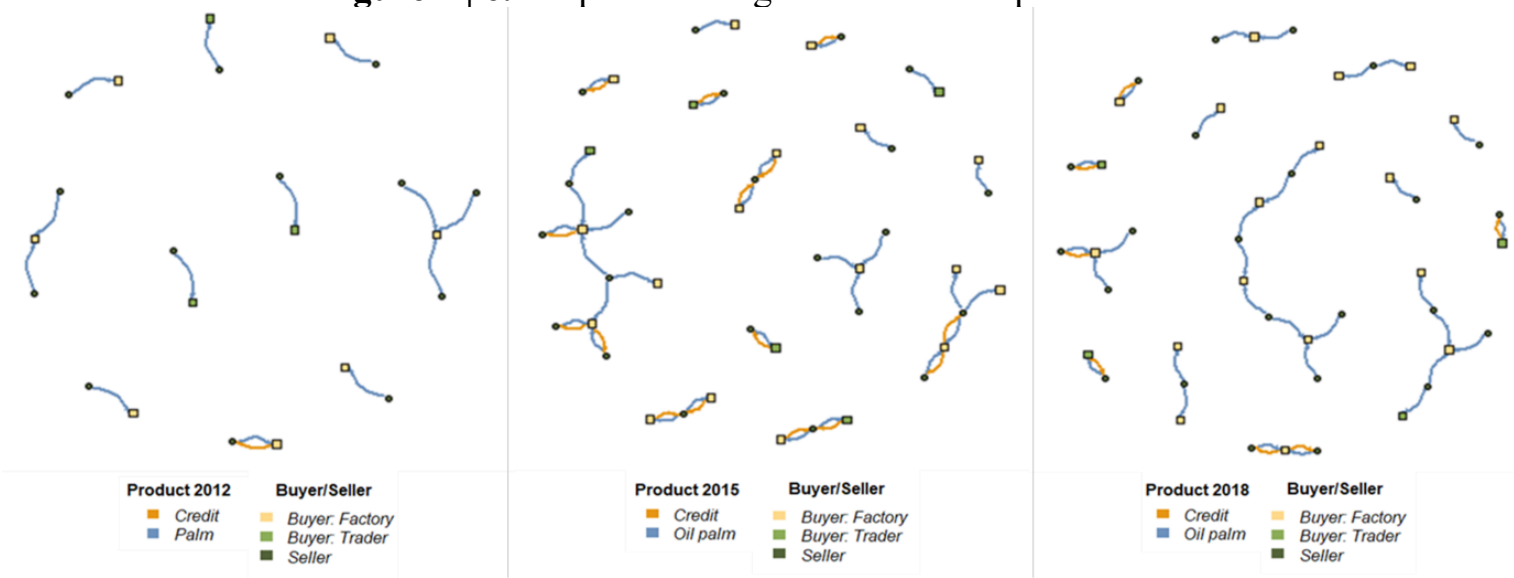

Already in 2012, are some rubber buyers with a higher in-degree observable. Interestingly, it is not those buyers, with one exception, who provide loan to their clients. This pattern changes in 2015 and 2018. Not only increases the highest in-degree in the rubber transaction 
but also the highest out-degree rises, especially in 2015. In contrast, the oil palm panel does not highlight any buyer, particularly. The highest in- and out-degree remains low over the years.

An additional feature of the panel dataset is the provision of an explicit statement about the maintenance of links for both, crop and credit. For the rubber panel, we can find 15 corresponding links between 2012 and 2015 which makes a share of 13.39\%. The rubber network in 2018 provides a share of $11 \%$ (in total 11 links) of corresponding links compared to 2012 and $30 \%$ (in total 30 links) compared to 2015 . The oil palm network in 2015 reveals four links (8.89\%) already present in 2012 . The share increases to $10.52 \%$ of corresponding links in 2018 compared to 2012 (in total 4 links) and 39.47\% (in total 15 links) compared to 2015. For both crops, in total, three links lasted throughout the years.

Table $4 \mid 4$. Network summary statistics of the panel dataset

\begin{tabular}{|c|c|c|c|c|c|c|}
\hline & \multicolumn{2}{|c|}{2012} & \multicolumn{2}{|c|}{2015} & \multicolumn{2}{|c|}{2018} \\
\hline & Rubber & Oil palm & Rubber & Oil palm & Rubber & Oil palm \\
\hline Number sellers & 72 & 13 & 66 & 22 & 67 & 24 \\
\hline Number buyers & 45 & 10 & 46 & 21 & 43 & 19 \\
\hline Auction & 2 & & & & 1 & \\
\hline Factory & 12 & 7 & 16 & 17 & 18 & 15 \\
\hline Trader & 25 & 3 & 21 & 5 & 16 & 4 \\
\hline Warehouse & 6 & & 9 & & 8 & \\
\hline Links crop & 79 & 13 & 86 & 30 & 81 & 31 \\
\hline Average in-degree & 1.76 & 1.3 & 1.91 & 1.36 & 2.11 & 1.48 \\
\hline Highest in-degree & 8 & 3 & 12 & 4 & 12 & 3 \\
\hline Links credit & 13 & 1 & 26 & 15 & 19 & 7 \\
\hline Average out-degree & 1.18 & 1 & 1.63 & 1.15 & 1.46 & 1.67 \\
\hline Highest out-degree & 2 & 1 & 7 & 2 & 4 & 2 \\
\hline
\end{tabular}

\section{4 | 5. Results and discussion}

\subsection{Cross-sectional dataset}

The coefficients estimated by the ERG-model can be interpreted as log-odds in logistic regressions. The direction of the coefficient indicates the likelihood of a link formation in the trading network. Link formation indicates the formation of trading connections between sellers and buyers.

First, we present the results of the ERG-model for the cross-sectional dataset, specified in crop and year (Table 4|5). As expected, two significant drivers of trading relations are the crop price and the provision of a loan. With positive and significant coefficients in all three years, credits, are in particular critical in the channel choice of rubber. Kopp and Salecker 
(2018) report similar results in their study on rubber trade in Jambi. The crop price is of crucial importance in the trading network of oil palm, as suggested by Nakajima et al. (2010).

Table $4 \mid$ 5. ERGM estimates of the cross-sectional dataset (standard errors in parentheses)

\begin{tabular}{|c|c|c|c|c|c|c|}
\hline & \multicolumn{2}{|c|}{2012} & \multicolumn{2}{|c|}{2015} & \multicolumn{2}{|c|}{2018} \\
\hline & Rubber & Oil palm & Rubber & Oil palm & Rubber & Oil palm \\
\hline Age & $\begin{array}{c}0.059 \\
(0.049)\end{array}$ & $\begin{array}{c}0.105 \\
(0.094)\end{array}$ & $\begin{array}{l}0.076 * \\
(0.042)\end{array}$ & $\begin{array}{c}-0.064 \\
(0.059)\end{array}$ & $\begin{array}{c}0.052 \\
(0.045)\end{array}$ & $\begin{array}{c}0.006 \\
(0.045)\end{array}$ \\
\hline Education & $\begin{array}{c}0.274 * * \\
(0.110)\end{array}$ & $\begin{array}{c}0.149 \\
(0.267)\end{array}$ & $\begin{array}{c}0.340^{* * *} \\
(0.118)\end{array}$ & $\begin{array}{c}0.186 \\
(0.158)\end{array}$ & $\begin{array}{c}0.413 * * * \\
(0.113)\end{array}$ & $\begin{array}{c}0.048 \\
(0.137)\end{array}$ \\
\hline Function & $\begin{array}{c}0.444^{* * *} \\
(0.115)\end{array}$ & $\begin{array}{c}0.857 * * * \\
(0.293)\end{array}$ & $\begin{array}{c}0.089 \\
(0.171)\end{array}$ & $\begin{array}{c}-0.635 * * \\
(0.384)\end{array}$ & $\begin{array}{c}-0.591 * * \\
(0.268)\end{array}$ & $\begin{array}{c}-0.622 * * \\
(0.287)\end{array}$ \\
\hline Experience & $\begin{array}{r}-0.00004 \\
(0.0006)\end{array}$ & $\begin{array}{c}0.005 \\
(0.036)\end{array}$ & $\begin{array}{l}-0.010 \\
(0.007)\end{array}$ & $\begin{array}{c}0.003 \\
(0.015)\end{array}$ & $\begin{array}{l}-0.007 \\
(0.007)\end{array}$ & $\begin{array}{c}0.010 \\
(0.009)\end{array}$ \\
\hline Quantity & $\begin{array}{c}-0.006 \\
(0.004)\end{array}$ & $\begin{array}{c}0.0001 \\
(0.0001)\end{array}$ & $\begin{array}{c}-0.014 * * * \\
(0.005)\end{array}$ & $\begin{array}{c}0.001 \\
(0.001)\end{array}$ & $\begin{array}{l}-0.0001 \\
(0.0002)\end{array}$ & $\begin{array}{l}-0.00006 \\
(0.00007)\end{array}$ \\
\hline Price crop & $\begin{array}{c}0.0750 * * * \\
(0.011)\end{array}$ & $\begin{array}{c}-0.076 \\
(0.063)\end{array}$ & $\begin{array}{c}0.350 * * * \\
(0.0424)\end{array}$ & $\begin{array}{c}0.416^{* * *} \\
(0.0779)\end{array}$ & $\begin{array}{c}0.0180 * * * \\
(0.006)\end{array}$ & $\begin{array}{c}1.371 * * * \\
(0.240)\end{array}$ \\
\hline Credit & $\begin{array}{l}0.266 * \\
(0.143)\end{array}$ & $\begin{array}{c}1.146^{* * *} \\
(0.287)\end{array}$ & $\begin{array}{c}-0.511 * * * \\
(0.192)\end{array}$ & $\begin{array}{l}-0.166 \\
(0.222)\end{array}$ & $\begin{array}{l}0.307 * \\
(0.161)\end{array}$ & $\begin{array}{c}0.231 \\
(0.156)\end{array}$ \\
\hline Storage & $\begin{array}{l}-0.002 \\
(0.004)\end{array}$ & $\begin{array}{l}0.0001 \\
(0.004)\end{array}$ & $\begin{array}{c}-0.008 \\
(0.008)\end{array}$ & $\begin{array}{c}0.001 \\
(0.002)\end{array}$ & $\begin{array}{c}0.002 \\
(0.004)\end{array}$ & $\begin{array}{l}-0.001 \\
(0.005)\end{array}$ \\
\hline Capacity & $\begin{array}{c}-0.028 * \\
(0.016)\end{array}$ & $\begin{array}{c}-0.083 * * * \\
(0.026)\end{array}$ & $\begin{array}{c}-0.366^{* * *} \\
(0.136)\end{array}$ & $\begin{array}{c}-0.423 * * \\
(0.170)\end{array}$ & $\begin{array}{l}-0.034^{*} \\
(0.019)\end{array}$ & $\begin{array}{l}-0.015 \\
(0.010)\end{array}$ \\
\hline Value house & $\begin{array}{l}-0.0001 \\
(0.0003)\end{array}$ & $\begin{array}{l}-0.001 \\
(0.001)\end{array}$ & $\begin{array}{c}0.0005 \\
(0.0004)\end{array}$ & $\begin{array}{l}-0.0003 \\
(0.0002)\end{array}$ & $\begin{array}{c}0.0004 \\
(0.0003)\end{array}$ & $\begin{array}{l}0.00009 \\
(0.0004)\end{array}$ \\
\hline Value land & $\begin{array}{c}0.0008 * * * \\
(0.0003)\end{array}$ & $\begin{array}{l}0.002 * \\
(0.001)\end{array}$ & $\begin{array}{c}0.0003 \\
(0.0004)\end{array}$ & $\begin{array}{c}-0.004 * * * \\
(0.001)\end{array}$ & $\begin{array}{c}0.000005 \\
(0.0006)\end{array}$ & $\begin{array}{c}0.0003 \\
(0.0003)\end{array}$ \\
\hline Land size & $\begin{array}{r}-0.0002 \\
(0.002)\end{array}$ & $\begin{array}{l}0.0006 \\
(0.001)\end{array}$ & $\begin{array}{c}0.006^{*} \\
(0.004)\end{array}$ & $\begin{array}{l}0.0001 \\
(0.002)\end{array}$ & $\begin{array}{c}0.002 \\
(0.006)\end{array}$ & $\begin{array}{c}-0.010 * \\
(0.005)\end{array}$ \\
\hline Info Politics & $\begin{array}{c}-0.28 \\
(0.247)\end{array}$ & $\begin{array}{l}-0.280 \\
(0.661)\end{array}$ & $\begin{array}{l}-0.007 \\
(0.319)\end{array}$ & $\begin{array}{c}-0.841 * * \\
(0.420)\end{array}$ & $\begin{array}{c}-0.524 * * \\
(0.257)\end{array}$ & $\begin{array}{l}-0.2037 \\
(0.354)\end{array}$ \\
\hline Internet & $\begin{array}{c}0.536 * * \\
(0.272)\end{array}$ & $\begin{array}{c}0.340 \\
(1.025)\end{array}$ & $\begin{array}{c}0.074 \\
(0.447)\end{array}$ & $\begin{array}{l}-0.356 \\
(0.497)\end{array}$ & $\begin{array}{l}-0.111 \\
(0.226)\end{array}$ & $\begin{array}{c}-0.580 \\
(0.365)\end{array}$ \\
\hline Location & $\begin{array}{c}-0.802 * * * \\
(0.22)\end{array}$ & $\begin{array}{l}-0.021 \\
(0.332)\end{array}$ & $\begin{array}{c}-0.667 * * * \\
(0.212)\end{array}$ & $\begin{array}{l}-0.257 \\
(0.241)\end{array}$ & $\begin{array}{c}-0.394 * * \\
(0.194)\end{array}$ & $\begin{array}{c}-1.057 * * * \\
(0.262)\end{array}$ \\
\hline Ethnicity & $\begin{array}{c}-1.078 * * \\
(0.460)\end{array}$ & $\begin{array}{l}-1.863 * \\
(1.040)\end{array}$ & $\begin{array}{l}-0.460 \\
(0.436)\end{array}$ & $\begin{array}{c}-2.238 * * * \\
(0.734)\end{array}$ & $\begin{array}{c}-3.305^{* * *} \\
(1.009)\end{array}$ & $\begin{array}{c}-1.693 * * \\
(0.735)\end{array}$ \\
\hline
\end{tabular}

Coefficients and standard errors in brackets

Significant effects: $* \mathrm{p}<0.1, * * \mathrm{p}<0.05, * * * \mathrm{p}<0.01$

The educational level has a positive and significant influence on the rubber network and a positive but insignificant impact on the decisions in the oil palm network. If the seller holds a particular function in the village, there are opposite effects throughout the years. While in 2012 function has a significant and positive effect on the formation of links, there is a reverse 
effect for oil palm in 2015 and both products in 2018. Since the world market prices collapsed before the survey round in 2015 , this could be a sign that sellers with additional functions in the village withdraw from rubber and oil palm trade and focus more on the respective positions.

Considering the wealth indicators value of the house has no significant impact on the link formation. Instead, the value of the land has a low positive and significant influence for both rubber and oil palm in 2012. However, the same variable turns into a significant negative effect for oil palm in 2015. Unexpected is the result of the transport capacity of the sellers. Except for the oil palm network in 2018, the transport capacity is reducing the likelihood of forming trading connections. This contradicts the assumption suggest by Nakajima et al. 2010) that sellers need to meet specific quantities. As mentioned in the description of the networks, a large portion of the sellers is selling to other, larger, traders. Those traders collect the crops by themselves, and the sellers in our sample do not have to transport the crops larger distances.

Different sources of information do not play a primary role in the choice of selling partners, although access to the internet has a positive and significant effect for rubber in 2012. In contrast, using information about politics has a significant negative impact on the link formation in the oil palm network in 2015 and the rubber network in 2018. Similar to the sellers with a particular function in the village, traders considering national and international politics on rubber and oil palm seem to exit the market possibly.

The unexpected and (strong) significant negative outcomes for homophily in location and ethnicity could emerge because of the respective definition of both variables. We only assigned one ethnicity to each buyer and did not differentiate between several employees with potentially different ethnicities. For the location, we used the regency the buyer is located in, as reported by the respondents and for example, not geographical distances. As a result, boundary problems can occur, because some sellers located on the edge of a region can decide to trade with a buyer in other regencies because it is closer in distance. This should be taken into account in future research.

Finally, we emphasise two more outcomes. First, factors like the experience in trading, the total traded quantity of the seller (with one exception), and the storage capacity do not have a significant influence on the formation of links throughout the years. Second, there are no 
remarkable differences in the parameters influencing the link formation in the rubber and the oil palm trading network.

\subsection{Panel dataset}

The ERG-model analysing the panel dataset confirms the main results of the first specification (compare Table 4|6). Again, we report positive and significant results for prices and the provision of credit. The transport capacity remains negative and significant. Interestingly, location is only significant for rubber sellers in 2012. The trading experience and the traded quantity again does not play any significant role in the marketing choice, with one exception experience in the oil palm trade in 2015.

For rubber in 2012, 2015, and 2018 and oil palm in 2018, the value of the house has a low positive and significant effect on the link formation. Information sources do not significantly affect the likelihood of a link formation in the rubber network. Because of a too-small sample, both information variables are excluded from the ERGM concerning oil palm trade.

The result for the factor function confirms the explanation of the result in the cross-sectional dataset. Sellers continuing trading during the collapse of the prices do not seem to have unique functions in the community. Therefore, they do not have alternatives, but they also do better in general than traders in the cross-sectional sample, as described in the data section.

All results considered, there are differences between rubber and oil palm, and there are discrepancies between the years. The link formation in oil palm trade is only significantly driven by the price and the capacity respective the value of land in 2012 and 2018. In contrast, the rubber trade has various more determinants.

As mentioned already, the world market prices of oil palm and rubber collapsed before the second survey round. This is reflected not only in the summary statistics but also in the statistical analysis of the panel sample. In 2015 different factors are present than in the 2012 and 2018, especially in the oil palm trade. For rubber, this is indicated in the importance of the links from the year before. Links 2012 and links 2018 describe the presence of corresponding links in the networks. For 2015, the reproduction of a seller-buyer connection from 2012 would lead to a decreasing likelihood that trade takes place. In 2018 the result was reversed. Establishing links from 2012 has a positive and significant impact on the trade 
connection. Although not significant, the formation of link present in the network from 2015 leads to reduced probability of a trading relationship.

Table $4 \mid$ 6. ERGM estimates of the panel dataset (standard errors in parentheses)

\begin{tabular}{|c|c|c|c|c|c|c|}
\hline & \multicolumn{2}{|c|}{2012} & \multicolumn{2}{|c|}{2015} & \multicolumn{2}{|c|}{2018} \\
\hline & Rubber & Oil palm & Rubber & Oil palm & Rubber & Oil palm \\
\hline Age & $\begin{array}{c}0.064 \\
(0.086)\end{array}$ & $\begin{array}{l}-0.031 \\
(0.191)\end{array}$ & $\begin{array}{c}0.014 \\
(0.031)\end{array}$ & $\begin{array}{c}0.030 \\
(0.136)\end{array}$ & $\begin{array}{c}-0.057 \\
(0.076)\end{array}$ & $\begin{array}{c}0.028 \\
(0.122)\end{array}$ \\
\hline Education & $\begin{array}{c}0.096 \\
(0.228)\end{array}$ & $\begin{array}{c}-0.154 \\
(1.067)\end{array}$ & $\begin{array}{c}0.614 * * * \\
(0.207)\end{array}$ & $\begin{array}{l}1.128 * \\
(0.601)\end{array}$ & $\begin{array}{c}0.878 * * * \\
(0.259)\end{array}$ & $\begin{array}{c}-0.788 \\
(0.484)\end{array}$ \\
\hline Function & $\begin{array}{c}0.001 \\
(0.317)\end{array}$ & $\begin{array}{c}1.234 \\
(1.567)\end{array}$ & $\begin{array}{l}-0.111 \\
(0.418)\end{array}$ & $\begin{array}{c}-0.736 \\
(0.792)\end{array}$ & $\begin{array}{c}-0.248 \\
(0.383)\end{array}$ & $\begin{array}{c}0.126 \\
(0.876)\end{array}$ \\
\hline Experience & $\begin{array}{l}-0.010 \\
(0.019)\end{array}$ & $\begin{array}{c}0.226 \\
(0.145)\end{array}$ & $\begin{array}{l}-0.017 \\
(0.015)\end{array}$ & $\begin{array}{c}0.246 * * \\
(0.098)\end{array}$ & $\begin{array}{l}-0.004 \\
(0.011)\end{array}$ & $\begin{array}{l}-0.066 \\
(0.050)\end{array}$ \\
\hline Quantity & $\begin{array}{c}-0.008 \\
(0.009)\end{array}$ & $\begin{array}{c}0.002 \\
(0.002)\end{array}$ & $\begin{array}{l}-0.004 \\
(0.006)\end{array}$ & $\begin{array}{l}-0.009 \\
(0.006)\end{array}$ & $\begin{array}{l}-0.0002 \\
(0.0001)\end{array}$ & $\begin{array}{c}0.001 \\
(0.003)\end{array}$ \\
\hline Price crop & $\begin{array}{c}0.061 * * * \\
(0.019)\end{array}$ & $\begin{array}{c}0.185^{*} \\
(0.099)\end{array}$ & $\begin{array}{c}0.384 * * * \\
(0.081)\end{array}$ & $\begin{array}{c}0.621 * * * \\
(0.201)\end{array}$ & $\begin{array}{c}0.016 \\
(0.012)\end{array}$ & $\begin{array}{c}2.685 * * * \\
(0.671)\end{array}$ \\
\hline Credit & $\begin{array}{c}0.040 \\
(0.281)\end{array}$ & $\begin{array}{c}-1.441 \\
(1.631)\end{array}$ & $\begin{array}{l}0.487 * \\
(0.258)\end{array}$ & $\begin{array}{c}1.540 * * * \\
(0.456)\end{array}$ & $\begin{array}{c}0.913 * * * \\
(0.256)\end{array}$ & $\begin{array}{l}-0.149 \\
(0.472)\end{array}$ \\
\hline Storage & $\begin{array}{c}0.031 * * * \\
(0.010)\end{array}$ & $\begin{array}{c}0.060 \\
(0.056)\end{array}$ & $\begin{array}{l}-0.005 \\
(0.013)\end{array}$ & $\begin{array}{l}0.031 * \\
(0.018)\end{array}$ & $\begin{array}{c}-0.004 \\
(0.005)\end{array}$ & $\begin{array}{l}-0.004 \\
(0.022)\end{array}$ \\
\hline Capacity & $\begin{array}{c}-0.178 * * * \\
(0.067)\end{array}$ & $\begin{array}{c}-0.192 * * \\
(0.079)\end{array}$ & $\begin{array}{c}-0.988 * * \\
(0.408)\end{array}$ & $\begin{array}{c}-10.632 \\
(608.920)\end{array}$ & $\begin{array}{c}-0.150 * * * \\
(0.045)\end{array}$ & $\begin{array}{l}-0.069 \\
(0.045)\end{array}$ \\
\hline Value house & $\begin{array}{l}0.001 * \\
(0.001)\end{array}$ & $\begin{array}{l}-0.015 \\
(0.010)\end{array}$ & $\begin{array}{c}-0.001 * \\
(0.001)\end{array}$ & $\begin{array}{l}-0.001 \\
(0.002)\end{array}$ & $\begin{array}{c}0.001 * * * \\
(0.0004)\end{array}$ & $\begin{array}{c}0.002 * * \\
(0.001)\end{array}$ \\
\hline Value land & $\begin{array}{c}0.0001 \\
(0.001)\end{array}$ & $\begin{array}{c}0.012 \\
(0.011)\end{array}$ & $\begin{array}{c}-0.003 * * \\
(0.001)\end{array}$ & $\begin{array}{c}-0.022 * * * \\
(0.008)\end{array}$ & $\begin{array}{l}-0.001 \\
(0.001)\end{array}$ & $\begin{array}{l}-0.001 \\
(0.003)\end{array}$ \\
\hline Land size & $\begin{array}{l}-0.006 \\
(0.004)\end{array}$ & $\begin{array}{l}-0.068 \\
(0.067)\end{array}$ & $\begin{array}{c}0.036 * * \\
(0.015)\end{array}$ & $\begin{array}{l}0.005 * \\
(0.003)\end{array}$ & $\begin{array}{c}0.033 * * * \\
(0.010)\end{array}$ & $\begin{array}{c}0.003 \\
(0.017)\end{array}$ \\
\hline Info Politics & $\begin{array}{l}-0.015 \\
(0.480)\end{array}$ & & $\begin{array}{c}-12.800 \\
(410.700)\end{array}$ & & $\begin{array}{c}-0.297 \\
(0.750)\end{array}$ & \\
\hline Internet & $\begin{array}{c}-0.033 \\
(0.772)\end{array}$ & & $\begin{array}{c}12.420 \\
(410.700)\end{array}$ & & $\begin{array}{c}-1.116 \\
(0.686)\end{array}$ & \\
\hline Location & $\begin{array}{c}-0.859 * * \\
(0.398)\end{array}$ & $\begin{array}{l}-0.159 \\
(0.830)\end{array}$ & $\begin{array}{l}-0.496 \\
(0.327)\end{array}$ & $\begin{array}{l}-0.030 \\
(0.500)\end{array}$ & $\begin{array}{c}-0.392 \\
(0.307)\end{array}$ & $\begin{array}{l}-0.085 \\
(0.502)\end{array}$ \\
\hline Ethnicity & $\begin{array}{c}-0.967^{*} \\
(0.556)\end{array}$ & & $\begin{array}{c}-1.548 \\
(1.063)\end{array}$ & & $\begin{array}{c}-1.130 * \\
(0.637)\end{array}$ & \\
\hline Links 2012 & & & $\begin{array}{c}-0.712 * * \\
(0.330)\end{array}$ & $\begin{array}{c}-0.282 \\
(0.647)\end{array}$ & $\begin{array}{c}0.849 * * * \\
(0.258)\end{array}$ & $\begin{array}{c}-0.407 \\
(1.144)\end{array}$ \\
\hline Links 2015 & & & & & $\begin{array}{c}-0.281 \\
(0.302)\end{array}$ & $\begin{array}{l}-0.460 \\
(0.602)\end{array}$ \\
\hline
\end{tabular}

Coefficients and standard errors in brackets

Significant effects: $* \mathrm{p}<0.1, * * \mathrm{p}<0.05, * * * \mathrm{p}<0.01$ 


\subsection{Goodness of fit}

For all model specifications' goodness of fit, we measured the goodness of fit parameters. As suggested by (Hunter et al. 2008) we test the fit of our models regarding the in- and outdegree, the edgewise shared partners, the geodesic distance and the model statistics. The individual values are shown in the abstract.

All our models perform well regarding the model statistics with p-values close to 1 . The other parameters exhibit some values below a p-value of 0.05 . This can be explained by the small density of our networks, and the high number of single components, instead of one complete network per crop and year. All estimates and the p-values can be found in Appendix A4.

\section{4 | 6. Concluding remarks}

Considering rubber and oil palm production and processing in Jambi, Indonesia, incorporate the role of intermediaries in the value chain. Intermediaries connect smallholder producers and oil palm mills and crumb rubber factories by distributing the products. At the same time, there are many distribution channels possible. Intermediaries can collect the products and sell directly to the factories or other traders. Additional they can utilise other platforms like auction markets or warehouses. Social networks are an appropriate tool to analyse local trade structures.

We used two samples of the same dataset to analyse rubber and oil palm trade in Jambi. Our dataset consists of a cross-sectional sample of in total 886 sellers from three survey rounds in 2012, 2015, and 2018. Additionally, a panel of 83 sellers outlasted the entire research time. While the number of rubber sellers decreased, the number of oil palm sellers increased in the time leading to a decline or rather a growth in the number of nodes and links in the employed networks. However, the rubber networks indicated a higher in- and out-degree for both cross-sectional and panel sample. Furthermore, changes in the choice of buyers appear. The number of trading connections to other traders diminishes, while the number of direct links to factories rises.

The statistical analysis using an ERG-model provides information on the factors influencing the formation of links in the trading network. The average price and the provision of loan are the primary drivers of the trade in Jambi. Further, various information sources, as well as the total traded quantity and the experience in trading of the seller lack in importance in 
the trading decisions. Estimations regarding the panel sample show disparities between rubber and oil palm trade. Furthermore, we noticed differences in the trading decisions of 2012 and 2018 with the outcomes of 2015, when the world market prices of both crops dropped.

In summary, this study provides initial insights into the development of trading relations among rubber and oil palm intermediaries in Jambi. Future research could take up these findings and extend the setting. Weighted social networks can be used to distinguish between several types of buyers. Directly trading to factories might be more profitable depending on the location and infrastructure. Information of the buyers can be included in the approach to obtain a more precise picture. Besides, developments on the world market or in national or provincial policies can be connected to the local trading networks. Finally, the suppliers of the sellers can be included in the networks to analyse the entire supply chain of rubber and oil palm. 


\section{4 | 7. Appendix}

Table $4 \mid$ A1. Goodness of fit for rubber and cross-sectional dataset

\begin{tabular}{|c|c|c|c|c|c|c|c|c|}
\hline \multicolumn{3}{|c|}{2012} & \multicolumn{3}{|c|}{2015} & \multicolumn{3}{|c|}{2018} \\
\hline Obs. & Mean & p-value & Obs. & Mean & p-value & Obs. & Mean & p-value \\
\hline \multicolumn{9}{|c|}{ Goodness of fit for in-degree } \\
\hline 216 & 150.02 & 0 & 202 & 159.57 & 0 & 185 & 129.78 & 0 \\
\hline 40 & 90.94 & 0 & 63 & 76.8 & 0.06 & 54 & 90.48 & 0 \\
\hline 18 & 36.8 & 0 & 15 & 39 & 0 & 16 & 38.08 & 0 \\
\hline 6 & 13.99 & 0.04 & 5 & 16.88 & 0 & 8 & 11.77 & 0.3 \\
\hline 8 & 4.81 & 0.18 & 5 & 5.98 & 0.8 & 1 & 3.49 & 0.3 \\
\hline 1 & 1.79 & 0.96 & 1 & 1.94 & 0.84 & 2 & 0.86 & 0.38 \\
\hline 1 & 0.41 & 0.68 & 3 & 0.53 & 0.02 & 0 & 0.31 & 1 \\
\hline 1 & 0.13 & 0.26 & 1 & 0.2 & 0.38 & 4 & 0.16 & 0 \\
\hline 2 & 0.08 & 0 & 2 & 0.07 & 0 & 1 & 0.01 & 0.02 \\
\hline 2 & 0.03 & 0 & 1 & 0.02 & 0.04 & 2 & 0.03 & 0 \\
\hline 2 & 0 & 0 & 0 & 0.01 & 1 & 0 & 0.02 & 1 \\
\hline 1 & 0 & 0 & 1 & 0 & 0 & 0 & 0.01 & 1 \\
\hline 1 & 0 & 0 & 1 & 0 & 0 & 1 & 0 & 0 \\
\hline \multicolumn{9}{|c|}{ Goodness of fit for out-degree } \\
\hline 83 & 136.94 & 0 & 99 & 139.34 & 0 & 90 & 125.86 & 0 \\
\hline 194 & 104.66 & 0 & 170 & 101 & 0 & 155 & 94.33 & 0 \\
\hline 22 & 41.9 & 0 & 23 & 43.24 & 0 & 22 & 39.29 & 0 \\
\hline 0 & 12.18 & 0 & 9 & 13.47 & 0.18 & 8 & 11.93 & 0.4 \\
\hline 0 & 2.78 & 0.12 & 0 & 3.27 & 0.08 & 0 & 2.92 & 0.12 \\
\hline 0 & 0.43 & 1 & 0 & 0.57 & 1 & 0 & 0.56 & 1 \\
\hline 0 & 0.07 & 1 & 0 & 0.11 & 1 & 0 & 0.09 & 1 \\
\hline 0 & 0.03 & 1 & & & & 0 & 0.02 & 1 \\
\hline 0 & 0.01 & 1 & & & & & & \\
\hline \multicolumn{9}{|c|}{ Goodness of fit for edgewise shared partner } \\
\hline 238 & 238.11 & 0.96 & 243 & 243.57 & 1 & 223 & 223.05 & 1 \\
\hline 0 & 0.87 & 0.92 & 0 & 0.91 & 0.88 & 0 & 0.81 & 0.92 \\
\hline \multicolumn{9}{|c|}{ Goodness of fit for minimum geodesic distance } \\
\hline 238 & 238.98 & 1 & 243 & 244.48 & 1 & 223 & 223.86 & 1 \\
\hline 0 & 202.54 & 0 & 0 & 195.3 & 0 & 0 & 192.22 & 0 \\
\hline 0 & 170.29 & 0 & 0 & 153.97 & 0 & 0 & 160.52 & 0 \\
\hline 0 & 143.96 & 0 & 0 & 119.95 & 0 & 0 & 132.24 & 0 \\
\hline 0 & 118.1 & 0 & 0 & 91.86 & 0 & 0 & 107.16 & 0 \\
\hline 0 & 96 & 0 & 0 & 69.09 & 0 & 0 & 86.6 & 0 \\
\hline 0 & 76.99 & 0 & 0 & 50.89 & 0.06 & 0 & 69.02 & 0.02 \\
\hline 0 & 61.81 & 0.1 & 0 & 36.17 & 0.14 & 0 & 54.86 & 0.06 \\
\hline 0 & 48.98 & 0.22 & 0 & 24.16 & 0.38 & 0 & 43.53 & 0.28 \\
\hline 0 & 38.06 & 0.44 & 0 & 15.16 & 0.84 & 0 & 33.66 & 0.64 \\
\hline 0 & 29.58 & 0.8 & 0 & 9 & 1 & 0 & 25.16 & 0.84 \\
\hline 0 & 22.06 & 0.98 & 0 & 4.94 & 1 & 0 & 17.07 & 1 \\
\hline 0 & 15.72 & 1 & 0 & 2.57 & 1 & 0 & 11.39 & 1 \\
\hline 0 & 10.65 & 1 & 0 & 1.38 & 1 & 0 & 7.13 & 1 \\
\hline 0 & 7.17 & 1 & 0 & 0.72 & 1 & 0 & 4.66 & 1 \\
\hline 0 & 5.04 & 1 & 0 & 0.38 & 1 & 0 & 3.19 & 1 \\
\hline 0 & 3.42 & 1 & 0 & 0.2 & 1 & 0 & 2.05 & 1 \\
\hline 0 & 1.84 & 1 & 0 & 0.13 & 1 & 0 & 1.29 & 1 \\
\hline 0 & 0.95 & 1 & 0 & 0.06 & 1 & 0 & 0.78 & 1 \\
\hline 0 & 0.4 & 1 & & & & 0 & 0.36 & 1 \\
\hline 0 & 0.18 & 1 & & & & 0 & 0.09 & 1 \\
\hline 0 & 0.08 & 1 & & & & & & \\
\hline 0 & 0.01 & 1 & & & & & & \\
\hline
\end{tabular}


Table $4 \mid$ A2. Goodness of fit model statistics for rubber and cross-sectional dataset

\begin{tabular}{lccccccccc}
\hline & \multicolumn{3}{c}{$\mathbf{2 0 1 2}$} & & & $\mathbf{2 0 1 5}$ & & \multicolumn{2}{c}{$\mathbf{2 0 1 8}$} \\
& Obs. & mean & p-value & Obs. & mean & p-value & Obs. & mean & p-value \\
\hline Age & 885.00 & 888.47 & 0.96 & 833.00 & 965.56 & 1.00 & 986.00 & 989.94 & 0.96 \\
Education & 128.00 & 128.96 & 0.90 & 83.00 & 105.74 & 1.00 & 143.00 & 143.16 & 0.96 \\
Function & 105.00 & 103.81 & 0.98 & 25.00 & 39.74 & 0.84 & 15.00 & 14.93 & 1.00 \\
Land size & 6282.00 & 6294.40 & 0.98 & 3294.89 & 4304.87 & 0.92 & 3351.14 & 3369.79 & 0.94 \\
Value house & 65066.40 & 64857.97 & 0.98 & 52801.81 & 64588.21 & 0.98 & 43350.00 & 43641.95 & 0.98 \\
Value land & 40109.43 & 40383.52 & 1.00 & 18100.67 & 25639.11 & 0.88 & 19075.65 & 19173.35 & 0.98 \\
Experience & 4935.19 & 4772.14 & 0.96 & 3538.00 & 4226.22 & 0.96 & 3883.00 & 3886.40 & 0.92 \\
Storage & 3435.05 & 3399.64 & 0.96 & 1489.79 & 1900.81 & 0.96 & 2506.30 & 2508.70 & 1.00 \\
Quantity & 3319.71 & 3320.18 & 0.94 & 1962.96 & 2685.83 & 0.88 & 11354.90 & 12018.48 & 0.86 \\
Capacity & 464.09 & 455.08 & 0.82 & 11.44 & 30.65 & 0.68 & 523.59 & 526.17 & 0.98 \\
Credit & 78.00 & 77.51 & 0.96 & 21.00 & 32.66 & 0.98 & 57.00 & 57.02 & 1.00 \\
Average price & 1903.53 & 1908.79 & 0.86 & 1364.21 & 1628.25 & 0.96 & 1915.31 & 1949.06 & 0.82 \\
Info politics & 32.00 & 31.57 & 1.00 & 8.00 & 17.03 & 1.00 & 34.00 & 33.33 & 0.88 \\
Info harvest & 13.00 & 13.19 & 1.00 & 0.00 & 2.14 & 1.00 & 17.00 & 17.19 & 1.00 \\
Internet & 25.00 & 24.64 & 0.96 & 0.00 & 8.05 & 1.00 & 35.00 & 34.47 & 0.98 \\
Location & 23.00 & 22.98 & 1.00 & 13.00 & 26.37 & 0.78 & 31.00 & 31.24 & 1.00 \\
Ethnic & 5.00 & 4.87 & 1.00 & 1.00 & 5.95 & 1.00 & 1.00 & 0.95 & 1.00
\end{tabular}


Table $4 \mid$ A3. Goodness of fit for oil palm and cross-sectional dataset

\begin{tabular}{|c|c|c|c|c|c|c|c|c|}
\hline \multicolumn{3}{|c|}{2012} & \multicolumn{3}{|c|}{2015} & \multicolumn{3}{|c|}{2018} \\
\hline Obs. & Mean & p-value & Obs. & Mean & p-value & Obs. & Mean & p-value \\
\hline \multicolumn{9}{|c|}{ Goodness of fit for in-degree } \\
\hline 0 & 150.02 & 0 & 202 & 159.57 & 0 & 185 & 129.78 & 0 \\
\hline 55 & 47.51 & 0.06 & 93 & 70.51 & 0 & 135 & 98.92 & 0 \\
\hline 17 & 23.37 & 0.14 & 29 & 48.13 & 0 & 43 & 55.59 & 0.1 \\
\hline 4 & 8.33 & 0.1 & 12 & 20.02 & 0.1 & 8 & 29.92 & 0 \\
\hline 2 & 2.93 & 0.84 & 5 & 6.61 & 0.78 & 4 & 13.66 & 0.02 \\
\hline 5 & 1.28 & 0 & 3 & 2.16 & 0.7 & 2 & 4.99 & 0.16 \\
\hline 0 & 0.42 & 1 & 2 & 0.81 & 0.42 & 2 & 2.05 & 1 \\
\hline 1 & 0.12 & 0.24 & 3 & 0.23 & 0 & 1 & 0.58 & 0.9 \\
\hline 0 & 0.03 & 1 & 0 & 0.19 & 1 & 3 & 0.25 & 0 \\
\hline \multirow[t]{5}{*}{0} & 0.01 & 1 & 0 & 0.1 & 1 & 1 & 0.01 & 0.02 \\
\hline & & & 2 & 0.15 & 0 & 4 & 0.03 & 0 \\
\hline & & & 0 & 0.04 & 1 & 1 & 0 & 0 \\
\hline & & & 0 & 0.03 & 1 & 1 & 0 & 0 \\
\hline & & & 0 & 0.02 & 1 & 1 & 0 & 0 \\
\hline \multicolumn{9}{|c|}{ Goodness of fit for out-degree } \\
\hline 29 & 44.7 & 0 & 56 & 67.48 & 0.1 & 71 & 84.62 & 0.04 \\
\hline 53 & 25.91 & 0 & 67 & 49.92 & 0 & 89 & 71.03 & 0.02 \\
\hline 2 & 9.92 & 0 & 19 & 21.65 & 0.6 & 34 & 34.77 & 0.98 \\
\hline 0 & 2.74 & 0.14 & 7 & 7.23 & 1 & 12 & 11.67 & 1 \\
\hline 0 & 0.58 & 1 & 0 & 2.09 & 0.26 & 0 & 3.05 & 0.12 \\
\hline 0 & 0.13 & 1 & 0 & 0.55 & 1 & 0 & 0.74 & 1 \\
\hline \multirow[t]{2}{*}{0} & 0.02 & 1 & 0 & 0.06 & 1 & 0 & 0.12 & 1 \\
\hline & & & 0 & 0.02 & 1 & & & \\
\hline \multicolumn{9}{|c|}{ Goodness of fit for edgewise shared partner } \\
\hline 57 & 56.61 & 1 & 126 & 125.61 & 0.98 & 143 & 191.04 & 0.94 \\
\hline \multirow[t]{2}{*}{0} & 0.45 & 1 & 0 & 0.89 & 0.78 & 0 & 1.15 & 0.74 \\
\hline & & & 0 & 0.02 & 1 & 0 & 0.01 & 1 \\
\hline \multicolumn{9}{|c|}{ Goodness of fit for minimum geodesic distance } \\
\hline 57 & 57.06 & 1 & 126 & 126.52 & 0.98 & 193 & 192.2 & 0.94 \\
\hline 0 & 37.85 & 0 & 0 & 105.25 & 0 & 0 & 166.52 & 0 \\
\hline 0 & 23.9 & 0 & 0 & 86.31 & 0 & 0 & 141.99 & 0 \\
\hline 0 & 13.91 & 0.08 & 0 & 68.64 & 0 & 0 & 117.7 & 0 \\
\hline 0 & 7.17 & 0.58 & 0 & 53.09 & 0 & 0 & 93.3 & 0 \\
\hline 0 & 3.48 & 1 & 0 & 39.26 & 0.06 & 0 & 69.53 & 0.02 \\
\hline 0 & 1.49 & 1 & 0 & 27.81 & 0.28 & 0 & 50.77 & 0.06 \\
\hline 0 & 0.46 & 1 & 0 & 20.05 & 0.54 & 0 & 36.94 & 0.22 \\
\hline 0 & 0.2 & 1 & 0 & 14.03 & 0.82 & 0 & 27.03 & 0.52 \\
\hline 0 & 0.08 & 1 & 0 & 9.43 & 1 & 0 & 19.53 & 0.8 \\
\hline \multirow[t]{7}{*}{0} & 0.02 & 1 & 0 & 5.86 & 1 & 0 & 12.97 & 1 \\
\hline & & & 0 & 3.52 & 1 & 0 & 8.77 & 1 \\
\hline & & & 0 & 2 & 1 & 0 & 6 & 1 \\
\hline & & & 0 & 0.98 & 1 & 0 & 4.01 & 1 \\
\hline & & & 0 & 0.24 & 1 & 0 & 2.52 & 1 \\
\hline & & & 0 & 0.05 & 1 & 0 & 1.28 & 1 \\
\hline & & & & & & 0 & 0.67 & 1 \\
\hline
\end{tabular}




$\begin{array}{lll}0 & 0.45 & 1 \\ 0 & 0.37 & 1 \\ 0 & 0.15 & 1 \\ 0 & 0.05 & 1 \\ 0 & 0.01 & 1\end{array}$


Table $4 \mid$ A4. Goodness of fit model statistics for oil palm and cross-sectional dataset

\begin{tabular}{lccccccccc}
\hline & \multicolumn{3}{c}{$\mathbf{2 0 1 2}$} & & & $\mathbf{2 0 1 5}$ & & \multicolumn{3}{c}{$\mathbf{2 0 1 8}$} \\
& Obs. & mean & p-value & Obs. & mean & p-value & Obs. & mean & p-value \\
\hline Age & 256.00 & 256.85 & 1.00 & 472.00 & 470.96 & 1.00 & 798.00 & 793.84 & 0.90 \\
Education & 20.00 & 19.70 & 1.00 & 59.00 & 58.22 & 1.00 & 74.00 & 73.18 & 0.88 \\
Function & 19.00 & 19.07 & 1.00 & 8.00 & 8.22 & 1.00 & 13.00 & 12.63 & 1.00 \\
Land size & 1720.00 & 1810.27 & 0.94 & 2346.45 & 2435.76 & 0.90 & 2763.45 & 2767.04 & 1.00 \\
Value house & 12265.10 & 12333.94 & 0.94 & 31536.00 & 31684.08 & 0.84 & 34996.00 & 35098.84 & 0.94 \\
Value land & 8949.05 & 9000.89 & 0.92 & 7497.02 & 7607.07 & 0.90 & 28008.98 & 28464.49 & 0.96 \\
Experience & 406.00 & 406.52 & 0.96 & 1019.50 & 1028.93 & 0.94 & 2197.50 & 2189.14 & 0.96 \\
Storage & 1602.58 & 1608.09 & 0.98 & 2266.56 & 2309.99 & 0.98 & 1045.00 & 1026.76 & 0.90 \\
Quantity & 29773.31 & 31098.20 & 0.98 & 14695.28 & 14721.24 & 0.94 & 46521.10 & 44754.54 & 0.80 \\
Capacity & 200.10 & 200.51 & 0.78 & 15.66 & 15.99 & 0.98 & 1089.13 & 1086.83 & 0.98 \\
Credit & 25.00 & 25.14 & 1.00 & 28.00 & 27.99 & 1.00 & 75.00 & 74.50 & 1.00 \\
Average price & 41.93 & 41.15 & 0.92 & 153.90 & 158.80 & 0.80 & 212.80 & 212.44 & 0.94 \\
Info politics & 5.00 & 5.08 & 1.00 & 7.00 & 6.59 & 0.98 & 15.00 & 14.59 & 0.90 \\
Info harvest & 4.00 & 4.17 & 1.00 & & & & 6.00 & 6.05 & 1.00 \\
Internet & 2.00 & 2.21 & 1.00 & 5.00 & 5.15 & 1.00 & 13.00 & 12.27 & 0.96 \\
Location & 12.00 & 12.28 & 1.00 & 21.00 & 20.74 & 0.88 & 16.00 & 16.08 & 1.00 \\
Ethnic & 1.00 & 1.00 & 1.00 & 2.00 & 1.86 & 1.00 & 2.00 & 2.17 & 1.00
\end{tabular}


Table $4 \mid$ A5. Goodness of fit for rubber and panel dataset

\begin{tabular}{|c|c|c|c|c|c|c|c|c|}
\hline \multicolumn{3}{|c|}{2012} & \multicolumn{3}{|c|}{2015} & \multicolumn{3}{|c|}{2018} \\
\hline Obs. & Mean & p-value & Obs. & Mean & p-value & Obs. & Mean & p-value \\
\hline \multicolumn{9}{|c|}{ Goodness of fit for in-degree } \\
\hline 72 & 64.69 & 0.14 & 66 & 65.58 & 0.96 & 67 & 53 & 0.5 \\
\hline 31 & 34.27 & 0.5 & 32 & 23.05 & 0 & 30 & 21 & 0.78 \\
\hline 5 & 12.06 & 0.02 & 7 & 12.4 & 0.04 & 6 & 3 & 0.1 \\
\hline 5 & 3.98 & 0.78 & 0 & 5.54 & 0 & 0 & 0 & 0.02 \\
\hline 0 & 1.11 & 0.64 & 2 & 2.52 & 1 & 4 & 0 & 0.18 \\
\hline 3 & 0.45 & 0 & 1 & 1.21 & 1 & 1 & 0 & 0.98 \\
\hline 0 & 0.24 & 1 & 0 & 0.36 & 1 & 1 & 0 & 0.58 \\
\hline 0 & 0.09 & 1 & 1 & 0.21 & 0.36 & 0 & 0 & 1 \\
\hline 1 & 0.05 & 0.1 & 1 & 0.07 & 0.14 & 0 & 0 & 1 \\
\hline 0 & 0.02 & 1 & 0 & 0.01 & 1 & 0 & 0 & 1 \\
\hline 0 & 0.03 & 1 & 0 & 0.02 & 1 & 0 & 0 & 1 \\
\hline \multirow[t]{5}{*}{0} & 0.01 & 1 & 0 & 0.01 & 1 & 0 & 0 & 1 \\
\hline & & & 1 & 0.02 & 0.04 & 1 & 0 & 0.1 \\
\hline & & & & & & 0 & 0 & 1 \\
\hline & & & & & & 0 & 0 & 1 \\
\hline & & & & & & 0 & 0 & 1 \\
\hline \multicolumn{9}{|c|}{ Goodness of fit for out-degree } \\
\hline 45 & 60.97 & 0 & 45 & 56.03 & 0.04 & 43 & 56.04 & 0 \\
\hline 65 & 37.53 & 0 & 51 & 33.22 & 0 & 56 & 34.25 & 0 \\
\hline 7 & 14.07 & 0.02 & 10 & 15.07 & 0.14 & 8 & 14.09 & 0.04 \\
\hline 0 & 3.54 & 0.1 & 5 & 5.06 & 1 & 3 & 4.35 & 0.68 \\
\hline 0 & 0.73 & 0.92 & 0 & 1.29 & 0.64 & 0 & 1.08 & 0.64 \\
\hline 0 & 0.11 & 1 & 0 & 0.27 & 1 & 0 & 0.17 & 1 \\
\hline 0 & 0.04 & 1 & 0 & 0.04 & 1 & 0 & 0.02 & 1 \\
\hline 0 & 0.01 & 1 & 0 & 0.02 & 1 & & & \\
\hline \multicolumn{9}{|c|}{ Goodness of fit for edgewise shared partner } \\
\hline 79 & 79.39 & 0.96 & 86 & 84.25 & 0.82 & 81 & 79.7 & 0.96 \\
\hline 0 & 0.68 & 0.96 & 0 & 1.16 & 0.78 & 0 & 1.07 & 0.78 \\
\hline 0 & 0.01 & 1 & 0 & 0.02 & 1 & & & \\
\hline \multicolumn{9}{|c|}{ Goodness of fit for minimum geodesic distance } \\
\hline 79 & 80.08 & 0.96 & 86 & 85.43 & 0.9 & 81 & 80.77 & 0.98 \\
\hline 0 & 52.17 & 0 & 0 & 64.17 & 0 & 0 & 53.76 & 0 \\
\hline 0 & 33.66 & 0 & 0 & 44.57 & 0 & 0 & 34.29 & 0 \\
\hline 0 & 19.83 & 0.02 & 0 & 29.92 & 0.04 & 0 & 19.87 & 0.04 \\
\hline 0 & 11.46 & 0.14 & 0 & 18.04 & 0.34 & 0 & 10.83 & 0.14 \\
\hline 0 & 5.98 & 0.68 & 0 & 10.22 & 0.72 & 0 & 5.98 & 0.72 \\
\hline 0 & 2.92 & 1 & 0 & 5.83 & 1 & 0 & 2.88 & 1 \\
\hline 0 & 1.29 & 1 & 0 & 3.02 & 1 & 0 & 1.34 & 1 \\
\hline 0 & 0.5 & 1 & 0 & 1.31 & 1 & 0 & 0.73 & 1 \\
\hline 0 & 0.17 & 1 & 0 & 0.6 & 1 & 0 & 0.5 & 1 \\
\hline 0 & 0.05 & 1 & 0 & 0.16 & 1 & 0 & 0.21 & 1 \\
\hline \multirow[t]{2}{*}{0} & 0.02 & 1 & 0 & 0.01 & 1 & 0 & 0.1 & 1 \\
\hline & & & & & & 0 & 0.02 & 1 \\
\hline
\end{tabular}


Table $4 \mid$ A6. Goodness of fit model statistics for rubber and panel dataset

\begin{tabular}{|c|c|c|c|c|c|c|c|c|c|}
\hline & \multicolumn{3}{|c|}{2012} & \multicolumn{3}{|c|}{2015} & \multicolumn{3}{|c|}{2018} \\
\hline & Obs. & mean & p-value & Obs. & mean & p-value & Obs. & mean & p-value \\
\hline Age & 309.00 & 313.64 & 0.92 & 393.00 & 388.28 & 0.86 & 370.00 & 367.44 & 1 \\
\hline Education & 33.00 & 33.82 & 0.96 & 42.00 & 41.83 & 0.9 & 35.00 & 34.25 & 1 \\
\hline Function & 14.00 & 13.72 & 0.88 & 7.00 & 6.80 & 1 & 8.00 & 8.31 & 1 \\
\hline Land size & 1942.00 & 1995.51 & 1 & 1142.80 & 1143.60 & 1 & 1465.50 & 1462.49 & 0.96 \\
\hline Value house & 17413.00 & 17898.77 & 0.92 & 20725.07 & 20872.06 & 0.94 & 20455.00 & 20645.85 & 0.92 \\
\hline Value land & 11534.00 & 11894.07 & 0.98 & 4860.07 & 4860.01 & 0.98 & 7841.15 & 7768.60 & 0.9 \\
\hline Experience & 788.33 & 804.94 & 0.84 & 1485.00 & 1479.79 & 0.96 & 1595.00 & 1599.51 & 0.96 \\
\hline Storage & 949.91 & 985.06 & 0.86 & 734.06 & 731.29 & 0.84 & 1028.70 & 1027.44 & 0.84 \\
\hline Quantity & 982.75 & 991.87 & 1 & 1381.50 & 1352.16 & 0.76 & 10607.10 & 11670.13 & 1 \\
\hline Capacity & 75.85 & 80.84 & 0.92 & 4.18 & 3.85 & 0.82 & 121.00 & 119.75 & 0.9 \\
\hline Credit & 19.00 & 19.25 & 1 & 28.00 & 27.10 & 0.84 & 36.00 & 36.07 & 1 \\
\hline Average price & 675.11 & 680.20 & 0.9 & 580.37 & 577.04 & 0.86 & 703.51 & 704.76 & 0.92 \\
\hline Info politics & 7.00 & 7.39 & 0.98 & 3.00 & 2.76 & 1 & 4.00 & 4.02 & 1 \\
\hline Info harvest & 4.00 & 4.06 & 1 & & & & 3.00 & 2.96 & 1 \\
\hline Internet & 3.00 & 2.82 & 1 & 3.00 & 2.76 & 1 & 3.00 & 2.99 & 1 \\
\hline Location & 7.00 & 7.22 & 1 & 11.00 & 10.92 & 1 & 13.00 & 12.91 & 1 \\
\hline Ethnic & 4.00 & 3.94 & 1 & 1.00 & 1.06 & 1 & 3.00 & 2.87 & 1 \\
\hline Links 2012 & & & & 13.00 & 12.65 & 1 & 24.00 & 24.03 & 0.98 \\
\hline Links 2015 & & & & & & & 15.00 & 14.86 & 0.92 \\
\hline
\end{tabular}


Table $4 \mid$ A7. Goodness of fit for oil palm and panel dataset

\begin{tabular}{|c|c|c|c|c|c|c|c|c|}
\hline Obs. & $\begin{array}{l}2012 \\
\text { Mean }\end{array}$ & p-value & Obs. & $\begin{array}{l}2015 \\
\text { Mean }\end{array}$ & p-value & Obs. & $\begin{array}{l}2018 \\
\text { Mean }\end{array}$ & p-value \\
\hline \multicolumn{9}{|c|}{ Goodness of fit for in-degree } \\
\hline 13 & 14.97 & 0.46 & 22 & 25.01 & 0.42 & 24 & 27.08 & 0.22 \\
\hline 8 & 5.1 & 0.16 & 18 & 12.11 & 0.08 & 14 & 9.67 & 0.16 \\
\hline 1 & 2.06 & 0.72 & 1 & 4.32 & 0.04 & 4 & 4.77 & 0.94 \\
\hline 1 & 0.58 & 0.86 & 2 & 1.59 & 0.98 & 3 & 2.08 & 0.66 \\
\hline 0 & 0.21 & 1 & 1 & 0.59 & 0.9 & 0 & 0.84 & 0.86 \\
\hline 0 & 0.06 & 1 & 0 & 0.28 & 1 & 0 & 0.4 & 1 \\
\hline \multirow[t]{4}{*}{0} & 0.02 & 1 & 0 & 0.06 & 1 & 0 & 0.1 & 1 \\
\hline & & & 0 & 0.02 & 1 & 0 & 0.05 & 1 \\
\hline & & & 0 & 0.01 & 1 & 0 & 0.01 & 1 \\
\hline & & & 0 & 0.01 & 1 & & & \\
\hline \multicolumn{9}{|c|}{ Goodness of fit for out-degree } \\
\hline 10 & 14.43 & 0 & 22 & 23.81 & 0.66 & 21 & 24.03 & 0.36 \\
\hline 13 & 5.89 & 0 & 16 & 12.91 & 0.32 & 17 & 12.73 & 0.22 \\
\hline 0 & 1.83 & 0.22 & 4 & 5.37 & 0.66 & 7 & 6.11 & 0.9 \\
\hline 0 & 0.74 & 1 & 2 & 1.45 & 0.78 & 0 & 1.69 & 0.28 \\
\hline 0 & 0.1 & 1 & 0 & 0.34 & 1 & 0 & 0.39 & 1 \\
\hline \multirow[t]{2}{*}{0} & 0.01 & 1 & 0 & 0.09 & 1 & 0 & 0.04 & 1 \\
\hline & & & 0 & 0.03 & 1 & 0 & 0.01 & 1 \\
\hline \multicolumn{9}{|c|}{ Goodness of fit for edgewise shared partner } \\
\hline 13 & 11.96 & 0.86 & 30 & 29.47 & 1 & 31 & 31.22 & 1 \\
\hline \multirow[t]{2}{*}{0} & 0.26 & 1 & 0 & 0.52 & 1 & 0 & 0.61 & 1 \\
\hline & & & & & & 0 & 0.01 & 1 \\
\hline \multicolumn{9}{|c|}{ Goodness of fit for minimum geodesic distance } \\
\hline 13 & 12.22 & 0.88 & 30 & 29.99 & 1 & 31 & 31.84 & 1 \\
\hline 0 & 4.26 & 0.18 & 0 & 16.24 & 0 & 0 & 13.51 & 0 \\
\hline 0 & 1.21 & 1 & 0 & 8.14 & 0.06 & 0 & 5.43 & 0.28 \\
\hline 0 & 0.31 & 1 & 0 & 3.64 & 0.7 & 0 & 1.99 & 1 \\
\hline \multirow[t]{4}{*}{0} & 0.05 & 1 & 0 & 1.43 & 1 & 0 & 0.66 & 1 \\
\hline & & & 0 & 0.49 & 1 & 0 & 0.26 & 1 \\
\hline & & & 0 & 0.1 & 1 & 0 & 0.09 & 1 \\
\hline & & & 0 & 0.02 & 1 & 0 & 0.02 & 1 \\
\hline
\end{tabular}


Table $4 \mid$ A8. Goodness of fit model statistics for oil palm and panel dataset

\begin{tabular}{|c|c|c|c|c|c|c|c|c|c|}
\hline & \multicolumn{3}{|c|}{2012} & \multicolumn{3}{|c|}{2015} & \multicolumn{3}{|c|}{2018} \\
\hline & Obs. & mean & p-value & Obs. & mean & p-value & Obs. & mean & p-value \\
\hline Age & 53 & 50.49 & 0.82 & 150 & 150.5 & 0.96 & 148 & 153 & 0.92 \\
\hline Education & 6 & 5.49 & 0.82 & 6 & 5.74 & 0.94 & 13 & 13.82 & 0.92 \\
\hline Function & 2 & 1.85 & 1 & 3 & 2.91 & 1 & 4 & 4.26 & 1 \\
\hline Land size & 196 & 181.71 & 0.82 & 889 & 853.54 & 0.94 & 390 & 384.09 & 0.82 \\
\hline Value house & 3680.1 & 3496.87 & 0.86 & 5640 & 5577.8 & 0.96 & 7920 & 8068 & 0.9 \\
\hline Value land & 2466.05 & 2308.62 & 0.84 & 1802 & 1779.02 & 0.98 & 2990.2 & 3074.88 & 0.86 \\
\hline Experience & 123 & 118.92 & 0.88 & 185 & 182.93 & 0.9 & 310 & 315.63 & 1 \\
\hline Storage & 361 & 343.23 & 0.8 & 407 & 417.62 & 1 & 111 & 110.92 & 0.86 \\
\hline Quantity & 3915.3 & 3638.97 & 0.66 & 2630 & 2652.05 & 0.98 & 2654.1 & 2783.53 & 0.92 \\
\hline Capacity & 27 & 28.23 & 1 & & & & 64 & 69.30 & 0.94 \\
\hline Credit & 1 & 0.93 & 1 & 12 & 11.81 & 1 & 11 & 10.84 & 0.96 \\
\hline Average price & 30.13 & 29.24 & 0.8 & 38.18 & 38.08 & 1 & 34.81 & 35.67 & 0.98 \\
\hline Location & 2 & 1.84 & 1 & 5.00 & 5.26 & 1 & & & \\
\hline Ethnic & 1 & 0.77 & 1 & & & & 5 & 5.25 & 1 \\
\hline Links 2012 & & & & 3 & 3.09 & 1 & 1 & 0.93 & 1 \\
\hline Links 2015 & & & & & & & 8 & 8.42 & 1 \\
\hline
\end{tabular}




\section{Chapter 5 | General conclusion}

\section{5 | 1. Main findings}

Social networks gain in importance in the context of economic and agricultural economic research. In an attempt to obtain an overall picture of interdependencies and underlying mechanisms in the economic decision-making of individuals, the social environment needs to be considered and incorporated. Social networks in agricultural economics are in particular prominent in the diffusion and adoption of technology, mainly in developing countries, which leads to a fast-growing body of literature. In many studies, an individual farmer's social environment is often restricted to farming or non-farming neighbours and extension agents. Other sources of information are primarily failed to be included analysing social networks. In other aspects of agricultural economics, like global and local trade, the usage of social networks is unrepresented at all. In this dissertation we use social network analysis to address various sources of information for the adoption of technology, the role of network effects in the adoption process and the structure of local trading networks.

In the first essay, we have developed five network structures to illustrate the spread of information from the origin to the individual farmer, possibly adopting automatic milking (AMS) systems in Germany. Besides the classical neighbourhood structure, we included the sales structure network of the manufacturer, the dairy factory network, the public farm advisory service network and the organic farming association network. We used these five networks as a spatial weight matrix in a spatiotemporal endemic-epidemic model. This statistical model was applied to capture the dynamic nature of diffusion and adoption processes. The model performance substantially improved when considering the networks.

The use of the neighbourhood network resulted in the best model performance as well as in the largest share of the network effect in the mean explaining the diffusion of AMS. Next comes the sales structure network. However, the exogenous effect is primarily determining adoption. Disaggregated in consecutive years, is the exogenous effect responsible for triggering the first adoption in the beginning. Over time, the network effect demonstrates increasing importance.

In the second essay, we examine the relevance of the neighbourhood and the sales structure network while controlling for economic aspects affecting the adoption of AMS in Germany. AMS are promoted to substitute labour, and our results confirm this strategy. The number of family and hired labour is crucial for the decision to adopt. Besides, the orientation of 
milk production, represented by the average herd size and milk production, is a major driver of adoption. Further, we elaborate that the agglomeration effect, which is defined as the spillover effects within the same administrative district, and the network effect, which captures spillover effects between districts, continue to be considerably important. For the neighbourhood network structure, both effects account for almost $50 \%$ of the mean explaining the adoption pattern. For the sales structure network, the share of network and agglomeration effects are still more than $30 \%$. In summary, despite the inclusion of substantial economic factors, the spillover effects remain decisive.

In the third essay, we analyse the local trade of rubber and oil palm by intermediaries in the province of Jambi in Indonesia. Networks for both products based on a cross-sectional and a panel sample provide insights into the structure and development of local trade patterns. Over the considered period, the number of oil palm traders extended, while the number of rubber sellers decreased. However, the number of trading relations directly to factories occurring transactions increased. Sellers, active throughout the survey rounds, obtain higher prices and trade higher quantities on average.

To analyse parameters influencing the link formation between sellers and buyers, we used an exponential random graph $\left(\mathrm{p}^{*}\right)$ model. For both cross-sectional and panel sample, the average price and the provision of loan by the buyer are the crucial factors for trade relations; the total traded quantity and the trading experience influence neither rubber nor oil palm trade. For the panel sample, the decline of the world market price is recognisable. However, links formed in past trade networks are only significantly influential for the rubber trade.

\section{5 | 2. Limitations and suggestions for future research}

Finally, we would like to address some limitations of this dissertation and at the same time encourage future research on social networks. The dataset of the first and second essay did not contain any information on individual relationships, information sources. For this reason, we had to design the networks build on various assumptions. Although the assumptions are based on reasonable structural and scientific evidence, we do not know the individual farmer's motivation to adopt an automatic milking system.

As we exclusively considered German dairy farmers, the networks display Germany without connecting farmers at the border to farmers in neighbouring countries. The same occurs within the administrative districts. For farmers in the border regions, fellow farmers in the 
adjacent district or country can be geographically closer than farmers in the same district. Besides, we excluded direct personal contact between non-adjacent districts using communication technologies.

Further, we solely had access to the data of one manufacturer. As this manufacturer is the market leader, the dataset covers a large share of the AMS adopters in Germany. Due to data constraints on the adoption of AMS in several federal states of Germany, it was unfeasible to complete the dataset by the other suppliers on the market.

In the second essay, we used secondary data to account for economic factors influencing the adoption of AMS between 1997 and 2013. Because of data security reasons and constraints in the original dataset, the data could not be provided on the individual level or level of the administrative districts. Therefore, we had to combine different datasets. Furthermore, because of the NUTS 2 level of most of the explaining variables, some over- or underestimation of single variable could appear.

However, the inclusion of social networks in agricultural economics could be enhanced by expansion in new research areas. In developed countries, the role of public advisory services in the dissemination of information on specific regulations in developed countries can be examined using social networks. The availability of individual network data could introduce the inclusion of risk preferences and risk assessment. Additional, considering upstream and downstream industries, market integration of particular products or regions can be studied.

Global and local trade networks remain unnoticed in agricultural research. Especially the trading structure in the case of Jambi can be further explored using networks. In Jambi, rubber and oil palm is for the most part produced by smallholders. Due to issues in the infrastructure and formal institutions, the local trade is also predominantly organised by small traders. At the same time, Indonesia is internationally the largest producer for both products and a significant player on the international market. This means that local trade networks are not only formed by local forces and circumstances, but also by global trends and fluctuations. Our first analyses show that those movements can be recognised in the pattern of the networks. Relating both in a more comprehensive way provide promising outcomes and deepen the understanding of the local mechanisms forming trade relationships.

Social networks add another layer to the research on economic behaviour and decisionmaking. Individual economic behaviour is often not exclusively rational, due to the social nature of people or external conditions, like imperfect markets, failing institutions or missing 
infrastructure. Then, the disregard of social structures can lead to over- or underestimation of economic factors. However, collecting network data is costly and in particular, including the collection of network data in large projects can be challenging. Therefore, future research needs to address many aspects to refine the integration of social networks in agricultural economics. 


\section{Chapter 6 | References}

An, H., W. Zhong, Y. Chen, H. Li, and X. Gao. 2014. 'Features and Evolution of International Crude Oil Trade Relationships: A Trading-Based Network Analysis'. Energy 74: 254-59.

Anselin, L. 1995. 'Local Indicators of Spatial Association - LISA'. Geographical Analysis 27 (2): 93-115.

Baerenklau, K. A. 2005. 'Toward an Understanding of Technology Adoption: Risk, Learning, and Neighborhood Effects'. Land Economics 81 (1): 1-19.

Baptista, R. 2000. 'Do Innovations Diffuse Faster within Geographical Clusters?' International Journal of Industrial Organization, no. 18: 515-35.

Barnes, M. L., J. Lynham, K. Kalberg, and P. Leung. 2016. 'Social Networks and Environmental Outcomes'. Proceedings of the National Academy of Science 113 (23): 6466-71.

Beaman, L., A. BenYishay, J. Magruder, and A. M. Mobarak. 2016. 'Can Network TheoryBased Targeting Increase Technology Adoption?' SSRN Electronic Journal.

Bergman, K., and E. Rabinowicz. 2013. 'Adoption of the Automatic Milking System by Swedish Milk Producers', AgriFood Economics Centre Working Paper, no. 7.

Bewley, J. M., and R. A. Russell. 2010. 'Reasons for Slow Adoption Rates of Precision Dairy Farming Technologies: Evidence from a Producer Survey'. North American Conference on Precision Dairy Management. Ontario.

Blume, L.E., D. Easley, J Kleinberg, and E. Tardos. 2009. 'Trading Networks with PriceSetting Agents. Games and Economic Behavior 67: 36-50.

Bodin, Ö., and B.I. Crona. 2009. 'The Role of Social Networks in Natural Resource Governance: What Relational Patterns Make a Difference?' Global Environmental Change 19: 366-74.

Borgatti, S.P., and D.S. Halgin. 2011. 'On Network Theory'. Organization Science 22 (5): 1168-81.

Bramoullé, Yann, Habiba Djebbari, and Bernard Fortin. 2009. 'Identification of Peer Effects through Social Networks'. Journal of Econometrics 150: 41-55.

Broekel, T., and M. Hartog. 2013. 'Explaining the Structure of Inter-Organizational Networks Using Exponential Random Graph Models'. Industry and Innovation 20 (3): 277-95.

Brown, P., G. Hart, B. Small, and O. Montes de Oca Munguia. 2016. 'Agents for Diffusion of Agricultural Innovations for Environmental Outcomes'. Land Use Policy, no. 55: 318-26.

Brown, P., and S. Roper. 2017. 'Innovation and Networks in New Zealand Farming'. Australian Journal of Agricultural and Resource Economics 61: 422-42.

Conley, T. G., and C. R. Udry. 2010. 'Learning about a New Technology: Pineapple in Ghana'. American Economic Review 100 (1): 35-69.

Corcoran, M., L. Datcher, and G. Duncan. 1980. 'Information and Influence Networks in Labor Markets'. Five Thousand American Families: Patterns of Economic Progress 8 (1): 37.

Coughlan, A.T., E. Anderson, L.W. Stern, and A. El-Ansary. 2006. Marketing Channels. 7th edition. Prentice Hall.

De Benedictis, L., and L. Tajoli. 2010. 'Comparing Sectoral International Trade Networks'. In Aussenwirtschaft, 65. Jahrgang:167-89. Zürich: Rüegger.

Delre, S., W. Jager, T. H. A. Bijmolt, and M. A. Janssen. 2010. 'Will It Spread or Not? The Effects of Social Influences and Network Topology on Innovation Diffusion'. Journal of Product Innovation Management, no. 27: 267-82. 
Diaz-José, J., R. Rendón-Medel, B. Govaerts, J. Aguilar-Ávila, and M. Munoz-Rodriguez. 2016. 'Innovation Diffusion in Conservation Agriculture: A Network Approach'. European Journal of Development Research, no. 28: 314-29.

Diederen, P., H. Van Meijl, A. Wolters, and K. Bijak. 2003. 'Innovation Adoption in Agriculture: Innovators, Early Adopters and Laggards'. Cahiers d'Economie et de Sociologie Rurales, INRA Editions, no. 67: 29-50.

Directorate General of Estate Crops. 2017a. Tree Crop Estate Statistics of Indonesia 20162018 Palm Oil. Edited by D. Hendaryati and Y. Arianto. Jakarta: Secretariate of Directorate General of Estate Crops, Directorate General of Estate Crops (DGEC), Ministry of Agriculture, Republic of Indonesia. http://ditjenbun.pertanian.go.id. 2017b. Tree Crop Estate Statistics of Indonesia 2016-2018 Rubber. Edited by D. Hendaryati and Y. Arianto. Jakarta: Secretariate of Directorate General of Estate Crops, Directorate General of Estate Crops (DGEC), Ministry of Agriculture, Republic of Indonesia. http://ditjenbun.pertanian.go.id.

Duijn, M.A.J. van, and J.K. Vermunt. 2006. 'What Is Special about Social Network Analysis?' Methodology 2 (1): 2-6.

Easley, D., and J Kleinberg. 2010. Networks, Crowds, and Markets: Reasoning about a Highly Connected World. New York: Cambridge University Press.

Eastwood, C., L. Klerkx, and R. Nettle. 2017. 'Dynamics and Distribution of Public and Private Research and Extension Roles for Technological Innovation and Diffusion: Case Studies of the Implementation and Adaptation of Precision Farming Technologies'. Journal of Rural Studies, no. 49: 1-12.

Fafchamps, M., and B. Minten. 2002. 'Returns to Social Network Capital among Traders'. Oxford Economic Papers 54: 173-206.

FAO, Food and Agricultural Organization of the United Nations. 2019. 'FAOSTAT', 2019. http://www.fao.org/faostat/en/\#data/QC.

Feder, G., R. Murgai, and J. B. Quizon. 2004. 'The Acquisition and Diffusion of Knowledge: The Case of Pest Management Training in Farmer Field Schools, Indonesia'. Journal of Agricultural Economics 55 (2): 221-43.

Feder, G., and R. Slade. 1984. 'The Acquisition of Information and the Adoption of New Technology'. American Journal of Agricultural Economics 66 (3): 312-20.

1985. 'The Role of Public Policy in the Diffusion of Improved Agricultural Technology'. American Journal of Agricultural Economics 67 (2): 423-28.

Feder, G., and D. L. Umali. 1993. 'The Adoption of Agricultural Innovations. A Review'. Technological Forecasting and Social Change, no. 43: 215-39.

Floridi, M., F. Bartolini, J. Peerlings, N. Polman, and D. Viaggi. 2013. 'Modelling the Adoption of Automatic Milking Systems in Noord-Holland'. Bio-Based and Applied Economics 2 (1): 73-90.

Foster, A. D., and M. R. Rosenzweig. 1995. 'Learning by Doing and Learning from Others: Human Capital and Technical Change in Agriculture'. The Journal of Political Economy 103 (6): 1176-1209.

. 2010. 'Microeconomics of Technology Adoption'. Annual Review of Economics 2: 395-424.

Fritsch, M., and M. Kauffeld-Monz. 2008. 'The Impact of Network Structure on Knowledge Tansfer: An Application of Social Network Analysis in the Context of Regional Innovation Networks'. The Annals of Regional Science 44 (1): 3-27.

Genius, M., P. Koundouri, C. Nauges, and V. Touvelekas. 2013. 'Information Transmission in Irrigation Technology Adoption and Diffusion: Social Learning, Extension Services, and Spatial Effects'. American Journal of Agricultural Economics 96 (1): 328-44. 
Gillespie, J., R. Nehring, and I. Sitienei. 2014. 'The Adoption of Technologies, Management Practices, and Production Systems in U.S. Milk Production'. Agricultural and Food Economics 17 (2): 1-24.

Glückler, J. 2007. 'Economic Geography and the Evolution of Networks'. Journal of Economic Geography 7: 619-34.

Granovetter, M. 1973. 'The Strength of Weak Ties'. American Journal of Sociology 78: 1360-80.

- 1985. 'Economic Action and Social Structure: The Problem of Embeddedness'. American Journal of Sociology 91 (3): 481-510.

- 2005. 'The Impact of Social Structure on Economic Outcomes'. The Journal of Economic Perspectives 19 (1): 33-50.

Grassi, R. 2010. 'Vertex Centrality as a Measure of Information Flow in Italian Corporate Board Networks'. Physica A (389): 2455-64.

Hailu, G., and B. J. Deaton. 2015. 'Agglomeration Effects in Ontario's Dairy Farming'. In Agriculture in an Interconnected World. Milan.

Hansen, B. G. 2015. 'Robotic Milking-Farmer Experiences and Adoption Rate in Jæren, Norway'. Journal of Rural Studies, no. 41: 109-17.

Heikkilä, A.-M., S. Myyrä, and K. Pietol. 2012. 'Effects of Economic Factors on Adoption of Robotics and Consequences of Automation for Productivity Growth of Dairy Farms'. 32. Factor Markets Working Paper. Brussels: Centre for European Policy Studies.

Hein, A. 2011. 'Strukturwandel Und Technischer Fortschritt in Der Landwirtschaft: Eine Analyse Der Diffusion Automatischer Melkverfahren in Deutschland'. https://oega.boku.ac.at/fileadmin/user_upload/Tagung/2001/hein.pdf.

Held, L., M. Höhle, and M. Hofmann. 2005. 'A Statistical Framework for the Analysis of Multivariate Infectious Disease Surveillance Counts'. Statistical Modelling 5 (3): 187-99.

Hoang, L. A., J.-C. Castella, and P. Novosad. 2006. 'Social Networks and Information Access: Implications for Agricultural Extension in a Rice Farming Community in Northern Vietnam'. Agriculture and Human Values 23: 513-27.

Hunter, D.R., M. Handcock, C.T. Butts, S.M. Goodreau, and M. Morris. 2008. 'Ergm: A Package to Fit, Simulate and Diagonse Exponential-Family Models for Networks'. Journal of Statistical Software 24 (3): nihpa54860.

Ioannides, Y. M., and L. Datcher. 2004. 'Job Information Networks, Neighborhood Effects, and Inequality'. Journal of Economic Literature 42 (4): 1056-93.

Jackson, M.O. 2008. Social and Economic Networks. Princeton: Princeton University Press.

Just, D., and D. Zilberman. 2002. 'Information Systems in Agriculture'. ARE Update 6 (1): 3-6.

Kelley, M. R., and S. Helper. 1999. 'Firm Size and Capabilities, Regional Agglomeration, and The Adoption of New Technology'. Economics of Innovation and New Technology 8 (1-2): 79-103.

Knox, E.G., and M.S. Bartlett. 1964. 'The Detection of Space-Time Interactions'. Journal of the Royal Statistical Society. Series C (Applied Statistics) 13 (1): 25-30.

Kondylis, F., V. Mueller, and S. Zhu. 2014. 'Seeing Is Believing? Evidence from an Extension Network Experiment'. 7000. Policy Research Working Paper. Washington D.C.: World Bank.

Kopp, T., Z. Alamsyah, R.S. Fatricia, and B. Brümmer. 2014. 'Have Indonesian Rubber Processors Formed a Cartel? Analysis of Intertemporal Marketing Margin Manipulation'. EFForTS Discussion Paper Series 3: Georg August-Universität Göttingen, Collaborative Research Centre 990-EFForTS. 
Kopp, T., and B. Brümmer. 2017. 'Traders' Market Power along Indonesian Rubber Value Chains'. China Agricultural Economic Review 9 (2): 169-87.

Kopp, T., and J. Salecker. 2018. 'Modelling Social Evolutionary Processes and Peer Effects in Agricultural Trade Networks: The Rubber Value Chain in Indonesia'. ArXiv Preprint arXiv:1811.11476.

Kranton, R.E., and D.F. Minehart. 2001. 'A Theory of Buyer-Seller Networks'. The American Economic Review 91 (3): 485-508.

Krishnan, P., and M. Patnam. 2013. 'Neighbors and Extension Agents in Ethiopia: Who Matters More for Technology Adoption?' American Journal of Agricultural Economics 96 (1): 308-27.

Krugman, P. 1993. Geography and Trade. Sixth Printing, 1996. Cambridge, Massachusetts; Leuven, Belgium: The MIT Press, Leuven University Press.

Kubitza, C., V.V. Krishna, Z. Alamsyah, and M. Qaim. 2018. 'The Economics behind an Ecological Crisis: Livelihood Effects of Oil Palm Expansion in Sumatra, Indonesia'. Human Ecology 46: 107-16.

Lakner, S., S. Von Cramon-Taubadel, and B. Brümmer. 2011. 'Technical Efficiency of Organic Pasture Farming in Germany: The Role of Location Economics and of Specific Knowledge'. Renewable Agriculture and Food Systems 27 (3): 228-41.

Läpple, D., G. Holloway, D. J. Lacombe, and C. O'Donoghue. 2017. 'Sustainable Technology Adoption: A Spatial Analysis of the Irish Dairy Sector'. European Review of Agricultural Economics 44 (5): 810-35.

Läpple, D., A. Renwick, J. Cullinan, and F. Thorne. 2016. 'What Drives Innovation in the Agricultural Sector? A Spatial Analysis of Knowledge Spillovers'. Land Use Policy, no. 56: $238-50$.

Läpple, D., A. Renwick, and F. Thorne. 2015. 'Measuring and Understanding the Drivers of Agricultural Innovation: Evidence from Ireland'. Food Policy, no. 51: 1-8.

Larue, S., and L. Latruffe. 2009. 'Agglomeration Externalities and Technical Efficiency in French Pig Production'. Working Paper SMART - LERECO N09-10.

Lentz, H.H.K, A. Koher, P. Hövel, J. Gethmann, C. Sauter-Louis, and T. Selhorst. 2016. 'Disease Spread through Animal Movements: A Static and Temporal Network Analysis of Pig Trade in Germany'. PLoS ONE 11 (5): e0155196.

Levy, M.A., and M.N. Lubell. 2018. 'Innovation, Cooperation, and the Structure of Three Regional Sustainable Agriculture Networks in California'. Regional Environmental Change 16: 1235-46.

Lewis, D. J., B. J. Barham, and B. Robinson. 2011. 'Are There Spatial Spillovers in the Adoption of Clean Technology? The Case of Organic Dairy Farming'. Land Economics 87 (2): 250-67.

Ma, X., D. J. Spielman, H. Nazli, P. Zambrano, F. Zaidi, and S. Kouser. 2014. 'The Role of Social Networks in an Imperfect Market for Agricultural Technology Products: Evidence on Bt Cotton Adoption in Pakistan'. In , 1-30. Selected Paper. Minneapolis.

Maertens, A. 2017. 'Who Cares What Others Think (or Do)? Social Learning and Social Pressures in Cotton Farming in India'. American Journal of Agricultural Economics 99 (4): 988-1007.

Maertens, A., and C. B. Barrett. 2012. 'Measuring Social Networks' Effects on Agricultural Technology Adoption'. American Journal of Agricultural Economics 95 (2): $353-$ 59.

Malmberg, A. 1997. 'Industrial Geography: Location and Learning'. Progress in Human Geography 21 (4): 573-82. 
Mansfield, E. 1963. 'The Speed of Response of Firms to New Techniques'. Quarterly Journal of Economics 77: 290-311.

Manski, C. 1993. 'Identification of Endogenous Social Effects: The Reflection Problem'. Review of Economic Studies, no. 60: 531-42.

Mantel, N. 1967. 'The Detection of Disease Clustering and a Generalized Regression Approach'. Cancer Research 27 (2): 209-20.

Marshall, A. 1938. Principles of Economics. 8. edition. London: Macmillan.

Matuschke, I., and M. Qaim. 2009. 'The Impact of Social Networks on Hybrid Seed Adoption in India'. Agricultural Economics 40: 493-505.

Meyer, S., L. Held, and M. Höhle. 2016a. 'Hhh4: Endemic-Epidemic Modeling of Areal Count Time Series'. Journal of Statistical Software Section 5. 2017. 'Spatio-Temporal Analysis of Epidemic Phenomena Using the R Package Surveillance'. Journal of Statistical Software 77 (11): 1-55.

Meyer, S., I. Warnke, W. Rössler, and L. Held. 2016b. 'Model-Based Testing for SpaceTime Interaction Using Point Processes: An Application to Psychatric Hospital Admissions in Urban Area'. Spatial and Spatio-Temporal Epidemiology 17: 15-25.

Milgram, S. 1967. 'The Small-World Problem'. Psychology Today 2: 60-67.

Nakajima, T., H. Matsuda, and A. Rifin. 2010. 'The Structural Change in the Suppy Chain of Oil Palm - A Case of North Sumatra Province, Indonesia'. In $16^{\text {th }}$ EAAE Seminar 27 - 30. October 2010. Parma.

Nicolas, G., B. Durand, R. Duboz, R. Rakotondravao, and V. Chevalier. 2013. 'Description and Analysis of the Cattle Trade Network in the Madagascar Highlands: Potential Role in the Diffusion of Rift Valley Fever Virus'. Acta Tropica 126 (1): 19-27.

Niu, C., and C. Ragasa. 2018. 'Selective Attention and Information Loss in the Lab-to-Farm Knowledge Chain: The Case of Malawian Agricultural Extension Programs'. Agricultural Systems, no. 165: 147-63.

Ortiz-Pelaez, A., D.U. Pfeiffer, R.J. Soares-Magalhaes, and F.J. Guitian. 2006. 'Use of Social Network Analysis to Characterize the Pattern of Animal Movements in the Initial Phases of the 2001 Foot and Mouth Disease (FMD) Epidemic in the UK'. Preventive Veterinary Medicine 76 (1-2): 40-55.

Paul, M., and L. Held. 2011. 'Predictive Assessment of a Non-Linear Random Effects Model for Multivariate Time Series of Infectious Disease Counts'. Statistics in Medicine 3: $1118-36$.

Paul, M., L. Held, and A.M. Toschke. 2008. 'Multivariate Modelling of Infectious Disease Surveillance Data'. Statistics in Medicine 27: 6250-67.

Pierpaoli, E., G. Carli, E. Pignatti, and M. Canavari. 2013. 'Drivers of Precision Agriculture Technologies Adoption: A Literature Review'. Procedia Technology, no. 8: 61-69.

Prell, C., and K. Feng. 2016. 'The Evolution of Global Trade and Impacts on Countries' Carbon Trade Imbalance'. Social Networks 46: 87-100.

Rees, A.J., and G.P. Shultz. 1970. Workers in an Urban Labor Market. Chicago: University of Chicago Press.

Reyes, J., S. Schiavo, and G. Fagiolo. 2010. 'Using Complex Networks Analysis to Assess the Evolution of International Economic Integration: The Cases of East Asia and Latin America'. The Journal of International Trade and Economic Development 19 (2): 215-39.

Richards, P. 2018. 'It's Not Just Where You Farm; It's Whether Your Neigbor Does Too. How Agglomeration Economies Are Shaping New Agricultural Landscapes'. Journal of Economic Geography 18: 87-110. 
Robins, G. 2015. Doing Social Network Research. Network-Based Research Design for Social Scientists. Los Angeles, London, New Delhi, Singapore, Washington DC: SAGE Publications.

Robins, G., L. Bates, and P. Pattison. 2011. 'Network Governance and Environmental Management: Conflict and Cooperation'. Public Administration 89 (4): 1293-1313.

Robins, G., P. Pattison, Y. Kalish, and D. Lusher. 2007a. 'An Introduction to Exponential Random Graph (P*) Models for Social Networks'. Social Networks 29: 173-91.

Robins, G., T. Snijders, P. Wang, M. Handcock, and P. Pattison. 2007b. 'Recent Developments in Exponential Random Graph ( $\left.\mathrm{P}^{*}\right)$ Models for Social Networks'. Social Networks 29 (2): 192-215.

Rogers, E.M. 1995. Diffusion of Innovations. 4. edition. New York: Free Press.

Sampson, G.S., and E.D. Perry. 2019. 'The Role of Peer Effects in Natural Resource Appropriation - The Case of Groundwater'. American Journal of Agricultural Economics 101 (1): 154-71.

Sauer, J., and D. Zilberman. 2012. 'Sequential Technology Implementation, Network Externalities, and Risk: The Case of Automatic Milking Systems'. Agricultural Economics, no. 43: 233-51.

Schewe, R., and D. Stuart. 2015. 'Diversity in Agricultural Technology Adoption: How Are Automatic Milking Systems Used and to What End?' Agriculture and Human Values, no. 32: 199-213.

Schmidtner, E., C. Lippert, and S. Dabbert. 2015. 'Does Spatial Dependence Depend on Spatial Resolution? An Empirical Analysis of Organic Farming in Southern Germany'. German Journal of Agricultural Economics 64 (3): 175-91.

Schmidtner, E., C. Lippert, B. Engler, A. M. Häring, J. Aurbacher, and S. Dabbert. 2012. 'Spatial Distribution of Organic Farming in Germany: Does Neighbourhood Matter?' European Review of Agricultural Economics 39 (4): 661-83.

Schrödle, B., L. Held, and H. Rue. 2012. 'Assessing the Impact of a Movement Network on the Spatiotemporal Spread of Infectious Diseases'. Biometrics 68: 736-44.

Schwarze, S., M. Euler, M. Gatto, J. Hein, E. Hettig, A.M. Holtkamp, L. Izhar, et al. 2015. 'Rubber vs. Oil Palm: An Analysis of Factors Influencing Smallholders' Crop Choice in Jambi, Indonesia'. In EFForTS Discussion Paper Series. Vol. 11. Göttingen: Universität Göttingen, SFB 990 EFForTS, Ecological and Socioeconomic Functions of Tropical Lowland Rainforest Transformation Systems (Sumatra, Indonesia).

Scott, J. 2013. Social Network Analysis. Third edition. Los Angeles, London, New Delhi, Singapore, Washington DC: Sage Publications Ltd.

Subramanian, A., and M. Qaim. 2011. 'Interlocked Village Markets and Trader Idiosyncrasy in Rural India'. Journal of Agricultural Economics 62 (3): 690-709.

Sujarwo, R.M., T. Kopp, R. Nurmalina, and R.W. Asmarantaka. 2014. 'Choice of Marketing Channels by Rubber Small Traders in the Jambi Province, Indonesia'. In Tropentag 2014. Prague.

Sullivan, J., and L. Xie. 2009. 'Environmental Activism, Social Networks and the Internet'. The China Quarterly 198: 422-32.

Sumane, S., I. Kunda, K. Knickel, A. Strauss, T. Tisenkopfs, Ignacio Des los Rios, Maria Rivera, Tzruya Chebach, and Amit Ashkenazy. 2017. 'Local and Farmer's Knowledge Matters! How Integrating Informal and Formal Knowledge Enhances Sustainable and Resilient Agriculture'. Journal of Rural Studies, 1-10.

Sunding, D., and D. Zilberman. 2001. 'The Agricultural Innovation Process: Research and Technology Adoption in a Changing Agricultural Sector'. In Handbook of Agricultural Economics, First Edition. Vol. Editors: Bruce L. Gardner, Gordon C. 
Rausser. Volume 1 A, Agricultural Production. Amsterdam, Netherlands: Elsevier Science B.V.

Valente, T. W. 1996. 'Social Network Threshold in the Diffusion of Innovations'. Social Networks 18: 69-89.

Valente, T. W., S. R. Dyal, K.-H. Chu, and H. Wipfli. 2015. 'Diffusion of Innovations Theory Applied to Global Tobacco Control Treaty Ratification'. Social Science \& Medicine, no. 145: 89-97.

Ward, P. S., and V. O. Pede. 2014. 'Capturing Social Network Effects in Technology Adoption: The Spatial Diffusion of Hybrid Rice in Bangladesh'. Australian Journal of Agricultural and Resource Economics 59: 225-41.

Wasserman, S., and K. Faust. 2009. Social Network Analysis: Methods and Applications. 19th printing. New York: Cambridge University Press.

Watts, D., and P. S. Dodds. 2007. 'Influentials, Networks, and Public Opinion Formation'. Journal of Consumer Research 34 (4): 441-58.

Watts, D., and S. Strogatz. 1998. 'Collective Dynamics of "small-World" Networks'. Nature 393: 440-42.

Wollni, M., and C. Anderson. 2014. 'Spatial Patterns of Organic Agriculture Adoption: Evidence from Honduras'. Ecological Economics 97: 120-28.

Woodford, K.B., M.H. Brakenrig, and M.C Pangborn. 2015. 'New Zealand Case Studies of Automatic-Milking-Systems Adoption'. Proceedings of the New Zealand Society of Animal Production 75: 127-31.

Xiong, H., D. Payne, and S. Kinsella. 2016. 'Peer Effects in the Diffusion of Innovations: Theory and Simulation'. Journal of Behavioral and Experimental Economics 63: 113.

Yang, Y., J.P.H. Poon, Y. Liu, and S. Bagchi-Sen. 2015. 'Small and Flat Worlds: A Complex Network Analysis of International Trade in Crude Oil'. Energy 93: 534-43.

Zhou, M., G. Wu, and H. Xu. 2016. 'Structure and Formation of Top Networks in International Trade, 2001 - 2010'. Social Networks 44: 9-21. 


\section{Dissertation Appendix: Declarations}

1. I, hereby, declare that this Ph.D. dissertation has no not been presented to any other examining body either in its present or a similar form

Furthermore, I also affirm that I have not applied for a Ph.D. at any other higher school of education.

Göttingen,

(Signature)

(Name in block capitals)

2. I, hereby, solemnly declare that this dissertation was undertaken independently and without any unauthorised aid.

Göttingen,

(Signature)

(Name in block capitals) 